\title{
THE APPLICATION OF
}

\section{STAKEHOLDER NETWORKING THEORY FOR STRATEGIC PLANNING \\ IN THE NEW ZEALAND PUBLIC SECTOR}

by

Louise Anne Proctor

\author{
A thesis \\ submitted to the Victoria University of Wellington \\ in fulfilment of the \\ requirements for the degree of \\ Master of Commerce and Administration \\ in Management
}

Victoria University of Wellington

2011 


\begin{abstract}
The New Zealand public sector is facing an increasingly pluralistic stakeholder landscape due to a range of political, economic, social, and technological factors, all of which require public sector organisations to develop new waysof understanding and responding to diverse and complex stakeholder needs. The purpose of this thesis is to investigate whether the theory of stakeholder networking can contribute to strategic planningin the public sector, to assist organisations in planning to meet strategic goals and ultimately move toward their strategic direction.
\end{abstract}

A qualitative research approach, known as participatory action research, was adopted. This required strong involvement with the two sample organisations, contributing to the development and application of the stakeholder networking process and also to the findings. Information gathering occurred through a variety of methods including focus groups, team meetings, interviews, document analysis and workshops.

A Stakeholder Networking Framework is proposed as an approach for public sector organisations to apply stakeholder networking theory in practice, which takes into account the key issues participants raised during application. Three primary uses of stakeholder networking theory for strategic planning were found, including a means for providing greater clarity to the stakeholder context surrounding strategic issues, identification of potential relationship strategies to meet strategic goals, and assisting with the prioritisation of stakeholders.

The Stakeholder Networking Framework has purposefully been developed in a way that is non-prescriptive and flexible, enabling it to be adapted by managers to suit the context specific needs of their organisation during application. Managers can then use the stakeholder network maps as outputs of the process to inform relationship management activities and strategic decision making.

This thesis fills a gap in the literature that provides practical research to public sector organisations and managers on how to integrate a stakeholder networking perspective into their strategic planning processes. It addresses common concerns that arise when trying to deliver such objectives in practice, drawing on the practical considerations of organisations' day-to-day realities 
This thesis is dedicated to

\section{Grandpa Hugh}

who has instilled in me the everlasting value of education and an ox-like determination to persevere to the end. 


\section{ACKNOWLEGEMENTS}

A lot of people have made their support available in a number of ways since I began my thesis and it is now my pleasure to thank those people who made completion possible. It has been a challenging experience but I genuinely value all that I have learnt and the opportunities that have arisen as a result of embarking on this journey.

Firstly, and most importantly, I owe my deepest gratitude to my supervisor, Urs Daellenbach, who never gave up on me. I could not have achieved this without his extensive academic knowledge, his ability to encourage me to see beyond my immediate research and make broader connections, or his patience. He has been an excellent sounding board and I appreciate the time he has dedicated and his contribution to my achievement.

Thank you to Anna Shires who was instrumental in establishing relationships with my research organisations at the outset of this thesis. My work experiences have greatly contributed to the motivation for this research and my ability to complete a thesis of such a practical nature. I could not have done this without the opportunities you have provided, which continually develop my understanding of organisational realities. Thank you also for allowing me the flexibility to work while completing my thesis.

Special thanks to Mum and Dad, who offer unwavering support in any possible way I could ever dream of. You are amazing parents and I hope that one day I can give back what you so generously provide. I would not be the person I am today with you.

To my family and friends, thank you for all the encouragement and your belief that I could do this. You have spurred me on with every kind word. I'm not quite Doctor Proctor as you all think would be so hilarious, but you never know....

And finally, Jon, who has never known me without this thesis. Thank you for putting up with me and believing in me through every moment of this thesis. Your strengths, which I so ardently admire about you,have been a real inspiration in completing my thesis. I now look forward to some much awaited times of freedom ahead. 


\section{TABLE OF CONTENTS}

Abstract ii

Thesis Dedication

Acknowledgements iv

Table of Contents v v

Tables and Figures viii

Chapter 1: Introduction 1

$\begin{array}{lll}1.1 & \text { Background and Rationale } & 1\end{array}$

1.2 Purpose of Research 5

$\begin{array}{lll}1.3 & \text { Research Objectives } & 6\end{array}$

$\begin{array}{lll}1.4 & \text { Structure of Thesis }\end{array}$

Chapter 2: Literature Review 9

2.1 Introduction to Chapter 9

$\begin{array}{lll}2.2 & \text { Stakeholder Theory } & 10\end{array}$

$\begin{array}{lll}2.2 .1 & \text { The Evolution } & 10\end{array}$

$\begin{array}{lll}\text { 2.2.2 Freeman's Contribution to Stakeholder Theory } & 12\end{array}$

2.2.3 The Stakeholder Concept and Implications for Managers 17

$\begin{array}{lll}\text { 2.2.3.1 The Variety of Stakeholder Definitions } & 18\end{array}$

2.2.3.2 Determining Stakeholder Salience 21

2.2.3.3 The Use of Stakeholder Theory on Practice 22

2.2.4 Stakeholder Dynamics 25

$\begin{array}{lll}2.3 & \text { Stakeholder Networking Theory }\end{array}$

2.3.1 Background and Principles of Social Network Analysis 30

2.3.2 Social Network Analysis and Stakeholder Theory 32

$2.4 \quad$ Stakeholder Theory and Strategic Management 35

2.4.1 The History 35

2.4.2 Support for a Stakeholder Approach to Strategic Management 37

2.4.3 Stakeholder Networking Theory and Strategic Management 40

2.5 Chapter Summary: The Research Gap 42

Chapter 3: Context - Public Sector 45

$\begin{array}{lll}3.1 & \text { Introduction to Chapter }\end{array}$ 
3.2. Strategic Management in the Public Sector 45

3.2.1 Stakeholder Theory and Strategic Management in the Public Sector 51

3.3 Stakeholder Networking in the Public Sector 53

3.4 The New Zealand Public Sector Stakeholder Environment 58

3.5 Chapter Summary: The Research Gap Refined 61

Chapter 4: Research Methods

4.1 Introduction to Chapter 63

$\begin{array}{lll}4.2 & \text { Research Objectives } & 63\end{array}$

$\begin{array}{lll}4.3 & \text { Selection of Organisations } & 64\end{array}$

4.3.1 Sampling Method 65

4.3.2 Sample Size 66

$\begin{array}{lll}4.4 & \text { Ethical Considerations } & 67\end{array}$

4.5 Research Framework 69

4.5.1 Advantages and Disadvantages of the Research Framework 73

4.6 The Research Process: Information Gathering 77

$\begin{array}{lll}\text { 4.6.1 Department of Conservation } & 78\end{array}$

4.6.2 Ministry of Agriculture and Forestry Biosecurity New Zealand 85

4.7 Challenges in the Research Process 87

$\begin{array}{lll}4.8 & \text { Methods of Data Analysis } & 88\end{array}$

$\begin{array}{lll}4.9 & \text { Limitations of Methods } & 91\end{array}$

$\begin{array}{lll}4.10 & \text { Chapter Summary } & 92\end{array}$

Chapter 5: Findings $\quad 93$

$\begin{array}{lll}5.1 & \text { Introduction to Chapter }\end{array}$

5.2 Department of Conservation Findings 94

5.2.1 Identification of Strategic Stakeholders 94

5.2.1.1 Stakeholder Identification Process 94

$\begin{array}{lll}\text { 5.2.1.2 Types of Stakeholders } & 100\end{array}$

$\begin{array}{lll}\text { 5.2.2 Stakeholder Network Mapping } & 103\end{array}$

5.3 Ministry of Agriculture and Forestry Biosecurity New Zealand 113 Findings

$\begin{array}{lll}\text { 5.3.1 Identification of Strategic Stakeholders } & 113\end{array}$

$\begin{array}{lll}\text { 5.3.1.1 Stakeholder Identification Process } & 113\end{array}$ 
5.3.1.2 Types of Stakeholders

$\begin{array}{lll}\text { 5.3.2 Stakeholder Network Mapping } & 116\end{array}$

5.4 Management Issues in the Application of Stakeholder Networking 117 Theory

$\begin{array}{ll}\text { 5.4.1 Recipients of the Process } & 120\end{array}$

$\begin{array}{lll}\text { 5.4.2 Developers and Conductors of the Process } & 123\end{array}$

5.5 The Use of Stakeholder Networking Theory for Strategic Planning 128

5.5.1 Usefulness of the Process of Stakeholder Networking 129

5.5.2 Usefulness of Stakeholder Network Maps 132

$\begin{array}{lll}5.6 & \text { Chapter Summary } & 136\end{array}$

$\begin{array}{ll}\text { Chapter 6: Discussion } & 137\end{array}$

$\begin{array}{lll}6.1 & \text { Introduction to Chapter } & 137\end{array}$

6.2 A Framework for the Application of Stakeholder Networking Theory 138

6.3 The Use of Stakeholder Networking for Strategic Planning in the 151 Public Sector

$\begin{array}{lll}6.4 & 155\end{array}$

$\begin{array}{lll}6.5 & 160\end{array}$

$\begin{array}{lll}6.6 & \text { Limitations } & 163\end{array}$

$\begin{array}{lll}6.7 & \text { Concluding Remarks } & 166\end{array}$

$\begin{array}{lr}\text { References } & 169\end{array}$

Appendices

$\begin{array}{lll}1 a & \text { Research Information Sheet for DOC } & 181\end{array}$

$\begin{array}{lll}\text { 1b Research Information Sheet for MAF BNZ } & 184\end{array}$

2 Interview Schedule for DOC and MAF BNZ 187

3 Research Agreement Form for DOC and MAF BNZ 190

4 Department of Internal Affairs Relationship Continuum 192 
TABLES AND FIGURES

\begin{tabular}{|l|l|c|}
\hline \multicolumn{2}{|c|}{ List of Tables } \\
\hline Table & Name & Page \\
\hline 5.1 & DOC's Generic Groups of Stakeholders & 101 \\
\hline 5.2 & MAF BNZ's Generic Groups of Stakeholders & 115 \\
\hline 5.3 & Summary of Participants and Activities & 117 \\
\hline 5.4 & $\begin{array}{l}\text { Summary of management issues in applying the process for } \\
\text { stakeholder networking theory }\end{array}$ & 119 \\
\hline
\end{tabular}

\begin{tabular}{|l|l|c|}
\hline \multicolumn{2}{|c|}{ List of Figures } \\
\hline Figure & Name & Page \\
\hline 1.1 & Research elements of this thesis & 7 \\
\hline 2.1 & Stakeholder literature map & 12 \\
\hline 2.2 & Stakeholder view of the firm & 14 \\
\hline 4.1 & Stakeholder identification questionnaire template, DOC & 81 \\
\hline 4.2 & Relationship between DOC and Stakeholder A and Stakeholder B & 83 \\
\hline 4.3 & Cross relationship between Stakeholder A and B & 84 \\
\hline 5.1 & Stakeholder identification process for DOC & 99 \\
\hline 5.2 & $\begin{array}{l}\text { Stakeholder Network Map 1 - Large scale conservation initiative } \\
\text { in a region of New Zealand }\end{array}$ & 106 \\
\hline 5.3 & $\begin{array}{l}\text { Stakeholder Network Map 2 - Network of engagement between } \\
\text { DOC and one specific stakeholder }\end{array}$ & 108 \\
\hline 5.4 & $\begin{array}{l}\text { Stakeholder Network Map 3 - Growing engagement with target } \\
\text { markets in one division of DOC }\end{array}$ & 110 \\
\hline 5.5 & $\begin{array}{l}\text { Stakeholder Network Map 4 - Growing engagement with target } \\
\text { markets in one division of DOC }\end{array}$ & 112 \\
\hline 5.6 & Stakeholder identification process for MAF BNZ & 114 \\
\hline 6.1 & Proposed 'Stakeholder Network Framework' & 139 \\
\hline
\end{tabular}




\section{CHAPTER 1 \\ INTRODUCTION}

\subsection{Background and Rationale}

Thinking about the original motivation for this thesis takes me back to a memory when it occurred to me that during all my years as a tertiary student there was one particular topic that always got me asking the "what if..." "questions. And it wasn't a topic that just came up in one management paper; it came up in all my papers across psychology, management, economics, commercial law and even accounting sometimes. Stakeholders. From what I was being told and what the literature was saying, they are everywhere and they are important.

What interested me most at the time was the increasing pressure that organisations now face from stakeholders that have never before been on their radar,demanding ethical, environmental, legal, commercial, and public standards as defined by wider society. With advancements in technology continuing to break down traditional boundaries that previously protected organisations from the public eye, they have to learn to operate with a much greater level of transparency and take into account a much broader range of stakeholder groups. Do you think that Nike ever suspected 20 years ago that dedicated groups around the globe would convene through online forums to fight against the social injustice of sweatshops? Or that retailing giant Wal-Mart would ever be so audacious as to ask suppliers to reveal the environmental costs that go into making their products, in order to steer potential U.S. environmental labelling regulations in its favour?

Management literature has a tendency to simplify the stakeholder landscape, but there is a body of research around the concept of 'pluralism' that focuses on the complexity organisations face with more demands from more stakeholders (Denis, Langley, \& Rouleau, 2007; Glynn, Barr, \& Dacin, 2000; Jarzabkowski \& Fenton, 2006). In explaining the pluralism argument, Denis et al. (2007) state that these 
demands can be diverse, conflicting, and complex; and that the stakeholder power may be quite diffused. If an organisation has one primary stakeholder, the diversity is less problematic because this stakeholder's power supersedes the claims that others might promote. But if an organisation has numerous stakeholders with similar power, legitimacy and urgency (Mitchell,Agle \& Wood, 1997), with diverse demands (with this combination representing pluralism), then they face a much more complex stakeholder landscape.

A shift in organisations' attitudes towards stakeholders over the last decade suggests that this complexity is being understood and strategies are being developed to manage it. For example, look at the contrast between Nike being forced to respond on the back foot after more than 10 years of stakeholder pressure by finally admitting the extent of labour abuse with the release of their 'Corporate Responsibility Report' in 2004; and Wal-Mart taking a more proactive approach in early 2009 to significant changes afoot in their political stakeholder landscape. This is supported by existing research that proposes organisations are more and more aware of the value in understanding who their stakeholders are and developing relationships and strategies that lead to opportunities for creating organisational value (Harrison \& St. John, 1996; Cross, Liedtka \& Weiss, 2005; Svendsen \& Laberge, 2005). The global uptake of triple bottom line reporting, which involves the measurement, management and reporting of economic, environmental and social performance indicators (Miller, Buys\&Summerville, 2007), also suggests that organisations are beginning to think more broadly about how they create value.

Upon transitioning from university into the practical realities of working as a strategic management consultant, my stakeholder perspective was broadened from that of a private sector profit-driven view when my work took me into the public sector environment. I was immersed in the politics of budget allocations, competition for government funding, constant pressure from the public and various interest groups for protection and consideration of their interests, increasing demand for more products and services delivered efficiently by Government without impacting the taxpayer or New Zealand's broader fiscal situation... The list goes on 
and it crystallised that public sector organisations are under increasing pressure to meet growing demand across a wide range of social products and services; while at the same time, considering the varied interests of multiple stakeholder groups and ensuring public value is created through the most efficient utilisation of resources (taxpayer money).

It would be difficult to argue anything other than that this represents a highly pluralistic stakeholder landscape for the public sector. It has been established in public management research that the multiplicity of stakeholder interests influencing public sector organisations is considerably more complex than for most private sector organisations whose focus is often limited to those stakeholders who impact the bottom line (Ring \& Perry, 1985; Davenport \& Leitch, 2005; McAdam, Hazlet \& Casey, 2005). And even though public sector organisations are not profit driven the pressure to operate in an environment where government budgets are continually being tightened while still having to meet growing demand means that decision making must still be driven by a financial perspective.

Therefore, not only do public sector organisations have the onerous role of achieving national goals and creating public value, but they must also operate within the financial constraints of tighter government budgets while constantly balancing the complexity of conflicting interests from multiple stakeholder groups; who have varying degrees of influence that are constantly changing.

So the obvious question is 'how are they going to meet the growing demand for public products and services in an efficient manner that does not put additional strain on New Zealand's resources?' An area where public sector organisations are particularly focussing attention is in shifting to a mindset of partnership and collaboration with key stakeholders; where they develop relationships and work with stakeholders across both the public and private sector to create opportunities for delivering products and services more efficiently and effectively, and in doing so create greater public value. A primary rationale is the sharing of resources for 
efficiency. In order to develop strong strategic relationships, public sector organisations have to integrate stakeholder thinking at a strategic level.

A good example of how public sector organisations are reflecting this shift at a strategic level is outlined in the MAF Biosecurity New Zealand strategic profile document, which discusses the challenges of thriving trade among the global markets that result in increasing biosecurity threats (MAF BNZ Profile, no date). In response to the task of protecting New Zealanders, its natural resources, plants and animals from the potential introduction of pests and diseases, MAF Biosecurity states ( $p$ 4);

We're not alone in this task - our staff, partner organisations, government agencies, businesses exporting and importing goods, the general public, and of course international visitors, all play a role in helping keep New Zealand free from biosecurity threats...Building a biosecurity system is a collaborative project. It takes a whole country.

The strategic profile goes on to describe the biosecurity system as a collaborative project that involves the whole country, outlining the many groups and organisations required to work together. Other public sector organisations are also taking a similar approach to working jointly with stakeholders to achieve their objectives and goals, evident through various strategic plans and related documents available within the public sector. In order to put this in to practice and ensure they do actually progress toward collaborative and partnership methods, organisational strategies need to filter down to the group plan level. The following quote from the plan of a group within Biosecurity New Zealand is an example of this(MAF BNZ Pest Management Group plan, 2007, page 8);

We want to develop a shared direction and vision of pest management with stakeholders and we want them to contribute positively to strategic direction setting.

With public sector organisations requiring such a strong strategic focus on stakeholders, I began to think back to the stakeholder management theories I came across while studying andI realised that the majority of them were developed from a 
private sector perspective in order to manage stakeholders more consciously to create organisational value and increase profits. So I could not help wondering how stakeholder theories might be applicable in a public sector context and whether these could contribute to the necessary strategic conversations and decisions that were required to move public sector organisations toward this new direction. This raised questions such as, who are the organisation's strategic stakeholders, what are the missing stakeholder relationships and where is focus needed to develop improved strategic relationships, how should existing stakeholder relationships be managed, are there stakeholders that could be leveraged to achieve other strategic goals, and which stakeholder relationships can be mobilised for strategic purposes?

Asking these questions brought about the motivation for this thesis.

\subsection{Purpose of Research}

Stakeholder literature has also been grappling with understanding multiple stakeholder influences in an attempt to progress from simply looking at singular relationships between an organisation and one stakeholder to analysing whole networks of stakeholders where an organisation's stakeholders are likely to have direct and indirect relationships with each other. Rowley (1997) created a foundation for this area with his stakeholder networking theory that is based on the principles of social network analysis. His investigation showed how the structure of an organisation's stakeholder network can influence the behaviour of an organisation in response to stakeholder pressure. He considered the entire network of relationships, not just individual links in isolation.

With a particular interest in the concepts underpinning Rowley's (1997) theory, I wanted to investigate whether stakeholder networking theory was applicable in the public sector and if so, could mapping an organisation's stakeholder network make a useful contribution to strategic planning in the public sector by assisting organisations to develop stakeholder relationships that would meet the challenges discussed above. 
I am not sure whether it was my inherent practical nature that led me into consulting, or my consulting experience that taught me the importance of practicality, but I had a strong desire from the outset for the knowledge that I generated through this research to have useful practical implications for public sector managers. I know that research papers always concludes with an 'implications for management practice' section, but I wanted to give this more prominence and proactively gather information on the practical challenges that organisations face when adopting new management practices. I have been exposed to numerous examples of organisations' failed attempts at implementing new approaches and therefore, recognised this as an opportunity to understand the management issues that might constrain public sector organisations in applying stakeholder networking theory so that they can plan for these before initiating the process and increase the likelihood of success.

\subsection{Research Objectives}

Drawing on the motivation and purpose of the research described above, the following research objectives were formulated:

1) To determine the applicability of stakeholder networking theoryin the public sector

2) To understand the management issues that arise in the practical application of stakeholder networking theory in the public sector

3) To investigate the use of stakeholder networking theory for strategic planning in the public sector

\subsection{Structure of Thesis}

The thesis is structured around effectively meeting the research objectives set out above. It provides a logical end-to-end account of my entire research journey from the original motivation in Chapter 1 through to considerations for future stakeholder research in Chapter 6. A more detailed description of each chapter is presented below. 
Beginning with an exploration of the existing literature that relates to the topics of stakeholder networking theory and strategic planning, Chapter 2 sets the scene by recapping the evolution of stakeholder theory and compares and contrasts different researchers' propositions of the stakeholder concept and how they have applied it. It then goes on to introduce the progression into stakeholder networking theory and how it came about from the fundamental principles of social network analysis. Finally, a review of research at the intersection of stakeholder theory and strategic management theory provides the foundation for linking this together with stakeholder networking theory. This leads to the research gap, as there has been limited research completed on how stakeholder networking theory can contribute to the practice of strategic management.

Chapter 3 then outlines the context in which the research is conducted - the public sector - and presents a view of the drivers in New Zealand's current political environment that are forcing public sector organisations to adopt more comprehensive and strategic stakeholder practices. Existing stakeholder networking and strategic management research in the public sector is also reviewed to further support the research gap.

The following diagram provides a visual representation of these key research elements underpinning my thesis, showing how they flow and link together. It also illustrates the logical structure in which they are reviewed across Chapter 2 and 3.

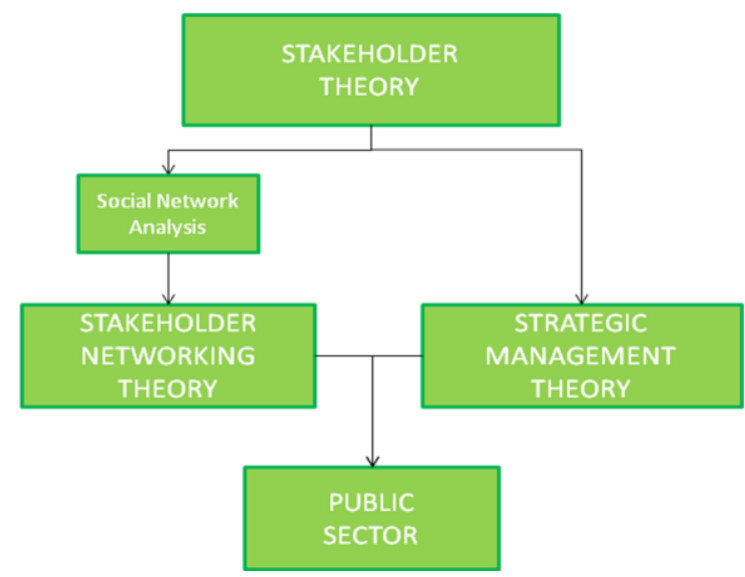

Figure 1.1. Research Elements of this Thesis 
Chapter 4 outlines the research approach to gathering and analysing the information to meet the research objectives. It provides a thorough description and rationale of the selected sampling techniques and specific research methods used, including the ethical considerations that had to be managed as a result of my previous involvement with the organisations and any differences of approach between the two sample organisations. Due to the practical nature of my research, the section on 'challenges in the research process' is a significant aspect to this chapter.

Chapter 5 presents the findings obtained through conducting the research as per the approach and methods explained in Chapter 4. The findings do not neatly fit under each research objective, as they are interrelated. The results are presented in terms of each research objective, firstly describing the process and results of stakeholder identification for each organisation, then the issues that arose during application of the process, and finally, the benefits and uses of stakeholder networking theory for strategic planning. It is worth noting that the findings for the two organisations are reported separately in order to compare and contrast the key differences.

The findings are then brought together and discussed in an integrated manner in Chapter 6, 'Discussion and Conclusion'. To interpret the findings relating to the applicability of stakeholder networking theory in the public sector, a Stakeholder Networking Framework has been proposed to guide organisations in the use of stakeholder networking theory. This development of this Framework considered the issues that participants reported during application and therefore has been designed to overcome these issues. The findings relating to the usefulness of stakeholder networking theory for strategic planning in the public sector are also further elaborated, before discussing implications for managerial practice and future research, and finally the limitations and thesis conclusions. 


\section{CHAPTER 2}

\section{LITERATURE REVIEW}

\subsection{Introduction to Chapter}

Stakeholder theory has disseminated through a wide variety of research fields (Donaldson \& Preston, 1995; Preble, 2005) since it was popularised by Freeman with his foundational book Strategic Management: A Stakeholder Approach (1984), lending evidence that it is a fundamental concept in the management of organisations.

In its infancy, the focus of stakeholder research was about organisations identifying and classifying their stakeholders in order to gain an understanding of their external environment, and manage the multiple drivers and influences (Mitchell et al., 1997). Perspectives on stakeholder theory have evolved from an entirely corporate-centric focus where stakeholders were viewed as subjects to be managed (Freeman, 1984), towards a more network-based and relational view of company-stakeholder engagement with consideration of mutuality, interdependence and power (Ambler \& Wilson, 1995). This field of stakeholder thinking developed into what is now known as stakeholder networking theory (Rowley 1997).

This chapter presents a review of the literature that illustrates this progression in stakeholder thinking, beginning with the earliest allusions to the stakeholder concept in the $18^{\text {th }}$ century right through to the latest thinking in stakeholder networking theory. This will include a review of Freeman's (1984) contribution to stakeholder theory, the range of literature that has attempted to define a stakeholder concept over the decades, the extension of thinking beyond the dyadic stakeholder perspective to stakeholder dynamics and multiplicity, and finally to the development of stakeholder networking theory that has arisen from a need to consider multi-stakeholder environments. 
The connection between stakeholder theory and strategic management is not new, which will be demonstrated through a review of related literature in the final section. However, the use of stakeholder networking theory in the field of strategic planning is not something that has been well explored. Having identified the limitations in this area, the chapter will draw to a close by identifying the research gap and setting the focus for the remainder of the thesis.

\subsection{Stakeholder Theory}

The stakeholder concept has a long and evolving history in the field of management. Andriof, Waddock, Husted, and Rahman (2002) provide a comprehensive review of the emergence of stakeholder thinking over the decades. This review has been adapted to provide the structure for the beginning section of this literature review and is supported by other relevant literature.

\subsubsection{The Evolution}

Evidence of the stakeholder idea can be traced back to the early application of moral philosophy concepts to economic theory in Adam Smith's seminal works The Theory of Moral Sentiments (1759) and The Wealth of Nations (1776), which proposed that societies function best when economic interests and ethical interests are aligned, advocating for collaborative initiatives and one large world community (both books cited in Andriof et al., 2002). By the 1930's, the underlying notion that society needed to be linked to business operations was prevalent due to the broader business environment perspectives of influencers such as Chester Barnard, Functions of the Executive(Andriof \& Waddock, 2002). Barnard (1984) stated that organisations must be certain about 1) the purpose of their decisions and actions; and 2) the physical and social world in which they exist, and the external forces and circumstances of the environment that are constantly changing.

Here began the roots of modern corporate social responsibility, which has subsequently been a significant influence to the fundamental concepts of stakeholder theory (Harrison \& Freeman, 1999; Friedman \& Miles, 2006). Andriof et al. (2002, 
p 12) list many authors that provided early support for the connection between business and society between 1932 and 1959. Ironically, these early efforts to expand organisation perspectives were inhibited by the emergence of the neoclassical economic view of the business environment, which interpreted the language of 'business and society' to mean the two could be separated and the business could exist independently of its surrounding society. Consequently, organisations adopted a corporate-centric perspective, which was limited to increasing revenues in order to satisfy investors (Andriof et al., 2002; Preble, 2005).

It was not until 1963, when the Stanford Research Institute (SRI) actually coined the term "stakeholder" to define those who have a critical interest in the operation and success of an organisation, that scholars began to increasingly apply stakeholder concepts within their field and entrench it into the management literature (Elias, Cavana \& Jackson, 2002; Freeman, 1984; Andriof \&Waddock, 2002). The original definition was reported by the Institute as "those groups without whose support the organisation would cease to exist" (Freeman, 1984, p 31). It was argued that organisations are seen as social institutions with responsibilities beyond their fiduciary responsibility to shareholders, directors and employees (Bowie, 1982, cited in Ambler \& Wilson, 1995). The original list of stakeholders that the SRI proposed included shareowners, employees, customers, suppliers, lenders and society; and they argued that unless executives understood the needs and concerns of these stakeholder groups, they could not formulate corporate objectives that would receive the necessary support for continued survival of the organisation (Freeman, 1984).

From this point in stakeholder history, the stakeholder concept was researched and developed as illustrated by Figure 2.1, reproduced from Elias et al. (2002). This diagram also provides the context for the remaining literature review.

After the SRI introduced the term "stakeholder", research was conducted under four primary fields, each exploring the stakeholder concept in relation to different management areas. Freeman (1984) labelled this the 'classical stakeholder literature'. The primary area of interest for this thesis is the integration of the 
stakeholder concept into the corporate planning and strategic management literature. However, before reviewing research conducted in this area, it is first necessary to define the stakeholder concept and explore its progression to stakeholder networking theory, in order to introduce all the research dimensions of the thesis. The link between stakeholder theory and strategic management will then be discussed in Section 2.4 drawing on a clear understanding of the stakeholder concept.

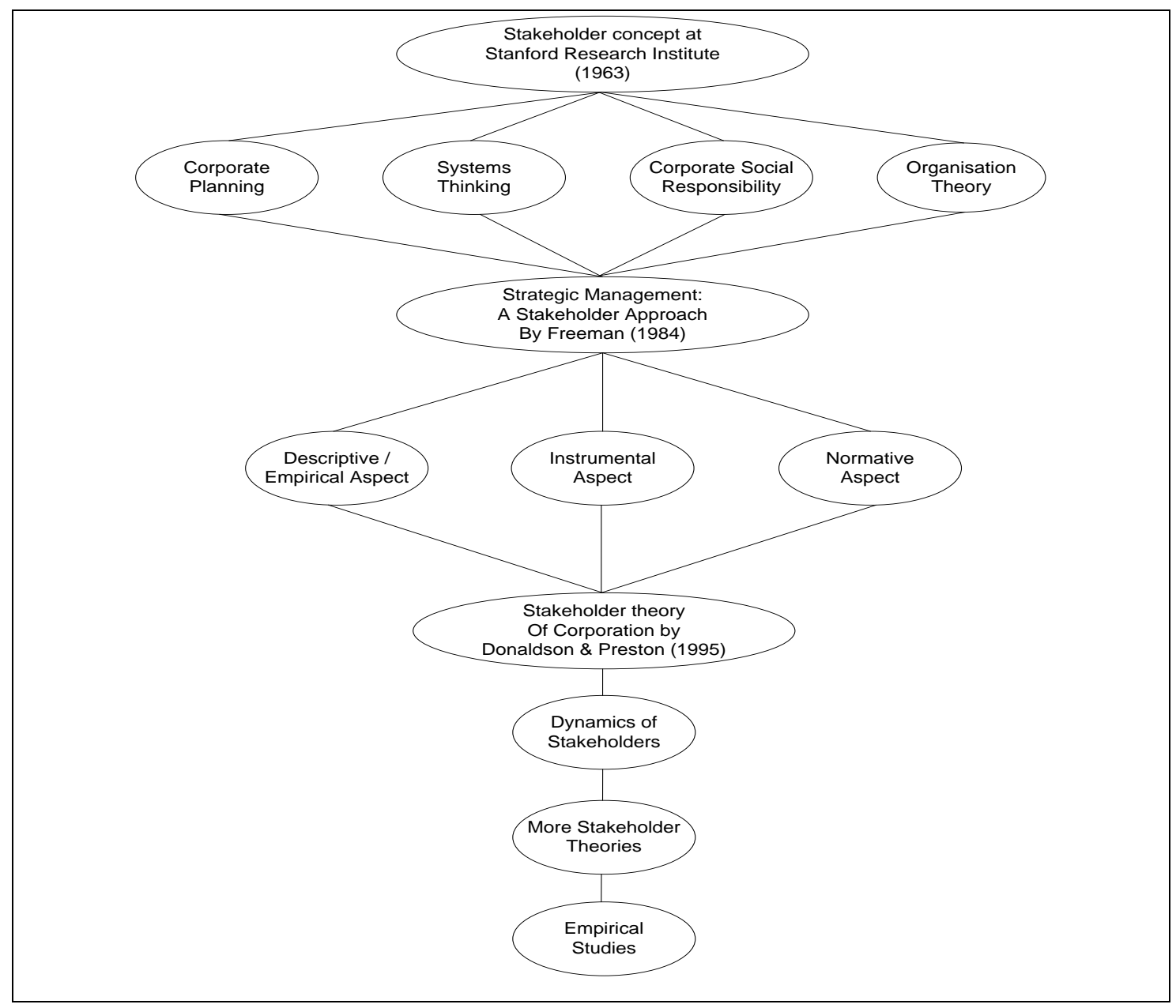

Figure 2.1. Stakeholder Literature Map (Elias et al., 2002).

\subsubsection{Freeman's Contribution to Stakeholder Theory}

Following the formalisation of the term stakeholder, Freeman instigated the next major development stage of stakeholder theory with his 1984 book (Freeman, 1984). The following review of his contribution comes from this book, Strategic Management: A Stakeholder Approach (1984), which includes all references to various organisation models and their progression. 
Freeman believed that organisations face increasingly turbulent times and that current organisation theories were inconsistent with the quantity and kinds of changes of the developing business environment. Up until the early 1980's, organisational models emphasised the static nature of organisations and only certain aspects of the external environment. For example, the production view of the firm is a simplistic model that focuses primarily on suppliers who contribute raw materials to the organisation which transforms them into products to be delivered to customers. Thus, organisations' dominant focus is on supplier and customer stakeholders. As organisations grew and more capital was required to support the purpose of the organisation, ownership and management came to be considered separately. Then, organisations had to satisfy not only suppliers and customers, but owners and employees as well. This became known as the managerial view of the firm. In this situation, Freeman argued that if organisations continued to manage using the concepts and techniques of the 'production view' without considering the additional stakes of owners and employees, the result would either be failure to achieve organisation objectives or debilitating labour strikes.

Similar to a conceptual shift being required from the 'production view' to the 'managerial view', Freeman (1984) reasoned that both these views were inappropriate for effectively handling the increasingly turbulent environment that organisations continue to face. Therefore, he argued that a new conceptual framework was needed to represent a more realistic view of the organisation that accounts for the emergence of numerous stakeholder groups and new strategic issues in order to be successful. The ideal view would take a system perspective to try and reduce the uncertainty of the external environment, as opposed to multiple siloed responses that result in fragmentation across the organisation.

Freeman (1984) represented this new perspective of how the organisation interacts with the more complex business environment using a map that illustrates all the generic "groups and individuals that can affect, or are affected by, the accomplishment of the organisational purpose" (Freeman, 1984, p 25). They are linked to the organisation, which is depicted at the centre of the map, using double ended arrows to emphasise the two way relationship (Figure 2.2). Mahon, Heugens 
\& Lamertz (2004) likened this framework to a 'hub-and-spoke' model that conceptualises the organisation at the centre of the stakeholder set and only considers relationships involving that organisation and one other party at any given time i.e. dyadic relationships or one-on-one relationships. Thus, the organisation in consideration is often referred to as the "focal organisation". Freeman proposed that each group has a stake in the organisation, hence the term stakeholder. He defined the term stakeholder as "any group who can affect or is affected by the achievement of the firm's objectives" (Freeman, 1984, p 46).

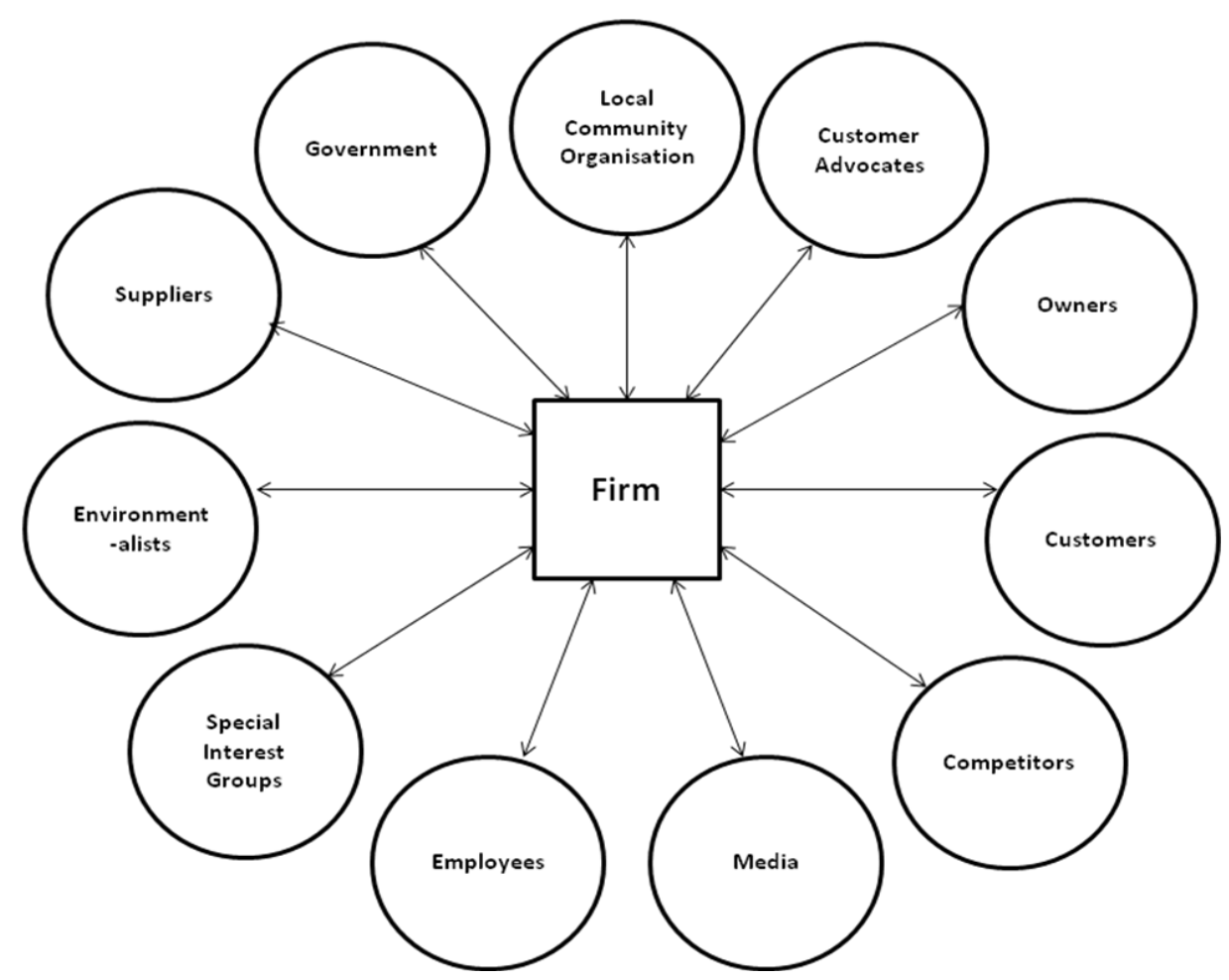

Figure 2.2. Stakeholder View of the Firm (Freeman, 1984, p 25)

Donaldson and Preston (1995) compare this model with the conventional inputoutput model of a private/corporate organisation to explain how the stakeholder view of an organisation differs from existing models. They describe that the stakeholder model proposes that all persons or groups with legitimate interests who participate in an organisation obtain benefits, and that there is no priority of one set of interests and benefits over another (Donaldson \& Preston, 1995). They proceed to highlight the different nature of stakeholder theory by describing other theories that attempt to explain organisation behaviour. In comparison to these other theories, stakeholder 
theory "views the organisation as a conduit for numerous participants to accomplish multiple purposes, which are often not congruent; and it is intended both to explain and to guide the structure and operation of the established corporation" (Donaldson \& Preston, 1995, p 70).

While the stakeholder model of the firm presents generic stakeholder groups, its purpose was to encourage managers to expand their perspective beyond only focussing on profit maximisation by considering the wider externalbusiness environment. Freeman (1984) was primarily referring to understanding and responding to all stakeholder groups other than solely stockholders. The main assumption behind the stakeholder model is that in dealing with these groups, an organisation develops strategies that guide behaviour and engagement in linewith the interests of those groups. In doing so, it is assumed that these stakeholder groups can be proactively managed toenable the organisation to achieve its goals and objectives (Freeman, 1984). This leads to Freeman's definition of 'stakeholder management' as a concept; it "refers to the necessity for an organisation to manage the relationships with its specific stakeholder groups in an action-oriented way" (Freeman, 1984, p 53).

To achieve this, Freeman (1984) provides a stakeholder analysis framework as a prescriptive managerial tool with two purposes; 1) to assist organisations in developing stakeholder management capability by having the necessary processes in place and using them effectively to manage relationships with its stakeholders; and 2) to define an organisation's stakeholder management capability in terms of how well the framework is integrated in organisation operations. The framework consists of three levels; the Rational Level identifies who are the stakeholders of the organisation and what are their perceived stakes; the Process Level focuses on what processes the organisation has in place to manage relationships with its stakeholders; and the Transactional Level looks at the "transactions or bargains" between the organisation and its stakeholders (that is, how does the organisation interact with its stakeholders and what resources are allocated to support interaction?). There must also be alignment between each of the levels; for instance, the processes used to manage relationships must fit with the identified stakeholders, and interaction at the 
transaction level must fit with the processes adopted. Freeman (1984) provides a more in depth discussion of the steps in each level of the framework for practical application.

The first level, Rational Level, is the part of the framework that focuses on the identification of stakeholders. It has four key steps;

1) Developing a stakeholder map

2) Preparing a chart of specific stakeholders

3) Identifying their stakes

4) Preparing a power versus stake grid

An example of a practical application of Freeman's (1984) stakeholder analysis framework can be found by Elias et al. (2002) who used the tool in conjunction with other methodologies to determine the stakeholder management capability of a major $R \& D$ infrastructure project. The framework was originally proposed for analysis of an organisation and therefore, the authors were able to conclude that it is an appropriate tool for analysing stakeholders in a project environment. They reported that the primary benefits of using the methodology were that it provided a systematic approach to identify and classify the stakeholders, and analyse their interests so that interaction and communication throughout the project could be more valid and meaningful (Elias et al., 2002).

Freeman's definition of stakeholder is purposefully all encompassing so as not to exclude any group or individual that could affect or is affected by organisational purpose, because they may prevent the organisation's accomplishments (Freeman, 1984). Freeman raises two areas of concern with such a broad definition. Firstly, he states that "when we put this concept into practice we must be willing to ignore certain groups who will have little or no impact on the corporation at this point in time" (Freeman, 1984, p 53). Secondly, strategies must also be put in place to deal with stakeholders who might be considered adversarial or have an illegitimate stake in the corporation, for example terrorists, as they too can substantially affect an organisation's operations. 
Freeman's view of the stakeholder organisation was the first detailed and elaborate description of a stakeholder approach. Subsequently, the stakeholder concept achieved greater prominence and significant themes of research evolved in an attempt to develop the beginnings of the stakeholder concept, and to establish stakeholder thinking as a theory in its own right as opposed to an advancement of other theories(Friedman \& Miles, 2006).

\subsubsection{The Stakeholder Concept and Implications for Managers}

Post Freeman's (1984) landmark book, authors have developed and refined definitions and concepts relating to stakeholder, stakeholder model, stakeholder management, and stakeholder theory; and applied them across a range of organisation contexts and situations to present evidence and contribute insights to the stakeholder literature (Donaldson \& Preston, 1995; Preble, 2005). However, still to this date, a universally accepted definition of the term stake or stakeholder remains elusive with authors continuing to resolve the stakeholder identification problem and raising practical implications for managers (Clarkson et al., 1994; Donaldson \& Preston, 1995; Mitchell et al., 1997; Andriof \& Waddock, 2002; Driscoll \& Starik, 2004; Bryson, 2004; Dunham, Freeman \& Liedtka, 2006; Achterkamp \& Vos, 2007). Freeman (1994) referred to this as "the principle of who or what really counts". The following section is a review of some these foundational different stakeholder concepts and stakeholder identification models that have been presented over the years to assist managers in adopting a stakeholder approach in practice.

Stakeholder theory is not just about organisations having stakeholders, which has often been the focus of research and has resulted in a lack of understanding as to the depth of this field(Donaldson \& Preston, 1995). A major premise is that it is the responsibility of managers, and the wider management function, to make decisions and operate in a way that considers benefits for stakeholders (Donaldson \& Preston, 1995). Therefore, these two dimensions of stakeholder research - 1) defining the stakeholder concept for identification of stakeholders and 2) the implications of the stakeholder concept for organisational managers - will be reviewed concurrently throughout this next section. 


\title{
2.2.3.1 The Variety of Stakeholder Definitions
}

Extensive research has been conducted on stakeholder theory and the outcome has been a diverse understanding of the stakeholder concept, which questions whether the growing body of literature actually forms an agreed scope of stakeholder theory (Harrison \& Freeman, 1999). Mitchell et al.'s (1997) thorough chronology of different stakeholder definitions that arose between 1963 and 1995 further illustrates this broad and inconclusive nature of the stakeholder concept, but also provides a clear idea of the essential characteristics that most authors perceive a stakeholder to possess. The following paragraph provides a summary of the variety of definitions documented in their review (Mitchell et al., 1997, p 853):

\begin{abstract}
We will see stakeholders identified as primary or secondary stakeholders; as owners and nonowners of the firm; as owners of capital or owners of less tangible assets; as actors or those acted upon; as those existing in a voluntary or involuntary relationship with the firm; as right-holders, contractors, or moral claimants; as resource providers to or dependents of the firm; as risk-takers or influencers; and as legal principals to whom agent-managers bear a fiduciary duty.
\end{abstract}

Some of the early stakeholder theories looked at transactional definitions, such as Hill and Jones (1992) who suggested that stakeholders are groups that supply an organisation with critical resources in exchange for their interests being satisfied. For example, shareholders supply capital in exchange for a return on their investment, employees supply their time in exchange for adequate income and working conditions, consumers supply money in exchange for goods and services that are of value to them, and suppliers provide raw materials in exchange for revenue. To determine which of these stakeholders are of most importance Hill and Jones (1992) suggested that the size of a stakeholders' stake in an organisation is a function of the amount of their 'specific asset' that they invest, whether it be time, money, raw materials etc. They propose that a 'specific asset' is an asset "that cannot be redeployed to alternative use without a loss of value" (Hill \& Jones, 1992, $\mathrm{p}$ 133). Therefore, a stakeholder would have a lower stake in an organisation if they could reinvest their asset somewhere else for the same value. Conversely, if a stakeholder had to reinvest their asset at a lower value, they are considered to have a high stake in the organisation. Hill and Jones (1992) argue that this is an important distinction, because stakeholders with a high stake will demand greater controls and 
governance structures around their contract of exchange in order to protect their asset-specific investments, creating implications for the way organisations balance these demands.

Taking a more social view of stakeholder identification, researchers have also looked at the relationship between stakeholders, social responsibility and organisational performance (Harrison \& Freeman, 1999; Steurer, Langer, Konrad \& Martinuzzi, 2005). Some theories have taken a very broad perspective, such as Argandona (1998) who suggests that stakeholder theory could be founded on the concept of common good, whereby an organisation's stakeholder list extends to the point where it "encompasses all men of all times, by virtue of the unity of the human family" (Argandona, 1998, p 1099). By considering all social relations an organisation maintains with this broad group of stakeholders, the common good of the relationship can be identified and the rights and duties of the stakeholder and the organisation can emanate from that common good. The result being that the organisation 'does good' to many groups, either by obligation or more voluntarily, which extends from groups within the organisation out to the "local community, the country and all humankind, including future generations" (Argandona, 1998, p 1099). The practical implications of this stakeholder concept for managers raise questions around balancing efficiency and the organisation's capacity with meeting stakeholders' needs.

Narrowing the focus of the social responsibility perspective of stakeholder theory, other researchers have argued for the need to measure an organisation's performance based on how effectively it responds to stakeholders (Clarkson, 1995; Perrini \& Tencati, 2006). For example, Clarkson (1995) developed a framework and methodology for analysing and evaluating corporate social performance, and proposed that in order to be socially responsible, organisations had to respond to stakeholder issues and pressures. Therefore, stakeholders were a fundamental dimension of the organisation that had to be understood so that performance could be measured. This was later supported by the Sustainability Evaluation and Reporting System (SERS) presented by Perrini and Tencati (2006) that was designed to monitor an organisation's performance against its stakeholder framework. 
Clarkson's resulting definition of stakeholders was (Clarkson, 1995, p 106):

persons or groups that have, or claim, ownership, rights, or interests in a corporation and its activities, past present or future. Such claimed rights or interest are the result of transactions with, or actions taken by, the corporation, and may be legal or moral, individual or collective. Stakeholders with similar interests, claims, or rights can be classified as belonging to the same group: employees, shareholders, customers, and so on.

As well as the transactional and social view of the stakeholder, researchers such as Goodpaster (1991) and Frooman (1999) have adopted an approach of splitting stakeholders into two groups - strategic and moral - based on Freeman's (1984) original stakeholder definition. The strategic stakeholder refers to one "who can affect a firm" (Freeman, 1984) and therefore, this group is viewed as stakeholders who interests should be managed. The moral stakeholder is one "who is affected by the firm" (Freeman, 1984), and it is suggested that these stakeholders require a balancing of interests.

Some authors argue that the excessive breadth in the stakeholder concept and the diversity of stakeholder identification models has arisen from all encompassing definitions such as Freeman's “any group who can affect or is affected by the achievement of the firm's objectives" (Freeman, 1984, p 46). This is because they lack rationale and criteria for identifying stakeholders of an organisation (Ambler \& Wilson, 1995; Donaldson \& Preston, 1995; Argandona, 1998; Gioia, 1999). It is suggested that this sort of definition opens the stakeholder set to an organisation's wider environment and while some stakeholders might impact or influence an organisation, they do not necessarily gain any particular benefit from the organisation, i.e. have a stake(Donaldson \& Preston, 1995). This is supported by Argandona (1998) who argues that while it might be prudent to take all stakeholders into account, it does not necessarily mean that an organisation has a duty to them. In fact, Gioia (1999) explains it more bluntly than that saying (p 229);

Everyone with any important decision experience in a business organisation knows that the constellation of legitimate stakeholder interests cannot be weighted equally when making corporate decisions. It is pragmatically naive to suggest 
otherwise....Trying to juggle all interests and accord them egalitarianism is a sure way for influential managers to find themselves bereft of their influence.

\subsubsection{Determining Stakeholder Salience}

As a result of the realisation that not all stakeholders are important, research began to investigate how to differentiate importance in order to identify legitimate stakeholders (Donaldson and Preston, 1995). Some theories have been quite simple in that stakeholders are classified according to whether they are primary or secondary stakeholders (Clarkson, 1995). Primary stakeholders are those whose continued and direct participation or input is crucial for the organisation's survival as a going concern, e.g. owners, investors, employees, suppliers, customers and competitors. Secondary stakeholders are described as those who might influence or be influenced in the past, present, or future by the organisation's operations, without directly engaging in transactions. Hence, they are not essential to the survival of the organisation. Examples here include local communities, local government, social activist groups and business support groups (Clarkson, 1995).

The theory of stakeholder salience(Mitchell et al., 1997) also sought to fill this need, which proposes that managers can determine a stakeholder's salience based upon their possession, or perceived possession, of one or a combination of the following three attributes -1 ) the stakeholder's power to influence the organisation, 2) the legitimacy of the stakeholder's relationship with the organisation, and 3) the urgency of the stakeholder's claim on the organisation. Power refers to a stakeholder's ability to bring about the outcomes they desire, legitimacy refers to whether a stakeholder's actions are perceived to be desirable, proper, or appropriate based upon society's norms and values, and urgencyrefers to the degree to which a stakeholder claim requires immediate attention due to its critical or highly important nature (Mitchell et al., 1997). The more characteristics the stakeholder possesses, the more salient they are. In addition to this, Driscoll and Starik (2004) propose a fourth stakeholder attribute of proximity based on the belief that spatial distance can be as important in stakeholder interactions as is time (i.e. the urgency attribute). They conclude that the natural environment, which encompasses the atmosphere, 
hydrosphere, lithosphere, ecosystem processes, and all human and non-human life forms, should be considered a primary stakeholder.

Moving beyond traditional stakeholder thinking that focuses on stakeholders as a threat to organisational success, Madsen and Ulhoi (2001) suggest that the importance of stakeholders should also be determined by considering those who offer opportunities for organisations. Therefore, adopting the rationale of the SWOT analysis, they propose a theory of SPOT analysis - secondary, primary, opportunity, threat - whereby, once stakeholders and their stakes have been identified, they can be categorised as either a threat to the achievement of the organisation's objectives; or as an opportunity for improving business by encouraging new ideas, exposing market niches, contributing information and knowledge, and communicating expectations (Madsen \& Ulhoi, 2001).

Overall, these sections illustrate that multiple models and theories of stakeholder identification have been proposed across a variety of organisation settings. This suggests that it can be a complex and complicated task that may vary depending on different organisation circumstances.

\subsubsection{The Use of Stakeholder Theory in Practice}

As well as research on defining and identifying stakeholders, stakeholder theory has also been used in a number of ways since its inception into management literature. Donaldson and Preston (1995) categorise these uses as descriptive/empirical, instrumental, and normative. Examples of research under each type are presented below to illustrate these categories of use and also to summarise the broad range of stakeholder literature that has been developed over the years.

Descriptivelempirical refers to how stakeholder theory is used to describe and explain specific corporate characteristics and behaviours, such as the nature of the firm, how managers think about managing, consideration of constituencies, how organisations are managed (Donaldson \& Preston, 1995). For example, Hill and Jones (1992) applied stakeholder theory in conjunction with agency theory to explain 
organisation strategic behaviour and the nature of contractual relationships between an organisation's stakeholders. The result was a modified agency theory that attempts to address the complexities of power differentials between managers and stakeholders, and resource dependencies of organisations.

Other examples include investigation of the impact of stakeholder initiatives on corporate management and recommendations for successful implementation of stakeholder initiatives (Grafe-Buckens \& Hinton, 1998); and identification of different ways in which stakeholders can participate in organisations, and when and how they should be engaged in decision making processes (Brugha, \& Varvasovszky, 2000; Green \& Hunton-Clarke, 2003).

Instrumental refers to how stakeholder theory is used to identify the connections, or lack of connections, between stakeholder management and the achievement of organisation objectives e.g. profitability and growth. Research in this area tends to generate implications suggesting that adherence to stakeholder principles and practices will result in better organisation performance (Donaldson \& Preston, 1995). Examples of instrumental research include, identifying the link between stakeholder theory and strategic thinking, and the impact on strengthening the value chain (Freeman \& Liedtka, 1997); demonstrating evidence of how successful stakeholder partnerships create valued benefits such as product success rates, increased manufacturing efficiency, development of distinctive competencies, reduced negative litigation and publicity, and favourable regulatory policies (Harrison \& St John, 1996); rationalising stakeholder management from an economic perspective and understanding the relationship with shareholder wealth (Clarkson, 1995; Blair, 1998; Hillman \& Keim, 2001); addressing how and why managers might pursue stakeholder identification and analysis in order to meet mandates, fulfil missions and create value (Bryson, 2004); and adopting innovative strategies for engaging stakeholders to assist in gaining competitive advantage and outperforming competitors (Howard, 1998; Harting, Harmeling, \& Venkataraman, 2006).

Normative refers to how stakeholder theory is used to understand the function of an organisation in relation to the moral and philosophical guidelines that direct the 
operation and management of the organisation (Donaldson \& Preston, 1995). Jonker and Foster (2002) present a largely normative theory that provides some understanding of what constitutes a stakeholder, what stakes they seek to protect and the way in which transactions between the stakeholder and the organisation are handled. The guiding principles and the complexity in adopting a stakeholder perspective are discussed. Kochan and Rubinstein (2000) seek to address the normative question "why should stakeholder models be given serious consideration at this moment in history?"

It can be seen that the stakeholder concept has been the topic of much management research since the 1980 's. Many different theories have been developed to try and define the stakeholder concept, which appear to change depending on the organisational context and the purpose for which managers are trying to understand their stakeholders. However, even though the stakeholder concept has been defined and investigated through a range of different perspectives, and numerous stakeholder identification models have been proposed, the actual identification issue is still unresolved (Argenti, 1993; Ambler \& Wilson, 1995; Hall and Vredenburg, 2005). Even recent studies refer to an apt quote from Mitchell et al. back in 1997 (cited in Dunham et al., 2006, p 23-24):

[they] review exhaustively the vast literature on the subject and conclude that stakeholder theory "offers a maddening variety of signals on how questions of stakeholder identification might be answered...Among the various ways of identifying stakeholders, as well as in the agency, behavioural, ecological, institutional, resource dependence, and transaction cost theories of the firm, we have found no single attribute within a given theory that can guide us reliably on these issues".

The implications of this complex stakeholder landscape for managers in practice have not been ignored (Argenti, 1993; Ambler \& Wilson, 1995; Hall and Vredenburg, 2005). It has been suggested that organisations which try to benefit all stakeholders are at a huge competitive disadvantage and that the task is plainly unmanageable (Argenti, 1993). It has also been questioned whether all of this research has led to clarity around how organisations are supposed to go about 
identifying their stakeholder groups or determining their stakeholders' interests objectively (Ambler \& Wilson, 1995; Harrison \& Freeman, 1999; Madsen \& Ulhoi, 2001; Preble, 2005; Dunham et al., 2006). This has been further supported by Hall and Vredenburg (2005), who refer to this challenge as stakeholder ambiguity (i.e. the difficulty in identifying stakeholders, engaging and communicating with them, and even clearly articulating their stakes and positions). They state that even though the stakeholder concept presents much opportunity for businesses, stakeholder ambiguity is difficult to manage because it is idiosyncratic and context-specific. They further propose that managers are not prepared with the required skills and experience to deal with stakeholder ambiguity and as a result often revert to formulaic decision making frameworks to deal with stakeholders, which misrepresent the challenges (Hall \& Vredenburg, 2005).

In summary, the context around the evolution of the stakeholder concept and stakeholder theory has been established. It can be seen that while growing popularity of stakeholder theory reflects an increasing recognition of how stakeholders influence organisations' decision making processes, the definitional and identification problems continue to plague stakeholder management literature. This has a number of implications for managers attempting to integrate a stakeholder perspective into their daily management practice in the absence of a well defined approach. The literature review will now move to the next biggest evolution in stakeholder theory, which is stakeholder dynamics.

\subsubsection{Stakeholder Dynamics}

Up until this point, the body of stakeholder literature has one thing in common; as per Freeman's first conceptualisation of the stakeholder organisation (refer back to Figure 2.2), research has traditionally concentrated on the focal organisation and its dyadic (one-on-one) relationships with stakeholders (Rowley, 1997; Jawahar \& McLaughlin, 2001; Andriof \& Waddock, 2002; Neville \& Menguc, 2006). It was recognised that although focussing on individual stakeholder relationships may be appropriate for static aspects of stakeholder relationships, such as identifying who the stakeholders of an organisation are and classifying types of stakeholders based on their stake; this simplistic dyadic approach was not a useful form of abstraction to 
advance thinking and understanding of more complicated stakeholder concepts that were beginning to arise, such as stakeholder dynamics and stakeholder influences (Ambler \& Wilson, 1995; Clarkson et al., 1994; Rowley, 1997; Davenport \& Leitch, 2005).

The need to broaden the stakeholder perspective had been alluded to in earlier research such as Freeman and Liedtka (1991) who concluded in their analysis of corporate social responsibility that "corporations are connected networks of stakeholder interests" ( $\mathrm{p}$ 96). However, it was not explicit and Davenport and Leitch (2005) argue that many of the frameworks for managing stakeholder relationships were developed during a time when organisations' external environments were not inundated with the complexity of social, ethical and environmental issues as they are today.

Subsequently, it has become apparent that organisations exist within a complex network of intertwining relationships (Neville \& Menguc, 2006) and that they face a significantly broader set of stakeholders, whose position can change from issue to issue depending on the factors involved (Mitchell et al., 1997; Husted, 2000; Kochan \& Rubinstein, 2000; Elias et al., 2002; Davenport \& Leitch, 2005). Further, the nature of issues can also change over time as different stakeholders become involved and additional influencing factors are introduced (Mahon \& Waddock, 1992). This is congruent with Freeman's (1984) original idea that stakeholders and their stakes change over time depending on the strategic issue under consideration.

These more dynamic aspects of stakeholder theory are researched under the broad name of Stakeholder Dynamics. The importance of this area of research, and why it is being discussed here, is that it was foundational in bridging the gap from traditional one-dimensional stakeholder perspectives to a broader multi-stakeholder view. Further, this group of literature also provided a platform for organisations to recognise key variations between its stakeholders and reflect these in stakeholder management strategies (Davenport \& Leitch, 2005). Thus allowing organisations to better plan and manage with an increasingly unpredictable external environment (Davenport \& Leitch, 2005). 
Notable research in this space includes Mitchell et al. (1997) who draw on their theory of stakeholder salience (i.e. the degree to which managers give priority to competing stakeholder claims), emphasising that a stakeholder's possible combination of three characteristics - power, legitimacy, urgency - will not always be the same one particular issue, or between issues (Mitchell et al., 1997, p 879);

Static maps of a firm's stakeholder environment are heuristically useful if the intent is to raise consciousness about "Who or What Really Counts"...or to specify the stakeholder configuration at a particular time point. But even though most theorists might try for static clarity, managers should never forget that stakeholders change in salience, requiring different degrees and types of attention depending on their attributed possession of power, legitimacy, and/or urgency, and that levels of these attributes (and therefore salience) can vary from issue to issue and from time to time.

Empirical evidence for the concept of stakeholder dynamics was provided by Elias, Jackson and Cavana (2004) in their study of stakeholder dynamics in relation to an environmental conflict project. They mapped the changing positions and described the different interests of a sample of four stakeholders involved with the project, to show how these altered over various time periods - one over a period of 35 years and the others over a period of $10-15$ years. Three of the four stakeholders became more supportive of the project, while the environmental stakeholder became more opposed. They illustrate a useful approach for retrospectively looking back across the life of a project to identify the key drivers for these changes.

This also challenges some two dimensional models, such as the power versus stake matrix (Freeman, 1984), which categorises stakeholders according to their type of stake (equity, economic, power) and type of power (formal / voting, economic, political) at a particular point in time. An example of how this is applied can be seen in Elias et al. (2002). This grid can only portray the dynamic nature of stakeholders in as far as placing them in more than one box to show they might have multiple positions, but it does not illustrate the dynamism that exists through multiple stakeholder interactions, lines of communication and influence, changes to the issue or stakeholder position. 
This suggests that stakeholder management is not as easy as once proposed by Freeman (1984) with the traditional dyadic model view, and that the practical realities of understanding and managing stakeholders requires organisation's to take a much broader and dynamic view of their stakeholder landscape.

Other researchers in this space have looked into what factors cause stakeholder dynamics (Rowley \& Moldoveanu, 2003; Davenport \& Leitch, 2005). That is, what makes stakeholders change and move within a given context? For example, Rowley and Moldoveanu (2003) construct a model of stakeholder group action that proposes stakeholders mobilise due to a desire to express an identity as well as to protect their interests. This challenges the traditional notion that stakeholders are driven to act based upon their interests. Similarly, Davenport and Leitch (2005) investigated the impact of the issue that underpins interactions between a stakeholder and an organisation. In other words, what makes a stakeholder act in a certain way? Davenport and Leitch (2005) propose an Issue-Impact-Action framework that can identify and understand issue-based stakeholder action; and also suggest how organisations might respond with appropriate strategies to the different modes of stakeholder mobilisation based on typical responses to the issue impact.

This has important practical implications for managers, because while it is important to understand the different positions of stakeholders through models such as Mitchell et al. (1997), organisations must also be aware of the physical actions and behaviours that these might lead stakeholders to engage in. This adds another layer of complexity to the task of stakeholder management that organisations face.

Another theme of research within the large body of stakeholder literature that looked beyond the simple dyadic links between the organisation and each of its individual stakeholders was around stakeholder influences.This grew out of the increasing realisation that organisations do not simply respond to each stakeholder individually; they respond to the interaction of multiple influences from the entire stakeholder set (Ambler \& Wilson, 1995). Similarly, each organisation faces a different set of stakeholders for each strategic issue, which aggregate into unique patterns of influence, only relevant for that organisation (Andriof \& Waddock, 2002). 
Different research aspects that evolved out of this growing reality included, classifying organisations' stakeholder relationships to determine the types of influence stakeholders exert (Mitchell et al., 1997; Rowley, 1997; McGee, 1998, cited in Andriof \& Waddock, 2002); how stakeholders exert that influence, the types of strategies available to do this, and which strategies they are likely to select (Frooman, 1999; Frooman \& Murrell, 2005); and explaining and predicting how organisations respond and function with respect to stakeholder influences (Brenner, 1993, cited in Rowley, 1997).

As can be seenfrom a review of related literature, the combination of stakeholder influences and dynamics research evolved into a need for better managing the complexities of the stakeholder landscape. However, as indicated by later research, we are still in a state of stakeholder ambiguity (Hall \& Vredenburg, 2005) and theoretical and empirical development of the interactions between stakeholders is lacking (Neville \& Menguc, 2006). Not only that, it is also argued that theoretical development is often detached from practical reality (Gioia, 1999), which means stakeholder literature would also benefit from research that could make an applied difference.

\subsection{Stakeholder Networking Theory}

In response to shifting concentration from dyadic relationships, new methods were developed for analysing the complex array of multiple, interdependent relationships existing within organisations' stakeholder environment (Rowley, 1997; Andriof \& Waddock, 2002; Mahon et al., 2004; Neville \& Menguc, 2006). A more elaborate approach to stakeholder mapping was proposed by Rowley, 1997), in which multiple ties between the focal organisation and inter-stakeholder ties are considered.

This new development is known as stakeholder networking theory, which is underpinned by the fundamental principles of social network analysis theory. This section will begin by providing a background to social network analysis and will then move on to explain how it was eventually integrated in to stakeholder theory to become stakeholder networking theory. 


\subsubsection{Background and Principles of Social Network Analysis}

Social network analysis is a derivative of the social science field, which is increasingly used to understand behavioural and social phenomena in various contexts (Rowley, 1997). The theory has a complex history of diverse strands of research (Scott, 1991). However, a clear lineage can be constructed from three main lines: the sociometric analysts, who produced many technical advances by using the methods of graph theory; the Harvard researchers of the 1930's, who explored patterns of interpersonal relations and the formation of 'cliques'; and the Manchester anthropologists, who built on both these strands to investigate the structure of 'community' relations in tribal and village societies (Carrington, Scott \& Wasserman, 2005; de Nooy, Mrvar, Baragelj, 2005; Scott, 1991). Scott (1991) provides an illustrative summary of this lineage and an in depth analysis of each major development stage.

There are several comprehensive reviews of social network analysis that cover both the underlying principles and assumptions, and the practical aspects of the models and methods (de Nooy et al., 2005; Nohria \& Eccles, 1992; Scott, 1991; Wellman \& Berkowitz, 1988). It can be surmised from these reviews that the fundamentals of social network analysis focus on the conceptualisation of social structureas a network of social ties, whether it be the structure of human groups, communities, organisations, markets, society or the world system. The argument is that these ties are important because they transmit behaviour, attitudes, privileged information or goods, and they also provide access to opportunities and enable individuals to obtain resources (de Nooy et al., 2005; Jack 2005; Mahon et al., 2004). During its early days, social network analysis was used by anthropologists who studied kinship relations, friendship, and gift giving among people; social psychologists who focussed on affections; political scientists who studied power relations among people, organisations, or nations; and economists who investigated trade and organisation ties among firms (Scott, 1991).

The primary focus was to demonstrate the structure of interaction and interdependence of actors, and how their positions in networks influence their 
opportunities, constraints, and behaviours (Jack, 2005; Wasserman \& Galaskiewicz, 1994, cited in Rowley, 1997; Wellman \& Berkowitz, 1988).

The majority of network studies use either a "whole-network" or an "egocentric" design (Marsden, 2005). Whole-network studies examine sets of interrelated objects or actors that are considered to be bounded social collectives. Egocentric studies focus on a focal actor and the relationships in its locality (Marsden, 2005). Networks are constructed by identifying ties between actors within a given boundary, and presenting these in an illustrated form (Mahon et al., 2004).

The network is then analysed using fundamental concepts of network analysis theory, which includesdensity and centrality. Network density is a measure of the whole network, which describes the environment'sinterconnectedness between the actors, whereby the more actors that are connected to one another, the more dense the network (Scott, 1991; Vandekerckhove \& Dentchev, 2005). It is said that a higher density network often displays more efficient communication across the network and the production of shared expectations (Vandekerckhove \& Dentchev, 2005).

Network centrality refers to an individual actor's position in the network relative to others, which is commonly used to evaluate an actor's prominence or power within the network (Scott, 1991). The greater the centrality of an organisation as the focal point in a network, the more the firm will be able to resist stakeholder pressures (Vandekerckhove \& Dentchev, 2005).

From 1990, interest in social networks and the use of social network methodology began to grow at an increasing rate, predominately due to a realisation in the behavioural science field that the social context of actions matter (Carrington et al., 2005; Jack, 2005). This resulted in the dissemination of social network analysis through a variety of research fields, using it as a methodology to represent networks visually and then analyse the relational system in terms of detecting and interpreting patterns of social links (Rowley, 1997). 
The relevance of social network analysis for the 'management of organisations' context was recognised (Jack, 2005) and the impact of social network analysis on organisational studies at the centre of management research is easily determined by the number of researchers who adopt a network perspective - "roughly one third of the presentations at the Academy of Management annual meetings now have a network perspective" (Carrington et al., 2005, p 2).

\subsubsection{Social Network Analysis and Stakeholder Theory}

Thus far, social network analysis has been described without its links to stakeholder theory. Framing the stakeholder concept as a more complex and dynamic environment of multiple stakeholder interactions and influences, and bringing light to the idea of stakeholder networks led to the emergence of stakeholder networking theory.

One of the first researchers to respond to this was Rowley (1997) who stated that social network analysis had potential for examining fundamental elements of the stakeholder perspective and could move research in a valuable direction. He argued that similar to the social network theorists described above who conceptualise an organisation's environment as a set of social actors; traditional stakeholder theorists also view an organisation in terms of its relationships with a set of social actors in its environment. However, at this stage, stakeholder theory had limited advancements beyond dyadic level analysis, let alone the concept of stakeholder dynamics and influences. Rowley's rationale was "network models begin where stakeholder research stops - the dyadic relationship - and examine systems of dyadic interactions, capturing the influence of multiple interdependent relationships on organisations' behaviours" (Rowley, 1997, p 894) rather than just looking at direct relationships between a focal organisation and its stakeholders. The purpose was to generate a theory of stakeholder influences that addresses the question of how the structure of an organisation's entire network of stakeholders affects its behaviour in response to stakeholder pressures. Specifically, how the concepts of network density and centralityimpact a focal organisation's degree of resistance to stakeholder pressures. 
By examining the structural elements of density and centrality, Rowley analysed the level of power held by the focal organisation and the entire stakeholder set within different types of network configurations, and then considered the roles that the focal organisation adopts in these different structures. Rowley came up with four classification types, entitled compromiser, commander, subordinate, and solitarian, which he comprehensively describes (Rowley, 1997).

Since Rowley's application of social network analysis to stakeholder theory, there have been a few studies done to develop the literature and concept of stakeholder networking theory. Some research has looked at networks in action providing examples of collective stakeholder influence (e.g. Albert, Ashforth \& Dutton, 2000; Berry, 2003), while others have demonstrated and emphasised the benefits of stakeholder networking theory, which have been widely reported. For example, one of the common benefits reported is that stakeholder networking theory provides a greater understanding of a given context. For example, Ramirez (2001) proposes that mapping stakeholder networks of a given situation can enhance organisations' understanding of the context in which stakeholder relationships take place in that situation. He further argues that networks provide an essential lens through which to analyse multiple stakeholder situations, acting as a foundation for which to explore other organisational issues, for example, in this case it was about conflict and collaboration of stakeholder interactions. Stakeholder networks are just one aspect to a nine dimension typology that the author proposes for understanding stakeholder relationships.

While this research promotes the use of stakeholder networking theory to improve contextual understanding, and its flow-on benefits, they do not address the process for applying stakeholder networking theory or the issues associated with its application.

Another benefit that is often associated with the use of stakeholder networking theory is the achievement of organisational activities or goals. For example, Post, Preston and Sachs (2002) develop a new stakeholder view of the firm that stresses the role of stakeholder relationships in the creation of organisation wealth. Their 
analysis is centred on the concept that organisations exist within network of interrelated stakeholders that create, sustain and enhance its value-creating capacity and the organisation's overall wealth.

A different type of organisation activity was investigated by Ziervogel and Downing (2004)who looked at the function of stakeholder networks for disseminating information to reach a wide audience. They use the situation of diffusing seasonal climate forecasts and look at the interpretations that can be made from analysing stakeholder networks in this context. They find that analysing relational data in the form of stakeholder network maps enables existing or emerging patterns of information dissemination to be uncovered. The stakeholder network maps led to the identification and exploration of sub-networks, which they recognised as opportunities for focusing future forecast dissemination strategies.

Again, while the benefits of stakeholder networking theory are illustrated and discussed in both these different organisation contexts, neither study focuses on the process for identifying or mapping the stakeholder network for practical application.

Looking beyond the theory of stakeholder networking, Svendsen and Laberge (2005) recognised that the role of the network convenor is new for a lot of organisations, so their focus was on understanding how to establish networks and explored the mindsets, skills and engagement processes required to build and sustain multi-stakeholder networks. Their research was, thus, more practical rather than based on the theory of stakeholder networking or the process of applying the theory.

Despite continuing focus in the stakeholder networking theory field, limited research has attempted to significantly evolve the theory of stakeholder networking theory beyond Rowley's (1997) concepts. One example is Neville and Menguc(2006) who looked more closely at multiple stakeholder interactions, recognised a gap in the theoretical and empirical development of the interactions betweenmultiple stakeholders. To meet this gap, they developed a framework for understanding and measuring the effects upon the organisation of stakeholder interactions, which they 
refer to as stakeholder multiplicity. In doing this, they amalgamated two significant contributions to stakeholder management, which have been discussed already - that of stakeholder salience (Mitchell et al., 1997) and stakeholder networking theory (Rowley, 1997). It was argued that considering the complex interactions of the stakeholder network in terms of salience provides a more relevant and illustrative explanation of the nature and effects of stakeholder interactions upon organisations (Neville \& Menguc, 2006). However, in developing this framework, the application process for stakeholder networking theory is not discussed.

In summary, this section has demonstrated the progression from a dyadic stakeholder perspective to thinking more broadly about stakeholder networks by combining the concepts of social network analysis with stakeholder theory. There has been research conducted to identify the implications for organisations operating in a network of multiple stakeholder relationships, but as can be determined there is limited research that reports on the process of applying stakeholder networking theory and the issues that arise from its application.

The next section will review the literature associated with stakeholder theory and strategic management, and eventually stakeholder networking theory and strategic management. This will complete the review of literature that is relevant for this thesis and leads into the identification of the research gap.

\subsection{Stakeholder Theory and Strategic Management}

\subsubsection{The History}

As previously discussed in the chapter, the most prominent work that brought together strategic management and stakeholder theory was Freeman's (1984) book Strategic Management: A Stakeholder Approach. However, as illustrated by Elias et al. (2002) in Figure 2.1, the stakeholder concept was explored within four broad management areas before Freeman's foundational work (Corporate Planning, Systems Theory, Corporate Social Responsibility, Organisation Theory). Freeman (1984) provides a comprehensive review of the stakeholder and strategic 
management aspects relevant to each area, demonstrating that the concerns and issues they all sought to contribute to, were not mutually exclusive (Freeman, $1984 \mathrm{p}$ $43)$;

The concerns with formulating plans and systems of plans for business level entities, with the social responsibility of business and the need for integrative theories to explain the behaviour of a large population of organisations and their environments are of vital importance to managers and organisation researchers.

And from this evolved Freeman's (1984) foundational book that explicitly outlined an organisation's need for a stakeholder framework and discussed its centrality to strategic management practice. He proposed that the stakeholder concept could contribute to addressing some of these issues by integrating them with the strategic management of organisations; particularly around how organisations structure themselves to take actions and organise themselves to respond appropriately to the external environment (Freeman, 1984).

Freeman (1984) briefly touched on the different elements that constitute strategic management including strategic direction setting, which is usually based on an analysis of the internal organisation (strengths and weakness) and the external environment (opportunities and threats). The outputs of analysing these four areas typically provide the organisation's strategic issues that they can plan for. At a high level, Freeman (1984) states that the primary use of the stakeholder concept for strategic management is to enrich understanding of strategic tasks in light of the internal and external changes in the business environment by giving managers and researchers a framework.

Having proposed stakeholder theory as a necessary element of organisation strategy, Freeman highlights some of the key strategic questions that can be understood in terms of a stakeholder perspective (Freeman, 1984, p 44). Freeman based these on a strategy development process proposed by Lorange (1980, cited in Freeman, 1984):

- What is the direction or mission of the organisation? (Strategic Direction) 
- What paths or strategies will achieve such a mission? (Strategic Program Formulation)

- What resource allocations or budgets must be made for the strategies to be implemented? (Budgeting)

- How can we be sure the strategies are on track or in control? (Control)

- What are the macro-systems and structures necessary for implementation? (Structure and Systems)

He describes how the stakeholder concept can be built into the above strategic management process, based on the assumption that most organisations use the above process. The strategic management process is broken down into three main activities for this purpose - setting strategic direction, formulating strategies for stakeholders, and implementing and monitoring stakeholder strategies (Freeman, 1984).

\subsubsection{Support for a Stakeholder Approach to Strategic Management}

Since Freeman's (1984) proposed framework, there has been a lot of research that agrees with and has supported the need to include a stakeholder perspective into the strategic management of organisations, focussing on the various aspects and activities that constitute strategic management. For example, Brugha and Varvasovszky (2000) review a range of literature about the benefits for which stakeholder analysis has been used, which include evaluating threats and opportunities for change, in strategic planning and selection of strategic options, and in successfully implementing and managing strategic change. Congruent with this is the investigation by Post et al. (2002) who look at the critical nature of stakeholder relationships to solving core strategic problems, and therefore the need to understand an organisation's entire set of stakeholder relationships at any point in time.

More specific research has reported the use and benefits of a stakeholder perspective for various strategic management activities from strategic thinking right through to strategy implementation. For example, research has supported the benefits for strategic thinking by saying that strong stakeholder analysis leads to a different and more robust understanding of strategic thinking (Freeman \& Liedtka, 1997), while others have reported that continual negotiations with key stakeholders facilitate the translation of the CEO's insights into organisation strategies(Wells, Lee, McClure, Baronner \& Davis, 2004). 
The SRI has also proposed that a stakeholder perspective is a key input to the strategic planning process, stating that stakeholder analysis provides important information about which stakeholders are required to support successful delivery of an organisation's strategic priorities, providing an essential component for strategy development (Clarkson et al., 1994). Congruent with this, Buysse and Verbeke (2003) found in their study of environmental strategies across a range of Belgian organisations, that a deeper understanding and broader coverage of stakeholders was associated with more proactive and effective strategies. Moving from strategy development to strategy implementation, Post et al. (2002) propose that the key to effective strategy implementation is recognising stakeholder management as a core competence and therefore, maintaining favourable relationships with all stakeholders should become an integral part of organisational culture to support delivery of strategies.

With the literature strongly advocating the benefits and need for organisation's to include a stakeholder perspective into their strategic management practices, some have suggested that the continued competitive advantage and therefore survival of an organisation may depend on how well stakeholders are managed (Malvey, Fottler \& Slovensky, 2002). This has led to the development of frameworks and approaches for organisations to evaluate their performance in stakeholder management to ensure continued progress toward the strategic direction. For example, Kaplan and Norton's (2001) stakeholder scorecard, which tracks an organisation's progress in meeting its stakeholder goals and objectives; and Malvey et al. (2002) stakeholder report card, which assesses an organisation's stakeholder management practices.

A practical example of incorporating stakeholders into the strategic planning process was reported by Trisurat (2006) who investigated whether the participation of local stakeholders in a strategic planning process could promote the interests of a community-based wetland management project in Thailand. It was found that local communities must be involved from the start in the planning, implementing and monitoring stages and that without early involvement, the program objectives are unlikely to be successful. 
As well as the theoretical literature providing strong support, texts that provide practical advice on running strategic management processes also describe the need for stakeholder integration (Bryson 1988; de Wit \& Meyer, 2002; Bryson, 2004; Johnson, Scholes \& Whittington, 2005). Some of these are reasonably broad references, such as Johnson et al. (2005) who suggest decisions that managers have to make about the purpose and strategy of their organisation are influenced by stakeholder expectations. Therefore, they should be included in strategy formulation and should also be considered as key influencers of strategic change. Similarly, de Wit and Meryer (2002) make a generic reference to the use of stakeholder analyses for strategic management, particularly for understanding the stakeholder environment in relation to organisation mission and objectives.

However, while both these texts talk about how an organisation can use different techniques such as Freeman's (1984) stakeholder map and power versus interest matrix to understand the stakeholder environment and stakeholder influences, they do not explicitly illustrate how organisations can integrate a stakeholder perspective into the strategic management elements they state above, i.e. developing organisation purpose and mission, formulating strategies, and strategic change. This gap is supported by Gioia (1999) who argues that research too often shouts "from the sidelines that organisational decision makers should do the right thing" (p 228), without translating stakeholder theory into something that is pragmatic and applicable.

A more specific strategic management process is provided by Bryson $(1988,2004)$ in the form of a ten step process (2004, p 32). He describes the 10 steps comprehensively and explains the stakeholder input or stakeholder information suggested at each step. This framework will be explained in more detail in Chapter 3 because it was developed for not-for-profit and public sector organisations, which is the context of this thesis and covered explicitly in that chapter.

In summary, the body of literature on this topic primarily supports a stakeholder perspective for strategic management with limited research arguing against it. The most detailed and recent research that outlines an approach for integrating a 
stakeholder perspective into the strategic management process is proposed by Bryson (1988, 2004). The next section will talk about the integration of stakeholder networking theory and strategic management.

\subsubsection{Stakeholder Networking Theory and Strategic Management}

Back in the early 1960's, the concept of stakeholder networking had not yet become explicit. However, Levine and White (1961) alluded to the idea through the concept of an exchange system, which was the voluntary activity between two or more organisations. They also made the connection to strategic management concepts by recognising that one of the consequences of these exchange systems was the joint realisation of the organisations' respective goals and objectives.

The emergence of stakeholder networking theory eventually led to its official integration into the strategic management literature. There was recognition that the underlying assumption for a lot of existing stakeholder research in the strategic management field was that the stakeholder environment is static and no significant shift in stakeholder actions is anticipated (Gulati, 1998; Mahon et al., 2004). This led to investigation of the potential benefits for integrating a stakeholder network view into strategic management. Some examples are reviewed below, however available research in this area is limited.

There has been a series of work done by Gulati amalgamating the concepts of strategic alliances and social network analysis. First was to introduce a social network perspective to the study of strategic alliances to move beyond the current viewpoint that only considered alliances as dyadic exchanges and emphasise the dynamic nature in which these occur between multiple stakeholders within networks Gulati (1998). He then went on to investigate the role of stakeholder networks in deciding whether to form strategic alliances Gulati (1999) and understand the impact of strategic alliances and networks on organisational performance (Gulati, Nohria \& Zaheer, 2000). While this has culminated in an in depth study on strategic alliances over a period of three years, it does not review the use of stakeholder networking theory across other strategic management elements. 
Mahon et al. (2004) look at how social network analysis can be used to study the intricacies between stakeholder behaviour and non-market strategy, i.e. an organisation's pattern of actions taken in the non-market environment to create value by improving its overall performance. 12 different propositions are made to suggest the effects of stakeholder networks on strategic issue evolution, coalition and formation, and issue resolution. However, neither application considerations nor strategic planning practices are comprehensively addressed.

In terms of how stakeholder networks can influence strategy development, Stokes (2006) looked at the different types of inter-organisational relationships and networks that influence strategy development in the Australian tourism sector. It was found that loosely formed networks consisting of stable clusters and peripheral stakeholders were most likely to influence reactive strategies. While this has implications for managers in understanding stakeholder influence in strategy development, it does not address how stakeholder networking theory can assist strategy development in practice, or indeed other strategic management activities.

In relation to a different strategic management aspect, Vandekerckhove and Dentchev (2005) investigated the potential for stakeholder networking theory to overcome the cognitive limitations demonstrated by entrepreneurs, and assist them to identify new business opportunities. They found a number of uses of stakeholder networking theory in this context including helping stakeholders to better understand their issue involvement, understanding their stakeholders' behaviour and expectations, and creating a collaborative environment; all of which led to identifying new business opportunities. While this study provides a very useful insight into the benefits of stakeholder networking theory, it lacks practical application aspects that would assist organisational managers to apply the theory.

As mentioned, the research drawing together stakeholder networking theory and strategic management is more limited, but of that which has been conducted, there seems to be overall support for a stakeholder network perspective. However, there is no comprehensive research that explicitly outlines how to integrate a stakeholder networking perspective into a strategic planning process. 


\subsection{Chapter Summary: The Research Gap}

This chapter has provided a comprehensive review of the origin of the stakeholder concept from as early as the 1700's, right through its development stages in the 1930's and when the term was coined in 1963 by the SRI. The four areas of research that introduced the link between stakeholder theory and strategic management (Corporate Planning, Systems Theory, Corporate Social Responsibility and Organisational Theory) were reviewed, illustrating how these led to Freeman's (1984) foundational book Strategic Management: A Stakeholder Approach.

There has been much research since then to try and develop a universally agreed definition of the stakeholder concept, with the purpose of understanding 'how does an organisation identify the stakeholders that really matter for the managers of organisations?' However, as shown in the literature review, researchers have not successfully achieved this and the definitional and identification challenges continue to be investigated within the stakeholder management literature. This has resulted in the stakeholder concept being defined in many different ways to suit the context and purpose for which stakeholders are being analysed.

Another important aspect of research that was highlighted was the shift from thinking about organisations' dyadic (one-on-one) relationships with stakeholders to a view of stakeholder multiplicity. That is, organisations actually have multiple stakeholders that they are interacting with and being influenced by at any one time. Not only are there multiple stakeholders, but they are dynamic with constantly changing positions and stakes and therefore, relative importance to the organisation. This has a range of implications for managers in practice who are faced with managing the continual challenge of stakeholder ambiguity.

Stakeholder multiplicity and dynamics led to the broader consideration of organisations and stakeholders and the idea that organisations exist within a network of stakeholder relationships, of which they are only one player. Researchers began 
to investigate the impact of this network concept on the organisation. Rowley (1997) was a primary researcher in this space, exploring this concept by applying the theory of social network analysis to stakeholder theory to form the concept of stakeholder networking theory. Using this approach, he looked at the impact of stakeholder network influences on organisation behaviour. While subsequent research has supported stakeholder networking theory, advocating benefits for various situations including effective communication with a wide target audience or gaining a better understanding of the broader context and enhancing achieving of organisation goals, there is a gap in the research that investigates the practical process of applying stakeholder networking theory in an organisation context and understanding the management issues that are associated with application.

While this progression from a static stakeholder perspective to dynamic stakeholder networks was happening, there was a lot of research being developed to support a stakeholder perspective for strategic management. Literature in this field was reviewed, highlighting the various strategic activities that require a stakeholder understanding (e.g. strategic planning, selection of strategic options, managing strategic change, etc). Other research noted the benefits in adopting a stakeholder approach (e.g. stronger strategic thinking, translation of thinking into strategies, more effective strategies and strategy implementation, etc).

Of particular interest to this thesis was research that illustrated how and where in the strategic management process to integrate a stakeholder perspective. Freeman (1984) and Bryson $(1988,2004)$ both provide a comprehensive explanation of this with respect to general stakeholder information, but neither of them refer to stakeholder networking theory and how that could be used for strategic planning.

Bringing these elements together - stakeholder networking theory and strategic management - it can be seen from the review that there is limited research that amalgamates strategic management and stakeholder networking theory. Some research was reviewed that advocates a stakeholder network view for strategic 
management, but there is no comprehensive view of a strategic planning process that discusses the way in which stakeholder networking theory can be integrated into strategic management practice.

Thus, two research gaps have been identified. Firstly, there is a lack of research that makes the transition from stakeholder networking theory into management practice, focussing on the process for applying stakeholder networking theory and the management issues that arise from this application. Secondly, there is a gap in research that identifies the uses and benefits of stakeholder networking theory for strategic management of organisations. 


\section{CHAPTER 3 \\ CONTEXT: PUBLIC SECTOR}

\subsection{Introduction to Chapter}

Chapter 2 highlighted a research gap in the exploration of how stakeholder networking theory can be practically applied in strategic management practice. This chapter aims to set the context in which these two management fields will be explored for this thesis - the New Zealand public sector.

This chapter will review New Zealand's history of integrating strategic management practice into the public sector and the various contextual factors in New Zealand that are driving public organisations to constantly improve their stakeholder management processes.

These two dimensions of the New Zealand public sector will be brought together to demonstrate a research gap that provides practical advice to public sector managers on how to integrate a stakeholder networking perspective into strategic planning. Hence, the chapter culminates in the rationale for this thesis to explore the potential for stakeholder networking theory to be used as a tool to help with strategic planning in the New Zealand public sector.

\subsection{Strategic Management in the Public Sector}

The New Zealand public sector reforms of the 1980's saw the introduction of what was considered to be private sector strategic management into the public sector as part of a broader international trend to improve public organisations' ability to respond to future changes in its environment through greater efficiency and effectiveness - this movement is widely known as New Public Management (Schick, 1996; Stoney, 1998; Alford, 2001, Thiel \& Leeuw, 2002; Vigoda, 2002; Norman, 2003, Bovaird, 2005; Norman, 2006). 
A range of global economic and political pressures have been identified as being central to this period of public reform, including competition from emerging economies; the effects of de-industrialisation; and changes in the demographic makeup of society (Ferlie, Ashburner, Fitzgerald \& Pettigrew, 1996; Stoney, 1998). It has been noted that each of these pressures was seen to increase demand on state services, while simultaneously cutting the resources available for state expenditure (Stoney, 1998; Norman, 2003; Plant, 2006). The effect of these two factors were further enhanced by an increase in 'customer expectations' from the consumers of public products and services, as people were becoming used to the increasing emphasis on quality and value for money within the private sector(Sanderson, 1996; Flynn, 1995, cited in Stoney, 1998; Vigoda, 2002; Norman, 2003). Considering these pressures and taking account of rapid technological advancements across the globe, the context for continuing public sector reforms was considered inevitable (Stoney, 1998).

Tied to the philosophy of new public management is the assumption that public sector organisations could be more successful if they applied private sector strategic management techniques and processes (Skok, 1989; Thiel \& Leeuw, 2002; Norman, 2003; McAdam et al., 2005; Norman 2006). The key drivers behind New Zealand's public sector reform was a concern for efficiency and accountability; and in line with the new public management philosophy these concerns were met through the introduction of markets, sharper incentives, and the importation of private sector management techniques (Ferlie et al., 1996; Schick, 1996, Norman, 2003; Norman, 2006).

Schick (1996) emphasises that in managing reforms, they are never complete. Reforms have to be monitored for opportunities to be refreshed and revitalised to ensure that new practices are still serving the purpose for which they were introduced. Three areas requiring constant attention in the New Zealand public sector environment were highlighted, including strategic capacity, the resource base and accountability. Strategic capacity is the aspect of most relevance for this thesis, which relates to the capacity for strategic management. That is, a department's ability to respond to future changes in its environment. Skok (1989) provides a 
succinct and fairly consistent public sector definition of strategic management based on a review of the relevant literature (p 136);

Strategic management in the public sector is best understood as purposive action through which agency managers identify and realise their organisation's objectives within their operating environments.

It is argued that the early reforms in New Zealand did not adequately encourage the adoption of private sector principles of strategic management. Instead they emphasised annual actions and outputs to an extent which neglected medium and long term planning (Schick, 1996; Norman 2003). Even after attempts to correct this, the New Zealand public sector was still geared more to the short-term production of outputs than planning for the future (Schick, 1996, Norman 2003). Therefore, as the reforms progressed, New Zealand public sector organisations set out to have a much greater emphasis on the private sector principles of strategic management to meet stakeholder needs (Schick, 1996).

There has been much debate over the application of private sector strategic management principles in the public sector, resulting in arguments both for and against it (Skok, 1989; Yates, 1991; Mintzberg, 1996; Green, 1998; Stoney, 2001; Alford, 2001; McAdam et al., 2005). From the support perspective, researchers see parallels between managing public and private organisations where it is argued that strategic management is a necessary and positive response to the growing pressures for change in the public sector, and reinforces the shift towards new public management (Eppink \& de Waal, 2001; Stoney, 1998; Green, 1998). For example, Stoney (2001) demonstrated a critical relationship between a UK public organisation's ability to deliver services efficiently and its strategic management practices; while Green (1998) talks about improved communication and involvement of internal staff in the pursuit of overall objectives. Eppink and de Waal (2001) show examples of how some well known techniques have been applied in public sector, including PEST analysis, Porters 5 forces, scenario planning and strategic group analysis. 
Other researchers recognise fundamental differences, but also argue for similarities in some of these key dimensions that are commonly used to differentiate the public and private sector contexts (Yates, 1991; Llewellyn \& Tappin, 2003). For example, the dimensions that Yates (1991) challenges include 1) public organisations lack a clear financial bottom line, 2) public organisations differ in their ability to hire and fire, 3) public managers have short time horizons, 4) public decision-making is more complex, 5) decision-making in the public sector is more fragmented, and 6) public managers work in a fishbowl environment where they perform under high levels of scrutiny from media, interest groups and the general public. Llewellyn and Tappin (2003) argue against the difference that public sector do not need to sustain competitive advantage by highlighting the need for public organisations to overcome funding and resource shortages through securing external funding and attracting partnerships. It is argued that both of these needs could be achieved by having a strategic plan.

However, the arguments for strategic management in the public sector have not gone unchallenged (Ring \& Perry, 1985; Leitch \& Davenport, 2007) with some scholars and practitioners arguing that the two sectors are different, and therefore call for different management approaches (Alford, 2001). For example, McAdam et al. (2005) question whether simply translating the language of the private sector with minor modifications is sufficient. They suggest that such an approach could result in the public sector reality being subsumed within that of a contorted private sector reality, which does not accurately or appropriately represent the interests and needs of the stakeholders.

Commonly cited differences include 1) the private sector usually creates value in the form of products and services for paying customers, while public sector usually creates value through improving social outcomes for citizens, which can conflict with the actual consumers of the public services (Alford, 2001; Provan \& Milward, 2001; Moore, 2003); 2) private sector utilise predominantly economic resources to operate, while public sector not only rely on public funding, but also on public and political power as a source of authority to act (Alford, 2001); 3) securing competitive advantage is not relevant because public organisations are not typically in 
competition with others (Llewellyn \& Tappin, 2003). Ring \& Perry (1985) also mention policy ambiguity, the openness of government, attentive publics, the time problem and shaky coalitions as factors that differentiate the management of public organisations from the private sector.

Some researchers propose that in reality, very few organisations are purely public or purely private with most sitting somewhere on a continuum between these two extremes(Alford, 2001), often executing tasks purely for government, but also delivering products and services with a market orientation (Joldersma \& Winter, 2002). This gives support to those researchers such as Bryson (2004) who proposed an adapted strategic planning process for public organisations based on private sector principles (previously introduced in Section 2.4.2). In terms of integrating a stakeholder perspective into the strategic planning process, Bryson $(1998,2004)$ describes the recommended stakeholder information or input at each relevant step, which have been summarised below. The steps he proposes that require a stakeholder perspective include Step 1, 3, 4, 5 and 6.

1) Initiate and agree on a strategic planning process

2) Identify organisation mandates

3) Clarify or mission and values

4) Assess the external and internal environments to identify strengths, weaknesses, opportunities and threats

5) Identify the strategic issues facing the organisation

6) Formulate strategies to manage the issues

7) Review and adopt the strategies or strategic plan

8) Establish an effective organisation vision

9) Develop an effective implementation process

10) Reassess the strategies and the strategic planning process.

\section{$\underline{\text { Step } 1 \text { - Initiate and agree on a strategic planning process }}$}

Once the strategic planning process has been initiated, the next two important things to do are identify the key decision makers and who should be involved in the process. It is suggested that a stakeholder analysis will meet this need and ensure that stakeholder concerns are adequately represented throughout the strategic planning process, which is crucial for organisational success. Furthermore, stakeholder analysis allows decision makers and planning team members to immerse 
themselves in the networks and politics surrounding the organisation saying that (Bryson, 2004, p 36):

An understanding of the relationships - actual or potential that help define the organisation's context can provide invaluable clues for identifying strategic issues and developing effective strategies.

\section{$\underline{\text { Step } 3 \text { - Clarify organisational mission and values }}$}

Understanding stakeholder expectations and needs is an important input for clarifying organisational mission and values because organisations must justify their existence by how well they address their various stakeholders' values and meet their needs. He states that the organisation mission is a key source of inspiration and guidance for stakeholders and the purpose should not be formed in the absence of thinking about the purpose forwhom.

\section{Step 4 - Assess the external and internal environments}

Besides monitoring trends and events, strategic planning teams should also monitor important external stakeholder groups, particularly those that affect resources flows. This could highlight some key environmental factors that need to be planned for and potentially some critical success factors i.e. things that at an organisation must do to be successful in the eyes of its key stakeholders. It is emphasised that stakeholders judge an organisation according to the criteria they choose, which is not necessarily the same as what the organisation may choose. If these are not met, stakeholders could withdraw their support for the organisation.

\section{$\underline{\text { Step } 5 \text { - Identify the strategic issues facing the organisation }}$}

Identification of strategic issues is informed by a number of things, including a deep understanding of stakeholder interests, which will have been developed in the previous four steps. 
$\underline{\text { Step } 6 \text { - Formulate strategies to manage issues }}$

Solicit strategy proposals from, and test potential strategies with, key stakeholders to ensure they are acceptable and will result in meeting their needs.

In summary, Bryson's (2004) description of integrating a stakeholder perspective into the strategic planning process for public sector organisations is very comprehensive. However, there is no reference to stakeholder networking theory being used to inform this stakeholder perspective implying a dyadic perspective remains in place.

\subsubsection{Stakeholder Theory and Strategic Management in the Public Sector}

Along with the integration of strategic management practices in the public sector, stakeholder theory is also an aspect of management that has been extensively applied in the public sector over the last 20 years(Bryson, 2005; Bovaird, 2005). One of the drivers behind this stakeholder focus is the recognition that the public sector operates within a significantly more complex stakeholder landscape than the private sector, resulting in researchers exploring the impact of this on various management practices (Ring \& Perry, 1985; Bryson, 1995; Moore, 2003; Bovaird, 2005; McAdam et al., 2005; Davenport \& Leitch, 2007).

Researchers have investigated the various factors that contribute to this greater complexity, which include increased pressure on public sector organisations to become more responsive to citizens (Vigoda, 2002); operating within a political environment requires public sector organisations to give due consideration to the diverse aspirations of their stakeholders (Davenport \& Leitch, 2005); the drive to make public sector organisations more accountable to their stakeholders by requiring they go through a proper process of public consultation and engagement on an ongoing basis (Gregory, 2003); the need to tap into a wider range of productive capabilities outside the organisation due to limited public resources, including volunteers, non-profit organisations, local interest groups, the general public, etc (Alford, 2001; Bovaird, 2005); the different 'hats' that the general public can wear at any one time in relation to public issues, including interest group, voter, customer, 
and citizen (Bingham, Nabatchi, \& O'Leary, 2005); and the added complexity of having to balance the needs and interests of customers that actually consume public products and services with those of the general public whose interest is more about social outcomes and value for the taxpayer dollar (Alford, 2001; Provan \& Milward, 2001; Moore, 2003).

With all of these different dynamics at play, the public sector stakeholder landscape is constituted by multiple and diverse external stakeholder groups (McAdam et al., 2005; Davnport \& Leitch, 2007), which is defined as a 'pluralistic context' (Jarzabkowski \& Fenton, 2006). A pluralistic context is one shaped by divergent goals and interests of different groups, where the interests of external stakeholders lead to multiple strategic goals and objectives (Jarzabkowski \& Fenton, 2006).

As McAdam et al. (2005, p 258) state, "that the public sector has multiple stakeholders is not in dispute: yet managing these multiple relationships is problematic". As mentioned above, this dynamic has led to a lot of research investigating the implications of the public sector stakeholder landscape on management practice; and one of the key areas of interest for this thesis is strategic management in the public sector. The literature in this area makes it very clear that stakeholders are fundamental to the continued success of public organisations because they exist to satisfy key stakeholders (Bryson, Cunningham \& Lokkesmoe, 2002; Gregory, 2003; Bryson, 2004; McAdam et al., 2005; Bryson, Ackerman \& Eden, 2007) and therefore, public organisations should build their strategic ability around producing public value for their stakeholders (Bryson et al., 2002).

There has been other research that demonstrates the benefit of a stakeholder perspective for elements of a strategic planning process, such as strategic thinking (Bryson et al., 2002) developing an organisation's vision, values and strategic goals (Gregory, 2003), strategic initiative generation and providing feedback on strategic priorities (Plant, 2006). In order to achieve stakeholder integration for strategic planning, researchers have proposed various tools and approaches for determining which stakeholders are important for including in strategic planning processes, all of which relate specifically to the public sector e.g. stakeholder identification and 
analysis, and stakeholder prioritisation (Bryson, 2004), public participation theories (Arnstein, 1969, cited in Green \& Hunton-Clarke, 2003), stakeholder mapping (Scholes, 2001), emergent bottom-up stakeholder involvement (Plant, 2006), and empowering stakeholders to become involved by adopting a posture of strategic ambiguity (Davenport \& Leitch, 2005).

As can be seen from this review of a sample of stakeholder and strategic management literature in the public sector, there is a wide range of research that provides support for integrating a stakeholder perspective into strategic management practice and some even suggests tools and approaches for doing this. However, there is still a lack of research in public sector research on exactly how to systematically identify and analyse stakeholders in the public sector (Bryson, 2004) and there is limited practical guidance on how to apply stakeholder theories to strategic management processes to obtain the benefits so often discussed.

\subsection{Stakeholder Networking in the Public Sector}

Adding to the literature that talks about the complex stakeholder landscape of the public sector, there has been increasing research that talks about the interconnected nature of the world, particularly in the public sector (Bryson, 2004) and the movement toward theories of cooperation and networking in public administration (Bingham et al., 2005).

This is not a new concept with public policy researchers around the world having been proposing the connection between networks and stakeholder relationships since the 1960's (Provan \& Milward, 2001). It has been suggested that this was driven by the recognition that numerous activities in the public sector occur in interorganisational networks, where interdependence is prevalent; and public sector organisations must face the constant challenge of managing involvement from multiple organisations and solving complex problems collaboratively (Lawless \& Moore, 1989; O’Toole, 1997; Guffey, 2003). Bryson (2004, p 23) gives a good example of this in reality; 
Choose any public problem - economic development, poor education performance, natural resources management, crime, AIDS, global warming, terrorism - and it is clear that 'the problem' encompasses or affects numerous people, groups and organisations. In this shared-power world no one is fully in charge; no organisation 'contains' the problem. Instead many individuals, groups and organisations are involved or affected or have some partial responsibility to act.

There has not been a lot of research done to apply stakeholder networking in the New Zealand public sector, so this section will briefly talk about some international research in this field to illustrate its use in other public sectors, before introducing the few New Zealand examples.

In its early development stage (Levine \& White, 1961; Warren, Rose \& Bergunder, 1974, cited in Provan \& Milward, 2001), one of the primary targets for the application of stakeholder networking in the public sector was health services. There was a particular focus on the importance of cooperative relationships between individual organisations to understand the integration and coordination of health care providers and therefore, reduce gaps and overlaps of medical services to citizens. For example, Levine and White (1961) investigated 'organisation exchange' between pairs of organisations in the health system. They rated interaction levels in terms of referrals to other health agencies, and communication and joint activities with other agencies. It wasargued that due to typical scarcity issues in publicly funded organisations, inter-organisational exchanges are essential to goal attainment.

Similar to the way stakeholder research developed beyond examining dyadic links, the focus here expanded to consider multiple interactions that comprise full networks of relationships, which included understanding how public policy is implemented through networks of cooperating service providers (Jennings \& Ewalt, 1998; O'Toole, 1997). There have been mixed findings in this field that propose both positive and negative arguments for the use of network analysis in the public sector.

The prevailing view is that collaboration and cooperation between two or more organisations can result in the more effective and efficient delivery of a wider range 
of community-based services than could be achieved independently (Provan \& Milward, 2001). It is also suggested that networking is particularly appealing in the public sector due to the lack of a profit motive, as the risks associated with cooperation are lessened, where reduced autonomy, shared resources, and increased dependence that can be viewed to threaten a profit organisation's competitive ability (Provan \& Milward, 2001). This quote provides a succinct description of the value of networks in the public sector (Provan \& Milward, 2001, p 415):

In the public sector resources are often scarce, clients have multiple problems, service professionals are trained in narrow functional areas, and agencies maintain services that fit narrowly specified funding categories. Under conditions like these, networks of providers offer a way to provide services efficiently while still maintaining acceptable levels of organisational and professional autonomy.

Also offering support for networking in the public sector, Jennings \& Ewalt (1998) investigated network analysis in the context of delivering public employment and training services in the U.S. Through quantitative methods, they tested two hypotheses by measuring the percentage use of a range of networking techniques (for example, information sharing, interagency task forces, and working partnerships). Theyfound that greater efforts to coordinate the fragmented employment and training systems through networking led to higher levels of performance on delivering outcomes.

In contrast, research has also found challenges with the use of networks in the public sector. For example, Provan and Milward (2001) state that creating and utilising networks within the public sector can be problematic because there are multiple organisations each dealing with their own multiple sets of stakeholders. In the public sector environment, this creates tension around issues such as budget allocation, political turf battles, and regulatory differences. Therefore, Provan and Milward (2001) argue that some public organisations may compromise the quality of services they deliver by choosing to collaborate with those stakeholders that they find easy to understand and control. 
Another area that research has focussed on regarding stakeholder networking in the public sector follows on from Rowley's (1997) theory of stakeholder influences, focussing on investigating the use of network analysis to identify key influential stakeholders and understand how networks can be used as a means to influence dominant governance groups. For example, Gomes \& Gomes (2008) conducted research that analysed networks in which public organisations in Brazil make decisions. Through quantitative analysis, they could pinpoint specific stakeholders who were regarded as strongly influential and able to demand decision-makers' attention. Likewise, network analysis was used in a study that sought to identify the most powerful stakeholders that could impact a controversial policy change in the U.S. education sector (Miskel \& Song, 2004). Contrary to prior assumptions, a small clique of influential inside policy entrepreneurs were identified, enabling effective management of the group before it became a public issue.

Further investigation of ability to use networking as a means to influence organisations, Musso, Weare, Oztas, and Loges (2006) applied network theory to investigate whether neighbourhood councils had the potential to change dominant city governance groups in Los Angeles through network effects. They looked at using networks to develop relationships that would bridge traditional community gaps; broadening networks that would improve information flow and result in collective action; and creating new ties that would incorporate isolated groups into the system of political communication. It was found that while bonding ties help to facilitate collective action between minor stakeholder groups and mobilise diverse groups through information sharing, these network effects also maintain social stratification because they produce similar groups and involve status seeking. The rationale behind this study is comparable with action taken by a minority group of business leaders, who were representing several multinational corporations, trying to affect another U.S. public educational system policy (Sipple, 1999).

To a lesser extent, another approach to stakeholder networking research in the public sector has been the analysis of structural characteristics of public sector networks and the implications for management and policy decisions. Stokes (2006) looked at the characteristics of networks that influence strategy development in Australian 
public sector tourism agencies. It was found that soft, loosely formed networks consisting of some stable clusters of core stakeholders and more ad hoc stakeholders on the peripheral, drive mostly reactive strategies. The practical implication here is that understanding the context in which tourism strategies are set could facilitate different types of stakeholder engagement and network formation (Stokes, 2006). In a different tourism sector study, Timur (2005) studied how sustainable tourism policies could best be developed and implemented in urban tourism destinations, using network analysis to examine the relationships among the destination stakeholders. It was found that network analysis offered a useful tool for studying stakeholder interactions, which 1) determined a basic structure of how tourism functions in cities; and 2) identified the most important, important and unimportant stakeholders within a tourism network.

With regard to the New Zealand public sector context, there has been some stakeholder research conducted that addresses the New Zealand stakeholder landscape (e.g. Elias et al., 2002 \& 2004; Leitch \& Davenport, 2003), but stakeholder networking is not a field that has been widely explored. One example is study by Shannon and Walker (2006) who describe an attempt to use a community development process to empower a local South Island community (Timaru), which was in a state-local partnershipinvolving various stakeholder groups, including central government, local municipal authority and community organisations. The idea was to gain more governance control in the face of central government dominance, by developing more independent and autonomous local decisionmaking. The exercise built on existing local networks to encourage and promote more active involvement to achieve this autonomy and meet broader community objectives. This involved greater discussion, visioning, and planning processes with these networks. The project was successful in challenging central government dominance, raising issues concerning mana whenua ${ }^{1}$ initiatives, and involving those in the outlying rural community. The paper concluded that enhancing multistakeholder networks is an effective strategic approach to community empowerment that leads to achieving community governance at a local level for meeting local needs and objectives (Shannon \& Walter, 2006).

\footnotetext{
${ }^{1}$ Mana whenua are the indigenous people of that place.
} 
Another example is a recent case study known as "Hands Across the Water" (Cronin \& Jackson, 2004), which sought to test stakeholder 'dialogue' approaches between scientists and stakeholders of the New Zealand biotechnology community. The focus was a 'people-centric' network established by the Ministry of Research, Science and Technology (MoRST) that alerts scientists and policy analysts to emerging areas of science and technology. The network is made up of representatives from a range of stakeholder groups, including government agencies; and focuses on generating new knowledge, disseminating that knowledge beyond the network itself, and building future capability in the government and science sectors.

As can be seen from the review of stakeholder networking literature in the public sector, the limited amount of research that has been conducted to date focuseson three main areas, 1) research to support the role networks play in effective delivery of public services to numerous stakeholders; 2) understanding how network analysis can be used to identify influential stakeholders and also to build influential stakeholders; and 3) understanding the structural elements of public sector networks and implications for management decisions.

However, based on the review of the use of stakeholder theory for strategic management in Section 3.2.1, what appears lacking in the stakeholder networkingliterature is an exploration of the potential for stakeholder networking to be used as a practical tool for strategic planning in the public sector. Additionally, there is a clear lack of stakeholder networking research in the New Zealand public sector. The following section discusses some factors specific to the New Zealand context that drive the complexity of our public sector stakeholder landscape.

\subsection{The New Zealand Public Sector Stakeholder Environment}

In addition to the well established factors that contribute to a dynamic and complex public sector stakeholder environment described above in Section 3.2.1, there are several factors that are further driving the multiplicity and complexity of the stakeholder landscape in the New Zealand public sector, making it imperative for government agencies to develop new ways of understanding and managing their multitude of stakeholders. 


\section{$\underline{\text { Whole-of-Government Approach }}$}

From the early 2000's, the New Zealand Government committed to the idea of developing a 'whole-of-government' approach whereby 'government agencies will give priority to working together, breaking down silos and establishing co-ordinated, inter-sectoral policies and programmes" (Statement of Government Intentions, 2001, p 2). That is, it is expected that the public sector will be working like a single, integrated organisation, rather than a collection of independent service providers (Egovernment Strategy Update, 2001). The following is included in the State Services Commission (2005) definition of 'whole-of-government':

A term with several broad shades of meaning, depending on context. For example, it may mean:

- 'vertical alignment': single agency, multi-agency, sectoral or intersectoral alignment with government's broader goals and objectives;

- 'horizontal alignment': inter-agency or inter-sectoral planning, or integrated service delivery;

- a 'whole of government direction' given under the Crown Entities Act 2004 by the Ministers of State Services and Finance to one or more categories of Crown entities, or to one or more types of statutory entity, for the purpose of both:

- supporting a whole of government approach; and - improving public services, either directly or indirectly;

The rationale for this new approach arose from Government's recognition of increasing interaction across a range of government ministries and departments, which were working to deliver on the same wider government goals. Additionally, whole-of-government is developing as a good practice approach adopted by othergovernments around the world with success. For example, Australia made a formal commitment to whole-of-government responses for their priority challenges saying that "every major challenge of public administration - ensuring security, building a strong economy, coping with demographic change, crafting social policy - necessarily requires the active participation of a range of central and line agencies" (Connecting Government, 2004). The Canadian Government also formally introduced a whole-of-government framework in Canada Performance 2002 (Canada Performance, 2006), which evolved through a series of consultations over many years. 
The New Zealand Government's commitment to a whole-of-government approach has been published in high level government reports, through which government agencies are accountable. For example, the Statement of Government Intentions (2001)for an improved relationship between communities and Governmentwas signed by the Prime Minister and the Minister for the Community and Voluntary Sector, with the aim to create apartnership between community, voluntary and iwi/Maori organisations in order to work towards a healthy civil society. A second Government initiativeis the State Services Development Goals (2007), which includesa goal titled 'Coordinated State Agencies' where the aim by 2010 is to have agencies work together towards jointly-defined outcomes in response to government priorities and increasingly achieve measureable results by sharing capabilities and using effective networks.

The impact of such Government priorities and goals is the requirement for public sector organisations to work with a wider set of stakeholders to achieve objectives. Due to the nature of public accountability and reporting in the New Zealand public sector, it is necessary for government agencies to show evidence that all their work programmes and initiatives are supporting Government priorities by incorporating this approach. As a result, government agencies are facing a more complex set of stakeholders that they must work with to achieve wider government objectives.

\section{New Zealand Public Sector Consultation Requirements}

The New Zealand Public Acts that define a public sector organisation's legislative requirements all require a process of consultation to be conducted in preparation of plans and carrying out their operational activities, allowing them adequate time to respond to the proposals (Norman, 2003, 2006). An example of how this is conducted can be seen in a Ministry of Fisheries Stakeholder Consultation Process (Ministry of Fisheries, no date) document that outlines a standard process of engaging and consulting stakeholders in relation to fisheries management decisions

This legal requirement for stakeholder consultation is a feature for public sector organisations in many countries around the world and is taken more seriously now due to a constantly shifting philosophy towards user-centred public sector service 
provisions (Gregory, 2003). Again, this adds an extra dimension to the New Zealand public sector stakeholder landscape that creates additional pressure on public organisations to develop ways and means of adequately achieving this stakeholder engagement.

\section{$\underline{\text { New Zealand's Multi-cultural Population }}$}

In a Statistics New Zealand forecast from 2006 - 2026, the populations of New Zealand Maori, Asian and Pacific will continue to grow by $1.3 \%, 3.4 \%$ and $2.4 \%$ per year respectively (National Population Projections, 2006). Considering the need for public organisations to meet their full range of stakeholder needs and create public value, the added dimension of an increasingly multi-cultural population will create additional pressure on organisations to understand, manage and meet these constantly changing needs.

\section{$\underline{\text { Treaty of Waitangi Commitments }}$}

The need for New Zealand public organisations to understand, incorporate and address specific stakeholder concerns around the Treaty of Waitangi commitments creates another dimension of stakeholder pressure for them manage, adding to the multiplicity of stakeholder interests and pressures they face.

\subsection{Chapter Summary - Research Gap Refined}

Stepping back and looking at the big picture that has been described here, the New Zealand public sector stakeholder landscape begins to look very complicated and diverse. It consists of generic factors that drive stakeholder multiplicity and complexity in all public sector organisations (mentioned above in Section 3.2.1); there is the added complexity of the four factors discussed above; and there are other general pressures such as an increasing population, a developing economy, growing demand, and more varied stakeholder interests.

Bearing in mind the research presented above that strongly argues for a stakeholder perspective to be incorporated in public organisations' strategic management 
processes, there appears to be a relative paucity of research that applies new ways and means of achieving this. This gapis supported by O'Toole (1997)who questions how well public administrators are equipped to deal with challenges they confront from the complex patterns of operations; and states that research in this field contains little to help practicing managers in public administration to cope with network settings (O’Toole, 1997, p 45);

Practitioners need to begin to incorporate the network concepts into their administrative efforts. The challenge for scholars is to conduct research that illuminates this neglected aspect of contemporary administration.

More recent support for this gap is ina study by Bingham et al. (2005) who review the practices and processes for stakeholder and citizen participation in the work of government. They also conclude that public administration needs to address new processes to help public administrators develop and use informed good practices that will help them deal with the complexity of the increasingly dynamic stakeholder environment of the public sector. They argue that these processes should encourage building partnerships with citizens, the public and stakeholders to do the work of the government.

While practical examples of stakeholder networking being integrated into strategic planning might have taken place in reality across various contextsin the New Zealand public sector, there is very limited published research. Yet there is clearly an imperative, which is evidenced by public organisations such as Ministry of Agriculture and Forestry Biosecurity New Zealand highlighting in their strategic plan "the need for positive collaboration with stakeholders to achieve our goals”(MAF BNZ Strategic Plan, 2006, p 8).

What this thesis aims to investigate is whether stakeholder networking theory can be used to help New Zealand public sector organisations in their strategic planning process. The specific research objectives and the approach for investigating this will be discussed in Chapter 4. 


\section{CHAPTER 4}

\section{RESEARCH METHODS}

\subsection{Introduction to Chapter}

The preceding two chapters have presented an overview of the literature across the primary fields that relate to this thesis - stakeholder networking theory and strategic management theory - and highlighted the research gap that has led to this investigation of these two areas in the public sector context.

The purpose of this chapter is to outline the research process and methods that were designed and executed to carry out this investigation and meet the stated research objectives. In designing the research approach, some key considerations arose around sampling, ethics, and the information gathering process within the two sample organisations. These led to some interesting research challenges, which are carefully explored here to illustrate how these were managed.

\subsection{Research Objectives}

To address the research gap and make a contribution to themanagement literature, the following research objectives were specified.

1) To determine the applicability of stakeholder networking theoryin the public sector

2) To understand the management issues that arise in the practical application of stakeholder networking theory in the public sector

3) To investigate the use of stakeholder networking theory for strategic planning in the public sector

The research objectives target three main areas. Firstly, the application of the theory in practice; secondly, the management issues that might arise during application; and thirdly, the use of stakeholder networking theory for strategic planning. 
This first and second objectives are important for additional contribution to existing research becausestakeholder networking theory has had relatively limited application in practice and because research has tended to report only the analysis rather than describe and consider the process of application. It will therefore be useful for managers to understand some key issues in order to improve their use of stakeholder networking theory in practice. Further, according to O'Leary (2004), “applicability comes from the 'lessons learned' that might be applicable in alternative or broader populations" ( $\mathrm{p}$ 104). Any realised potential in this area will be discussed in Chapter 6.

\subsection{Selection of Organisations}

In line with my interest in investigating stakeholder networking theory in the public sector, it was necessary to find public sector organisationsthatwere currently undertaking strategic planning and prepared to try the integration of stakeholder networking theory in to their planning process.

The specific requirements of the sample organisations meant that the sample population was small and access issues were a concern. I was able to overcome this by leveraging off existing contacts I had made through my management consulting employment. Department of Conservation (DOC) and the Ministry of Agriculture and Forestry Biosecurity New Zealand (MAF BNZ) were clients of the company I was working for at the time and they met the requirements of a) public sector organisations, and b) undertaking strategic planning.

Through work contacts, I was introduced to the relevant people within the two organisations. Initial meetings were arranged where I went through the information sheet (Appendix 1) to explain my background and the rationale behind why I was conducting the research. I then gave them the opportunity to tell me about their organisation context and stakeholder environment in order to determine whether their organisation was an appropriate fit for my research and whether they would be interested in being involved in my research. 
While my work affiliationresolved some key access issues and presented an excellent opportunity for gathering rich data that would be otherwise unavailable, this method of sampling did create some ethical issues. The ways in which these were addressed to minimise their impact are discussed in more detail under 'Ethical Considerations', Section 4.4.

\subsubsection{Sampling Method}

This sample is referred to as a non-random sample, or apurposive sample, as opposed to a random sample (Miles \& Huberman, 1994; Cavana, Delahaye \& Sekaran, 2001; Silverman, 2006). That is, the organisations were selected intentionally. While the type of sample is known as purposive, the sampling method I used is called handpicked sampling (Creswell, 1998; Cavana et al., 2001; O'Leary, 2004)where certain organisations were selected with a particular purpose in mind. This was an important aspect to my sampling technique because it was necessary to ensure specific characteristics of the sample as discussed above i.e. public sector organisation, undertaking strategic planning, and would allow access to a researcher.

The main critique of the handpicked sampling technique is that it can result in the selection of a sample that is not representative and therefore, cannot credibly be generalised across a relevant sample population (Miles \& Huberman, 1994; Creswell, 1998; O'Leary, 2004). Some researchers think that the primary purpose of sampling is to study a representative subsection of a defined population in order to make inferences about the whole population (Gilbert, 2001). However, as Silverman (2006) states, this sort of sampling is often unavailable in qualitative research ( $p$ 304);

data are often derived from one or more cases and it is unlikely that these cases will have been selected on a random basis. Very often a case will be chosen simply because it allows access. Moreover, even if you were able to construct a representative sample of cases, the sample size would be likely to be so large as to preclude the kind of intensive analysis usually preferred in qualitative research. 
This is supported by O'Leary (2004) who writes that this selection technique allows researchers to study interesting samples and enhance learning by exploring the limits of defined situations.

Another potential issue in adopting the handpicked sampling technique is that it is exposed to unwitting biases or erroneous assumptions (O'Leary, 2004). An example of an unwitting biasrelates to the tendency to select a sample that reflects what the researcher might already suspect. It is unlikely that this bias was a factor in my research because I was investigating the applicability of a theory in a specific organisational context and I did not have any preconception as to whether it might or might not be applicable. The organisations were chosen on the basis of being in the public sector and undertaking strategic planning, and little was known about their stakeholder landscape or their planning processes. Neither organisation had previously used stakeholder networking theory in managing their stakeholders.

The second question mark around erroneous assumptions refers to a sample selection that is premised on incorrect assumptions (O'Leary, 2004) - whereby I might have intended to select the sample based on certain elements such as, the organisation was undertaking strategic planning, but in fact my assumption around strategic planning is for some reason incorrect. In terms of dealing with this bias, the initial meeting where I explained what my research was about and they gave me the context of their organisation offered more certainty that the organisation possessed the specific elements I was looking for.

\subsubsection{Sample Size}

In terms of sample size, I chose to research both DOC and MAF BNZ, but not any additional public sector organisations that I may have gained access to. There were two reasons behind my sample size decision. Firstly, given the time constraints of the thesis and the time consuming nature of the research process I was to undertake with the two organisations (see section 4.5, Research Process), two organisations was deemed a reasonable sample size that I could manage within the timeframe. I needed to be available when the organisations undertook their activities and could 
not orchestrate a schedule that revolved around suiting my timing needs. Therefore, it was necessary to adapt and make myself available to their schedules. At times, this resulted in intensive involvement in contrast to other times.

Secondly, I opted to research two organisations as opposed to just one to add a dimension of generalisability to the research and reduce the impacts of the handpicked sampling method, as discussed above in Section 4.3.1. In order to add credibility to the research, it was necessary to consider how I might be able to transfer findings and the lessons learned to other public sector organisations. According to Miles and Huberman (1994), multiple-case sampling adds confidence to findings because if a finding holds in a comparable setting then the finding is more robust.

\subsection{Ethical Considerations}

An application for approval of this research project was submitted to the Human Ethics Committee (HEC) prior to the start of data collection to ensure that it met ethical standards and that no harm to participants would occur. There were concerns that because the two organisations being researched were clients of the consulting company I was working for at the time, that there would be a conflict of interest. More specifically, this was because I was analysing the organisation's stakeholders and asking questions about power and influence, such as "does DOC / MAF BNZ incorporate (name of stakeholder) into its planning processes? Why / why not?” and "do you think that the relationship is balanced or is one organisation more powerful?"(Appendix 2, interview schedules) The HEC raised concern that my company of employment was a stakeholder and therefore, it may not be ethical to ask DOC or MAF BNZ questions of such a sensitive nature as it might influence their response.

Such concerns were resolved, however, after clarifying that despite this research idea being inspired from professional engagements with the two organisations, neither I nor the organisations considered there to be any conflict of interest for two reasons. Firstly, the research I intended to conduct was not for the use of my employer to deliver to the organisations as a piece of consulting work. The thesis idea arose 
during the courseof client engagements as it was at this time I was exposed to the inner workings of the public sector; but at the time the research began, client engagements had been closed off. It was because of my experience during these engagements that I had recognised issues related to effectivelyintroducing a stakeholder perspective in the strategic planning process across public sector; and I wanted to determine whether Rowley's academic theory of stakeholder networking had potential for practical application in the public sector to fulfil this gap.

Secondly, my research was only focussing on the two organisations' strategic relationships, which did not include my employer because their role was as consultants who were involved in facilitating and promoting the strategic planning process; not as a key stakeholder who could influence or provide input to the content of strategic planning. Therefore, my employer was quite removed from the type of stakeholder relationships that I was going to be researching.

There were also ethical considerations around using the names of third party stakeholders due to privacy issues, which were overcome by using generic names to describe groups of stakeholders by their interests. These were then used throughout the thesis and stakeholder network maps as required. For example, simply referring to groups called regional councils or energy companies, as opposed to naming them specifically, does not reveal which specific organisations within these two groups that DOC or MAF BNZ have relationships with.

Subsequent to gaining human ethics approval, I then had to go through an initiation phase with the organisations to get agreement from relevant people to conduct research, as described above in Section 4.3. I gave them a research agreement form (Appendix 3), which covered the whole research process, including all interviews, focus groups, and access to internal documents for analysis. Following the organisational approvals being given, I did not give a separate research agreement form to each individual person that was interviewed, but they were informed that I was using the organisation as a sample for a Masters thesis and were offered a copy of the information sheet that gave a succinct outline of my thesis and what I was aiming to achieve (Appendix 1). 
As discussed below in Section 4.5, my research approach was to undertake action research, which involves the generation of knowledge - organisational knowledge in the case of my sample organisations. Therefore, a significant moral issue is the use of this knowledge throughout the research process and upon completion; and the need for utmost transparency (Salkind, 2010). To manage this from the outset, I communicated my research intentions up front during the initiation phase when gaining access to the organisations, providing the context and rationale for my research and providing them with an opportunity to ask questions about my research approach and set their own boundaries. It was also agreed that I would obtain permission from the organisations before handing in my thesis, providing them with a chance to check that my write up did not in any way make harmful or politically sensitive statements that would cause concern.

\subsection{Research Framework}

In order to meet the research objectives of investigating the applicability of stakeholder networking in the public sector, the management issues that arise during application, and its use for strategic planning; a qualitative research approach was seen as the most appropriate for the investigative nature of the study. The rationale for this approach is discussed later in this section. There are a variety of qualitative research approaches that can be adopted and I chose a participation type research approach, known as action research(Miles \& Huberman, 1994; Denzin \& Lincoln, 2003; O’Leary, 2004), which O’Leary describes as (2004, p 139);

a research strategy that pursues action and knowledge in an integrated fashion through a cyclical and participatory process. In action research, process, outcome and application are inextricably linked.

Participatory action research is an alternative philosophy of social research, often associated with social transformation or community improvement/development in developing countries where remote communities face multiple social issues (Reason \& Bradbury, 2001; McNiff \& Whitehead, 2002; O’Leary, 2004; Salkind, 2010). Denzin \& Lincoln (2003) suggest there are three particular attributes that distinguish this type of research from conventional research - shared ownership of research 
projects, community-based analysis of social problems, and an orientation toward community action. What most researchers aim for is that it will lead to empowerment and ownership within the community, and hopefully create sustainable change that will outlive a traditional research project (O’Leary, 2004).

Since its origins, it has been applied in fields and settings more broadly than social research (Denzin \& Lincoln, 2003) as a general strategy for institutional change through joining forces with people to help them study or resolve a problem (Miles \& Huberman, 1994; Salkind, 2010). O'Leary (2004) has translated the original socialcentric attributes of this type of research into generic principles to assist further application across a wider variety of research contexts. The five basic principles of action research suggest that it will likely;

1) address a practical problem

2) generate knowledge

3) enact change

4) be participatory in nature

5) rely on a cyclical process

The remainder of this section illustrates alignment between these principles and the research I conducted in order to demonstrate how my research is considered to be action research. Some of the points described below refer to elements of the research process (i.e. information gathering). The information gathering process is described in more detail in the following section, which also addresses aspects relating to my involvement with the two organisations and the participants selected to work with.

The first principle is that research should address a practical problem. For both organisations, the focus was on the practical problem of how public sector organisations should respond to the need for integrating a stakeholder perspective into their strategic planning process, in order to meet growing pressures in the public sector environment. To address this practical problem, the thesis sought to investigate whether stakeholder networking theory could be a useful tool in facilitating this. Therefore, in line with the theory underpinning action research, the focus was on improving the capability of these organisations (transforming the 
research context) through a process of investigation (Miles \& Huberman, 1994; Denzin \& Lincoln, 2003; O’Leary, 2004; Salkind, 2010).

The second and third principles of action research go together as the focus is on generating knowledge that affects change; and likewise, implementing change that leads to the production of knowledge (O'Leary, 2004). This is congruent with Denzin \& Lincoln's (2003) notion that 'action learning' is a key part of action research, which refers to the fundamental idea of bringing people together to learn from each other's experiences and problem solve collaboratively. Due to the practical drive behind my research, I really wanted an aspect of it to be about transferring knowledge and exposing people to potentially different stakeholder perspectives; and according to Salkind (2010, p 7) "action research can provide a bridge across the perceived gap in understanding between practitioners and theorists".

My research approach demonstrates these principles through the nature of the research process; particularly for DOC (see Section 4.6 for further details) where I became part of a Project Team that had regular meetings with participants about stakeholder relationships over a long period of time, with an inevitable output of knowledge generation. In turn, the knowledge generated promoted the instigation of change as we learnt about parts of the theory that worked and those that did not. However, the enactment of change went beyond knowledge generation and was incorporated at a deeper level where new skills and procedures of stakeholder management started to become ingrained in organisation practice.

The fourth principle of action research is that it is participatory in nature, which places emphasis on the participation and collaboration between researchers, practitioners, and any other interested parties. The aforementioned Project Team that I joinedwhen researching DOC and the focus group sessions used within MAF $\mathrm{BNZ}$ align to this principle. Effectively, we were participating together, with minimal distinction between the 'researcher' and the 'researched' (O'Leary, 2004). This type of research approach meant that my research was somewhat intrusive, in that by being heavily involved in conducting the research I affected the application 
process. This is later addressed in the critique of action research at the end of this section, and I also talk about the challenges that action research pose to the researcher in Section 4.7. At the end of my research project, I reflected on how the process unfolded and connected this back to my research objectives. This is discussed further in Chapter 6.

Finally, the fifth principle of action research is reliance on a cyclical process, which refers to action research being a process of experiential learning where the goal is to continuously refine methods, data and interpretation in light of the understanding developed in earlier cycles. Again, this concept aligns to that of 'action learning' as described above (Denzin \& Lincoln, 2003) and with Lewin's (1946, cited in Salkind, 2010) model of action research. This was a key aspect to my research because the DOC Project Team continually sought to improve the way we operated to ensure we were utilising our resources effectively and efficiently, and that we were making the best use of participants' time. This emphasises the practical nature of undertaking action research within an organisation and being part of a functioning team that must manage typical organisation challenges on a daily basis while also meeting research objectives.

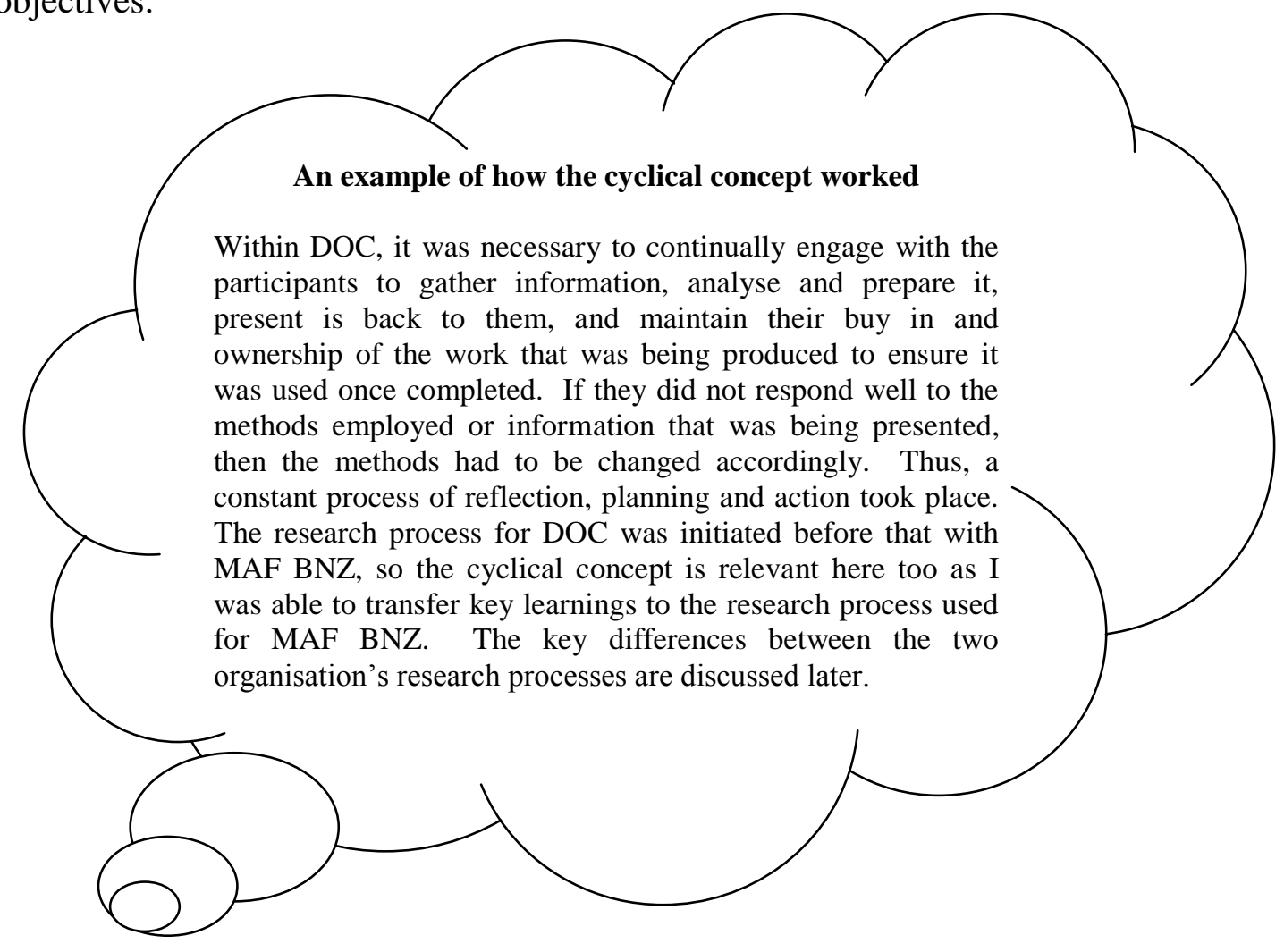




\subsubsection{Advantages and Disadvantages of the Research Framework}

The advantages and disadvantages of general qualitative research and action research (as a subset of qualitative research) have been well debated and documented in the literature (Miles \& Huberman, 1994; Creswell, 1998; Cavana et al., 2001; Reason \& Bradbury, 2001; McNiff \& Whitehead, 2002; Denzin \& Lincoln, 2003; O’Leary, 2004; Silverman, 2006; Salkind, 2010). I have reflected on the challenges of my chosen method process in Section 4.7, which relate specifically to the two organisation contexts and also touch on some of the key issues that action research typically pose for researchers. However, below are some of the key critiques that relate to the broader principles underpinning general qualitative research and action research.

Some researchers say that participatory action research lacks scientific rigour (Salkind, 2010) and, in the organisation specific setting, imposes "academic discourses over participants' own ways of describing and engaging their experience" (Denzin \& Lincoln, 2003, p 339). More simply, participants are unwittingly dominated by the academic theory brought by the researcher. I do not think this was a significant issue in either organisation as they were open to the idea of being exposed to a new theory that could potentially add value by contributing a new stakeholder perspective to their strategic planning process. The collaborative and participatory nature of action research also meant that we were working together and there were a number of opportunities to adjust the process and approach to suit the situation and needs of the organisation, as opposed to the 'academic' researcher having a dominant influence. Additionally, being a young female researcher working with established senior managers, employees and project teams within these organisations, I did not perceive my position as a researcher to be one of significant influence or power.

Qualitative research also emphasises the qualities of entities, processes, experiences and meanings that are not experimentally examined or measured in terms of quantity, amount, intensity or frequency. Qualitative researchers typically focus on the socially constructed nature of reality with the belief that these things change 
depending on the situation (Denzin \& Lincoln, 2003). So the researcher must understand the situation in order to interpret and give meaning to it. The alternative is quantitative research, which involves assigning mathematical symbols to words, actions and records so that they can be statistically analysed (Cavana et al., 2001). This emphasises the measurement and analysis of causal relationships between variables, not processes. It is said that quantitative research is value-free (Cavana et al., 2001).

Qualitative research typically occurs by engaging in intense research for a sustained period of time within a field or life situation, which is reflective of normal everyday life (Miles \& Huberman, 1994). For my research, the situation is the everyday operation of two organisations as they undertook their planning activities where I sought to gain a comprehensive, holistic view of stakeholder networking in application.

One of the disadvantages of qualitative research is its time consuming nature and therefore, the inability to research numerous cases. Thus, as addressed in Section 4.3.1, qualitative researchers usually work with small samples nested in their context and study them in-depth (Miles \& Huberman, 1994). This is often the subject of critique by quantitative researchers due to the perceived inability for generalisation. However, the question qualitative research poses is: "is any claim of replication possible in studies involving human researchers and participants...and is this desirable in contributing to our understanding of the social world?" (Salkind, 2010, p7-8). Action research provides the opportunity for exposure to deep and rich insights that might otherwise be unavailable to the researcher and overlooked. Often, the goal of generalisability is less concerning to the action researcher than capturing the richness of unique human experience and meaning that represents a slice of the social world (Salkind, 2010) - in this instance, a public sector organisation investigating the use of stakeholder networking theory in strategic planning. However, Salkind (2010) does list a range of circumstances when a certain level of generalisability of action research results may be possible. 
Another common criticism of qualitative research refers to its subjective nature, whereby the meanings and interpretation of information, data and experiences during the fieldwork are inevitably framed by the researcher's implicit concepts, which means the researchers' personal values and perceptions become attached to the information that would not have otherwise existed (Miles \& Huberman, 1994; Creswell, 1998; Cavana et al, 2001; Denzin \& Lincoln, 2003; Silverman, 2006; Salkind, 2010). Salkind (2010) also raises a similar critique from the quantitative school of thought that because the variables under inquiry are uncontrolled in the context, they offer little certainty of causation. O'Leary (2004) sums up the critical attitudes toward qualitative research quite succinctly ( $p$ 99);

...qualitative research is said to be a subjective, value-laden, biased, and ad hoc process that accepts multiple realities through the study of a small number of cases.

Thus, it is argued that action research data come with a lot of complexity that require plenty of care and self-awareness on the part of the researcher during interpretation to ensure good quality research, but it can still meet the determinants of reliability and validity (Miles \& Huberman, 1994; Salkind, 2010). In order to achieve this, Miles and Huberman (1994) and others propose a list of suggested questions for the researcher to use as a way of checking research meets a good standard against various criteria, including objectivity, reliability, credibility, transferability and others. Creswell (1998) proposes a structured approach to managing and analysing data to reduce any tendencies for the researcher to interpret data primarily through intuition and/or other narrow perspectives. Salkind (2010) encourages researchers to be as disciplined as possible in gathering, analysing and interpreting the data and information of their study by using triangulation strategies and participation validation.

In line with Salkind's (2010) statement, "ultimately, action researchers must reflect rigorously and consistently on the places and ways that values insert themselves into studies..."; it was something I managed consciously and carefully during my research. This was made easier through working in a Project Team at DOC where I was constantly able to check my interpretations with others and balance any 
anomalies. However, I had to be more aware of a non-biased data interpretation process with MAF BNZ as the same opportunity for feedback and interaction was not available in this context. Data triangulation was also used in both contexts, as discussed below in the respective information gathering sections.

Having considered key critiques of qualitative research, it is important to note the strengths, which illustrate its appropriateness for my research. Firstly, data are gathered in its natural setting during the course of everyday events and therefore reflect what "real life" is like in the two organisations. At such close proximity to the context, I was able to focus on and encompass the entire surrounding phenomena into the information gathered. Therefore, the local influences are not stripped away and an understanding of issues and complexities should be increased. This is known as local groundedness (Miles \& Huberman, 1994) and was particularly important for my research objectives because I needed to understand the management issues that arise during application. This is not the sort of information that interviewees will pass on to a researcher with whom they have no relationship. Additionally, it is much easier as a researcher to understand issues fully when you face them yourself, as opposed to relying solely on others to explain them to you.

Secondly, as described by Creswell (1998), variables required to gather quantitative data cannot always be easily identified for some topics. My topic of interest was one that needed to be explored through practical application in order to investigate whether stakeholder networking theory could be applied successfully in the public sector and to determine its use for strategic planning. Existing knowledge about this topic is limited because stakeholder networking theory has not been widely applied previously in the New Zealand public sector. Qualitative research has "been advocated as the best strategy for discovery, exploring new areas, and developing hypotheses" (Miles \& Huberman, 1994, p 10). Given that a primary rationale for conducting this study was to contribute to an area of literature that has limited research, it was important that my findings stimulate future research that could provide more valuable knowledge in this field. Therefore, gathering qualitative data seemed more applicable. 
Thirdly, the sustained period over which information is gathered presents an opportunity for studying and tracking a process (Miles \& Huberman, 1994; Creswell, 1998), which my research objectives required. The seven month involvement allowed me to follow the process of applying stakeholder networking from the beginning, through all the challenges to its completion. This is explained further in the next sections.

Finally, qualitative research also provides the researcher with an opportunity to become immersed in the context and gather extremely rich and useful information that would be unobtainable if the researcher was on the outside or if the participants were removed from their natural setting and studied in another context. As Creswell (1998) explains, removing participants from their setting can lead to contrived findings that are out of context.

In summary, the research framework I adopted was participatory action research, which is a qualitative approach. I have shown how my research aligns to this approach and framework and how undertaking action research was appropriate in order to fulfil my desire for a practical research approach that generated learning and knowledge, and instigated change. The following section presents the research process used to gather information within the two organisations.

\subsection{The Research Process: Information Gathering}

As described in the previous section, the participatory action research approach meant I became intimately involved with the employees of the two organisations while investigating the application of stakeholder networking theory in practice. This required that I negotiate internal access to the organisations so that I could come and go as necessary, making it easier to organise meetings and interviews with relevant people, gain access to stakeholder related documents on the intranet and in their internal libraries, and more easily engage in informal interactions. This also allowed me to build rapport with people over a period of time, which made 
interactions more open and honest. This internal access spanned a period of seven months to gather the information required for my thesis objectives.

In order to meet the research objectives, information had to be gathered to achieve the following activitiesfor both organisations:

1) Gather names of stakeholders

2) Understand their stake/interest in the organisation

3) Identify relationships between stakeholders

4) Draw the stakeholder network maps

5) Understand the management issues that arose during application of stakeholder networking theory, and

6) Determine the usefulness of the stakeholder network maps for strategic planning.

However, the research process varied slightly across the two organisations because of the differing contexts, information that was available, differing levels of maturity in planning, and participant involvement. Therefore, the following two sections will describe the process separately for DOC and MAF BNZ, and will explicate the methods that I used, how I used them, why I chose them, the advantages and disadvantages of the methods chosen, and the types of information they produced.

\subsubsection{Department of Conservation: Information Gathering}

At the time I approached DOC as a potential organisation to research for my thesis, the Relationships Manager was preparing to undertake a project to develop a relationship management framework that would contribute to DOC delivering on its strategic direction. This involved analysing the organisation's stakeholder relationships. I joined the Project Team that was formed to deliver this framework, which served as the platform for gathering and analysing information to meet the objectives for my thesis. 
It is important to note that while the six activities described above were conducted as part of a wider organisation project and my research objectives were met during the delivery of the project, the Project Team also had objectives that went beyond my requirements. Therefore, in order to maintain my confidentiality agreement, I will only describe the parts of the process and activities that directly relate to my thesis.

At the outset of the project, it was also necessary to put a boundary around which stakeholder relationships were to be the focus of the project, as it was not possible to examine them in entirety because of the extensive number (over 300 relationships). Therefore, it was decided to focus only on relationships held by the Executive Team and to categorise these as either strategic or non strategic. The Project Team was confident that all strategic stakeholder relationships would be captured through the Executive Team sample. DOC's Executive Team consists of one Director General (equivalent to a Chief Executive Officer) and eight General Managers (those who report directly to the Director General and are responsible for the overall management of one of eight divisions of the organisation). The organisation's eight divisions are Corporate Services, Marketing and Communications, Policy, Research Development and Improvement, People and Organisation Development, Kahui Kura Taiao, Northern Operations, and Southern Operations. Each of the nine participants will herein be referred to as an 'Executive Member'.

The first step was to develop an agreed definition of a strategic stakeholder relationship so that the Executive Members' relationships could be categorised as to whether they were in or out of scope of the project. This was based on how significant a stakeholder was in terms of contributing to 1) progressing DOC towards its strategic direction, 2) achieving its strategic goals, or 3) delivering its outcomes. The agreed definition of a strategic stakeholder relationship was;

“...astakeholder relationship that is actively managed to support the Department in delivering the strategic direction. Therefore, if the relationship does not exist in a strong/proactive form, then the Department will fail to deliver on the Strategic Direction, Outcomes and Goals". 
The Project Team decided to use the Department of Internal Affairs (DIA) relationship continuum (Putting Pen to Paper, 2007) to assist in determining whether a relationship was strategic or non-strategic. The continuum labels relationships as either Co-existence, Networking, Cooperation, Collaboration or Partnership (Appendix 4). The Project Team decided to categorise non-strategic relationships ('nice to have' relationships) as Co-existence, Networking, or Cooperation; and strategic relationships ('must have' relationships) as Collaboration or Partnership. This distinction affected which stakeholders would be in scope for the development of the stakeholder network maps.

The Project Team then had to understand what information was required about the Executive Members' stakeholder relationships and then develop a means by which to gather this information. The intention was to use Freeman's (1984) rational level analysis framework (introduced inSection 2.2.2), which has been applied extensively in the private sector but not as fully in the New Zealand public sector. However, after some review, the Project Team found that this framework was too 'generic' and did not suit the needs of the project objectives (see findings in Section 5.2.1.1). Therefore, a slightly different process for identifying stakeholders and related information was developed, which was more specific to DOCand would allow a more meaningful analysis across the wider set of project objectives. The findings from this process of stakeholder identification are presented in more detail in Chapter 5.

The new process for stakeholder identification involved developing a questionnaire in the form of a Microsoft Excel spreadsheet (Figure 4.1) that was sent out to Executive Members to complete and return. This was accompanied by an instruction sheet explaining each part of the questionnaire and a brief verbal explanation by the Project Leader. It is important to note that this table only illustrates those fields that relate to information gathered for my thesis objectives. The questionnaire was more elaborate with other information required for the overall project's purpose. 


\begin{tabular}{|c|c|c|c|c|}
\hline \multicolumn{3}{|c|}{ Must have relationships (Strategic Relationships) } & \multicolumn{2}{|c|}{$\begin{array}{l}\text { A relationship that is actively managed to support the Department in } \\
\text { delivering the strategic direction. Therefore, if the relationship does } \\
\text { not exist in a strong/proactive form, then the Department will fail in } \\
\text { the Strategic Direction, Outcomes and Goals. }\end{array}$} \\
\hline \multicolumn{3}{|c|}{ Nice to have relationships (Non-Strategic Relationships) } & \multicolumn{2}{|c|}{$\begin{array}{l}\text { A relationship that generally supports the delivery of the Strategic } \\
\text { Direction. Therefore, it is not critical to the success, but has a valid } \\
\text { role. }\end{array}$} \\
\hline \multirow{2}{*}{ Strategic Direction Target Area } & \multirow{2}{*}{ Stakeholder Name } & \multirow{2}{*}{$\begin{array}{l}\text { Stakeholder's Stake / } \\
\text { Interest }\end{array}$} & \multicolumn{2}{|c|}{ Current Status } \\
\hline & & & Continuum & Comments \\
\hline \multicolumn{5}{|l|}{ 1. Private Land } \\
\hline \multicolumn{5}{|l|}{ 2. Public Land } \\
\hline \multicolumn{5}{|l|}{ 3. National Community } \\
\hline \multicolumn{5}{|l|}{ 4. Global Community } \\
\hline \multicolumn{5}{|l|}{ 5. Recreation } \\
\hline \multicolumn{5}{|l|}{ 6. Business } \\
\hline \multicolumn{5}{|l|}{ 7. Heritage } \\
\hline \multirow{2}{*}{\multicolumn{5}{|c|}{ 8. Marine }} \\
\hline & & & & \\
\hline \multicolumn{5}{|l|}{ 9. Terrestrial } \\
\hline \multicolumn{5}{|l|}{ 10. Education } \\
\hline & & & & \\
\hline \multicolumn{5}{|l|}{ 11. Cultural } \\
\hline 12. Other & & & & \\
\hline & & & & \\
\hline
\end{tabular}

Figure 4.1. Stakeholder identification questionnaire template, DOC.

The questionnaire asked Executive Members to identify all their stakeholder relationships (Stakeholder Name column) against which area of DOC's strategic direction the relationship contributed to (Strategic Direction Target Area Column). This was a technique used to encourage Executive Members to think about strategic stakeholder relationships and the entire range of stakeholders while completing the exercise. They were also asked to briefly state what the stakeholder's stake/interest with DOC was (Column 3), where on the DIA continuum the relationship fell (Column 4) and any other general comments they wanted like to make (Column 5). This covered the first phase of information gathering.

The main advantage in using the questionnaire was that it allowed each Executive Member ample time to consider their stakeholder relationships thoroughly. However, at the same time, it created the risk that the necessary time would not be spent on completing them, which was out of the Project Team's control. Further, it was possible that the meaning of the columns could be misinterpreted and the information provided inconsistent. For example, some Executive Members had different interpretations of the DIA relationship categories and did not classify these 
in the same way. It was attempted to overcome this by following up with one-onone interviews with each Executive Member to clarify their responses and also to obtain additional information that had not been requested in the questionnaire.

The questionnaire was completed over a six to seven week period, during which time I conducted a separate document analysis to identify stakeholder names. Based on O'Leary's (2004)process of document analysis, I identified the documents that I wanted to explore, which included documents off the intranet, DOC publication documents, the annual report, and the statement of intent; and searched for repeated stakeholder names that might have indicated a strategic relationship. I kept a list of these and will refer to their use later in the process.

Once the spreadsheets had been returned, I input all of the raw data into a data table in Excel that had the same column headings as the original questionnaire and created a pivot table so that information could be presented in any format required.

The pivot tables were used to print reports for each Executive Member outlining which stakeholder relationships they had identified, the type of relationship, etc. Reports were presented to each Executive Member in follow-up one-on-one interviews, where the Project Team interviewees sought to;

1) narrow down the extensive lists to just the strategic relationships

2) confirm the stakeholders' interest / stake with DOC

3) identify cross relationships between stakeholders, and

4) obtain feedback on the process to date.

The stakeholder lists were reduced to include only strategic stakeholder relationships by clarifying whether the Executive Member actually did have a relationship with each of the stakeholders they identified and by determining whether it was a strategic relationship. It was at this point that I also asked Executive Members about any other stakeholders that I had identified during the document analysis that were not on their lists, exploring whether they were strategic stakeholders that should be 
included. The combination of the three methods to identify stakeholders (questionnaire, document analysis and interviews) provided triangulating data. That is, using more than one source to gather this information increased the authenticity of the data and reduced the chances that potentially important data were missed or misinterpreted (O’Leary, 2004).

Each stakeholder's interest / stake with DOC were explored through general discussion, in reference to what the Executive Member had recorded on the questionnaire. Most of the time, this did not change, but occasionally the discussion led to the Executive Member changing how they had categorised the stakeholder against the DIA continuum because it made them more cognisant of the type of relationship it was and therefore, whether it was strategic or not.

Regarding the third purpose of the interviews, cross relationships between stakeholders were identified. A cross relationship is when two of DOC's stakeholders have a relationship between themselves. For example, if DOC has a relationship with one stakeholder called A and another stakeholder called B (Figure 4.2), and A and B have their own relationship between themselves (Figure 4.3), then this would be a cross relationship. It was important to capture this information as it was essential for drawing the network maps at a later stage.

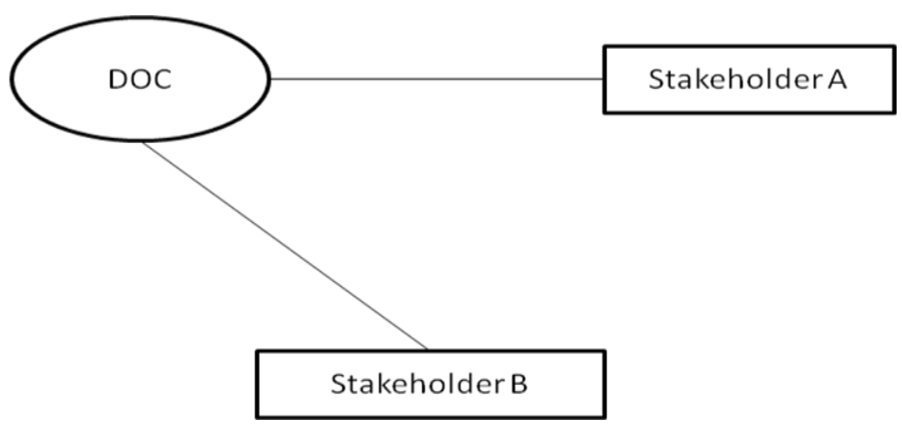

Figure 4.2. Relationship between DOC with Stakeholder A and Stakeholder B. 


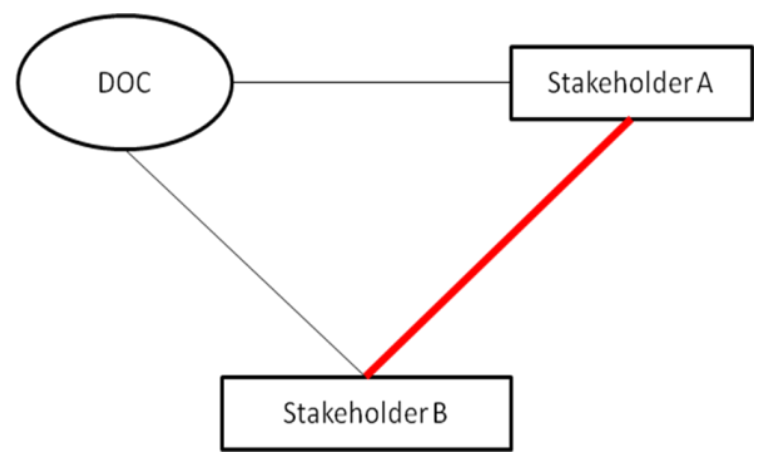

Figure 4.3. Cross relationship between Stakeholder A and B.

Finally, to gather information to contribute to the second research objective, interviews were used to gather insight from the Executive Members' perspective as to the process followed to date. That is, to ask questions about the process of stakeholder identification and any issues or feedback they could provide to that point. The Project Team spent a session following the completion of the interviews collating this information and identifying any other issues (from its project perspective) associated with applying stakeholder networking theory, to this point. This was to ensure information gathered on this topic was balanced from the perspective of the 'participants of the process' and the 'developers / conductors of the process'.

Following the interviews, I then had to spend some time focussing on collating and analysing the information. The first task was to formulate a confirmed list of stakeholder relationships, stakes and interest, and cross relationships based on the outcomes of each interview. This provided me with the necessary information to a) prepare a first list of management issues associated with applying stakeholder networking theory; and b) draw the stakeholder network maps, interpret them and draw conclusions that might assist the Executive Team with strategic planning.

This was then prepared into a presentation pack (combined with other material relating to the wider project objectives) and presented to the whole Executive Team together at a scheduled workshop, dedicated to 'strategic stakeholder relationships' (i.e. not as part of a general team meeting with other items on the agenda). With regard to my thesis objectives, the workshop was focussed on presenting the 
stakeholder network maps, discussing and determining their use for strategic planning, and obtaining additional feedback on the management issues relating to the application of stakeholder networking theory.

This research process concluded with a final collation and analysis phase of the information gathered in the last Executive Team workshop, and a final Project Team meeting to complete identification of the management issues that arose during the process of applying stakeholder networking theory. This then led to data analysis and the findings from this stage are discussed in more detail in Chapters 5 and 6.

\subsubsection{Ministry of Agriculture and Forestry Biosecurity New Zealand}

The process at MAF BNZ was different to thatdescribed for DOC because the context in which stakeholder relationships were being analysed turned out to be very different. At MAF BNZ, I was looking at the strategic relationships within the Pest Management Group, which is a small group within the wider MAF BNZ organisation. For clarity sake, I will just refer to this sample as MAF BNZ. In contrast to DOC, there was no internal project driving the identification and analysis of stakeholders. Instead, MAF BNZ was in the process of developing a new strategic plan which required collaboration and alignment with a wide range of stakeholders. Therefore, this created interest on their part in the potential for stakeholder networking to help with strategic planning.

Given that the research at MAF BNZ started after the initial stages at DOC had been completed, Freeman's rational level analysis was not applied. Instead, I had an initial meeting with the Manager of the Pest Management Group and explained what I wanted to achieve through the stakeholder identification phase. He recommended that I speak with three managers that have extensive knowledge of the group's stakeholder relationships across the three different functional areas of the group. Thus, I had good coverage and representation of the group to ensure a balanced stakeholder perspective.

With these three managers, I went through a process of stakeholder identification by holding a focus group session, where we discussed the nature of the group and its 
functions so that I could gain a comprehensive understanding of the sorts of stakeholders they engage with and the nature of relationships. I recordedspecific stakeholder names and took written notes on the stakes / interest with MAF BNZ as there were discussed.

After this session, I carried out further stakeholder identification by following the same document analysis process described above for DOC. I was provided with a broad range of organisation documents, such as current strategic plans, publications, lists of existing stakeholders, terms of reference documents, and documents which I retrieved off the internal intranet.

I then conducted another focus group session with the same three managers to cross check the names of stakeholders they had given me in the first session and those I had identified through document analysis. Again, this is a process of triangulation to ensure the data to be analysed were authentic, thorough and accurate. With a complete list, the focus group session continued addressing the following activities:

1) clarifying stakes / interests of all stakeholders on the list

2) identifying cross relationships between stakeholders, and

3) obtaining feedback on the process to date.

As for DOC, time was then spent on collating and analysing the information in order to draw the stakeholder network maps, interpret them and draw conclusions. This provided the input to the third and final focus group session, which was spent discussing the maps, identifying how useful they were to assist with strategic planning, and gathering final feedback on the management issues relating to the application of stakeholder networking theory.

This research process within MAF BNZ concluded with a final collation and analysis phase of the information gathered in the last focus group meeting; and reflection from my own perspective on the management issues that arose during the process of applying stakeholder networking theory in this slightly different context. Again, this led to data analysis and the findings from this stage are discussed in more detail in Chapters 5 and 6. 


\subsection{Challenges in the Research Process}

The main challenges I faced in undertaking this research process are congruent with the typical issues of action research identified by O'Leary (2004) and Creswell (1998). Therefore, this section follows on from the critique of action research that began in Section 4.6, with further illustration of how I tried to overcome these challenges.

The first significant challenge was that there was a degree of negotiation necessary with the organisations to undertake research with them in the initial instance, but after that had been accepted, there was then an expectation that my thesis research would meet certain objectives. This was more of a challenge within DOC because I was undertaking my research as part of an internal project that had been requested from the Executive Team. Therefore, the ultimate direction of the project was not entirely in my hands and there were a number of activities that were occurring simultaneously outside the scope of my research objectives. While this presented an excellent opportunity for my personal learning and development, it led to the second primary challenge.

The second challenge was that it was difficult to control the pace of the project because engaging Project Team members and necessary participants was slow, added to by the fact that it was a continual cycle of learning that kept evolving. Gathering information was time consuming as the data collection process started at the end of the year when government departments typically slow down, meaning that the process then had to regain momentum a couple of months later. Furthermore, scheduling of interviews, focus groups and deadlines for spreadsheets to be received had to fit in around the participants' time constraints, which did not necessarily coincide with mine and as a result delays were inevitable.

The third challenge follows from what O'Leary (2004) describes when noting that "facilitating collaborations is not always easy...individuals can usurp the democratic procedures...personal agendas can mean that strategic plans do not logically flow..." (p 141). With a large number of people involved in the research process in both organisations, there was a challenge to maintain buy-in and acceptance of the project 
in order for it to continue. Some aspects had to be covered thoroughly, perhaps on several occasions, and purposes re-justified upon request.

Finally, as the researcher, I have had to gain approval for reporting on certain findings and describing potentially sensitive information about the organisations. This has resulted in a required feedback process with the two organisations, lengthening the time required to write up the final thesis.O'Leary (2004) provides a very apt summary of the requirements of an action researcher, which can be otherwise difficult to explain (p 142):

In addition to methodological 'expert', the action researcher must also be a consummate organiser, effective communicator, skilled negotiator, conflict resolution specialist, well-organized time manager, strategic planner, efficient documenter, and be willing to get his or her 'hands dirty' as an on-the-ground implementer all of which might require the development of specialist skills. As you begin to see practice evolve and change occur, action research can be exceedingly rewarding. It is, however, a process that demands a tremendous amount of skill, learning, and patience.

Reflecting on this statement, I can now say that while the research approach and process was suitable for meeting my research objectives and I believe it has been successful, it was an ambitious undertaking for a young researcher in my position. O'Leary's description highlights the diversity of skills and competencies the researcher must balance throughout this research journey, not to mention weaving these together with the intricacies of each organisation's work environment. However, despite the challenges and delays, this exposure has been invaluable for developing my research and analysis capability for future research, and has greatly matured my understanding of organisations and the practical nature of applying academic theory in the work place.

\subsection{Methods of Data Analysis}

Having gathered all the necessary data around stakeholders, the management issues that arose during application of stakeholder networking, and the usefulness of stakeholder networking theory for strategic planning; analysis was undertaken using a variety of methods. Data analysis for DOC was more complex than for MAF BNZ 
because of the different contexts for which it was gathered. That is, at MAF BNZ, I only collected information that was relevant to my research objectives. Whereas, at DOC, a lot more information was collected as part of the overall Project Team's objectives that was outside the scope of my thesis, as discussed above in Research Process - Section 4.6.1.

Therefore, for DOC, I had to siphon out of the extensive Excel data table and all my written notes, only the information that related to my research objectives. To do this, I used the pivot table, mentioned above in Section 4.6.1, to extract the information that I required. For example, it was able to pull out the strategic stakeholder names and the links that had been reported with other stakeholders so that I could draw the stakeholder network maps. These pivot table reports turned out to be a particularly useful tool for the Project Team's objectives as well, as it allowed us to quickly present information back to the Executive Members in a variety of different forms, including which Executive Member had a relationship with which stakeholders; the number and type of relationships reported by each Executive Member; where there were duplications and/or inefficiencies in relationship management; and gaps in the management of specific relationships.

The extent of information gathered for MAF BNZ group was relatively smaller since I was not looking at a whole of organisation context. Therefore, stakeholder names and other related information gathered was still recorded in an Excel spreadsheet, but it did not require an extensive pivot table to extract the necessary information.

Once I had the necessary information, I used Rowley's (1997) stakeholder networking theory to draw and analyse the stakeholder network maps, which was based on the principles of social network analysis as described in Chapter 2, such as centrality and density. This allowed me (and the Project Team, in the instance of DOC) to determine the network characteristics, interpret the maps and draw appropriate conclusions for both contexts..

With regard to analysing data collected on the management issues that arose during the practical application of stakeholder networking and the usefulness of stakeholder 
networking theory for strategic planning, I undertook a process of thematic analysis. Thematic analysis is used to move from raw data to meaningful understanding through a process of generation/exploration of relevant themes (O'Leary, 2004). Despite whether themes emerged through reading literature, prior experiences of the researcher, or the data collection process, "there is a need for rich engagement with the documents, transcripts, and texts that make up a researcher's raw data" (O'Leary, 2004, p 196). In the case of my research, I kept a log of issues and lessons learned as I progressed through the research process, adding ideas as they came up in Project Team meetings, focus groups, other various engagements with people, and my own individual research activities.

I then collated this with the data that were gathered from interviews, meetings, focus groups (depending on the organisation) and explored the data for words that were used and concepts that were discussed. These are two methods of thematic analysis (O'Leary, 2004). Exploring words involves looking for repetition and exploring the context and usage of those words, which can lead to the identification of themes (O'Leary, 2004). In this case, I read through the notes that I had collated and highlighted repeated words before exploring the context in which they were used.

In using the method of exploring concepts, concepts can be uncovered deductively by searching for themes generated from the literature, the research questions, intuitions or prior experiences; or concepts may emerge inductively from their data without any preconceived notions (O'Leary, 2004). With limited literature in the stakeholder networking field, themes predominantly emerged inductively from the data. However, intuition and practical experience were used as deductive means as well. There is a risk in using purely inductive methods because they are prone to bias since the researcher's subjectiveness can influence the emergence of themes (O'Leary, 2004). I tried to overcome this by discussing themes with the Project Team, in the case of DOC, and searching for supporting arguments in existing stakeholder literature. However, as previously mentioned, the same opportunity for feedback and interaction was not available in MAF BNZ, so I had to be more consciously aware of this potential bias. 


\subsection{Limitations of Methods}

While attempts were made to reduce research design limitations, there were certain constraining factors that remained, which are highlighted here. Firstly, the time consuming nature of the research approach, meant that it was only feasible to research two organisations within the thesis timeframe. The difficulty of securing access for such intrusive research was also a constraining factor in this regard.

This raises questions as to whether the sample size was representative of the population, allowing findings to be transferred and generalised to other public organisations both within and outside of the New Zealand environment sector. However, as discussed in Section 4.3.1, this is not an uncommon occurrence for indepth qualitative research of this nature (Silverman, 2006); and while generalising the findings should be undertaken with a degree of caution,the two sample organisations should still provide a useful base from which to understand the issues around stakeholder networking in practice, even in organisations that have different operating factors driving decision-making and strategic planning.

The second limitation was that the information I gathered was dictated by resources and information available within the organisations. Firstly, organisations have different processes around the way they document their stakeholder management activities, so the documents available were dependant around their structures. Secondly, since interviews depend on the accuracy with which information can be recalled (Cavana et al., 2001) and it was not possible to interview every individual within each organisation, it is likely that both organisations have strategic stakeholder relationships that were not identified through the interviews that were conducted. However, given that I was able to interview key managers with significant history and experience within each organisation, it is likely that many of the key relationships were assessed.

The third limitation was that despite intentions to interview the two organisations' stakeholders to determine where they had relationships with each other so that I could reflect all stakeholder relationships accurately on the stakeholder network maps; the organisations' perceived sensitivity of allowing me to interview their 
stakeholders and time constraints as a result of the project pace (within DOC), did not allow me to get to this point within my thesis timeframe. It was intended that this information would contribute to the linking of stakeholders on the network maps and allow me to reflect the strength and direction of relationships by differentiating characteristics of the links. Instead, I had to rely on DOC and MAF BNZ's knowledge regarding which stakeholders were linked in order to complete the network maps. Therefore, the networks are portrayed from the perspective of the organisations only and might not reflect a true representation of the stakeholder network from multiple perspectives.

\subsection{Chapter Summary}

This chapter has described in detail the research framework, approach and process that was developed in order to achieve the research objectives. A key component of this chapter is the attempt to portray the intensive nature of carrying out participatory action research and the implications that arise from this level of involvement with participating organisations.

The initial steps of obtaining access to organisations that met the specified requirements, designing the research process, and gaining ethics approval, to then gathering the data, managing the lengthy stakeholder lists and interview transcripts, and then analysing it systematically; does not come without research challenges and limitations. These have been addressed by providing the rationale for the research design and illustrating how limitations of the methods were minimised where possible.

In summary, an action research approach was taken, which suited the requirements to gather rich qualitative data by becoming involved with the two selected organisations. Data were collected via a range of different methods, including interviews, surveys and questionnaires, focus groups and document analysis. Data were then analysed using pivot tables created in Microsoft Excel, with application of the principles of social network analysis and stakeholder networking theory, and thematic analysis. The findings that emerged as a result of the research process are presented in Chapter 5 and further discussed in Chapter 6. 


\section{CHAPTER 5}

\section{FINDINGS}

\subsection{Introduction to Chapter}

The process by which the research was conducted has been outlined in Chapter 4 and now the focus of this chapter is to present the findings that came out of that research process. They are reported in relation to the three discrete research objectives and below is an outline of how they are presented. Findings will be elaborated through interpretation and discussion in Chapter 6.

The first and second sections report the findings associated with DOC and MAF BNZ, respectively. Each section reports on 1) strategic stakeholder identification; and 2) stakeholder network mapping in that organisation. The results relating to stakeholder identification are separated into two sub-sections, a) the process followed for the identification of stakeholders; and b) the types of stakeholders identified, such as numbers of stakeholders, their characteristics, groupings, and different interests. Together, these two sections target the first research objective of investigating the applicability of stakeholder networking in the public sector. Due to confidentiality agreements, stakeholders have been identified by referring to broad categories instead of specific names. These categories are also reflected in the stakeholder network maps. This is consistent with previous literature but represents a problem for the application of stakeholder networking theory, which is discussed in Chapter 6.

The third section presents the findings related to the second research objective, which was to understand the management issues that arise in the practical application of stakeholder networking theory in the public sector. The findings from DOC and MAF BNZ have been combined in this section as the findings were consistent in both organisations, despite a slightly different process being followed and different outcomes from the stakeholder network mapping exercise. 
Finally, the fourth section presents the findings for the third research objective which was to investigate the use of stakeholder networking theory for strategic planning in the public sector. Findings for DOC and MAF BNZ have been reported together as they were similar in nature.

\subsection{Department of Conservation Findings}

\subsubsection{Identification of Strategic Stakeholders}

The purpose of this phase was to identify the strategic stakeholder relationships held by each of the nine Executive Members that they deemed necessary to deliver on DOC's strategic direction. As described above, findings in this section relate to the process of identifying stakeholders and the types of stakeholders that were identified.

\subsubsection{Stakeholder Identification Process}

Freeman (1984) argues that the applicability of stakeholder theory increases when it can make a valuable contribution to addressing specific aspects of stakeholder relationships. Freeman's (1984) stakeholder framework, as discussed in Chapter 2, provides a method for identifying and analysing stakeholders within a context so that the information can be applied. The method for stakeholder analysis has three levels and it is the Rational Level Analysis that focuses on identifying stakeholders and their perceived stakes.

Therefore, as mentioned in Chapter 4, it was intended to use Freeman's (1984) rational level analysis framework as a first step to stakeholder identification of DOC's strategic stakeholders. This level of analysis includes the following four steps:

1) Developing a stakeholder map

2) Preparing a chart of specific stakeholders

3) Identifying their stakes

4) Preparing a power versus stake grid 
The Project Team met to discuss and agree the stakeholder identification process to use. We examined the methodology of Freeman's (1984) framework and looked at examples of the outputs from various academic papers that had used the process. In particular, I provided a copy of Elias et al. (2002) to show how the process could be applied in an organisational context. Prior to this meeting, I had also prepared some draft outputs that could be expected to come out of applying the process, including a stakeholder map, and a table of stakeholders and their stakes. This was just a basic draft from my knowledge, and was only meant to illustrate the type of output that might result.

After considering the objectives of the project and my thesis requirements, it was decided that Freeman's (1984) framework was not an appropriate means for gathering the required information. The biggest weakness expressed was that the process and the outcomes of the process were too "generic", for two reasons. Firstly, the broad and generic stakeholder group names used in such diagrams to draw an indicative stakeholder map (Step 1) do not accurately reflect the diversity of stakeholder interests that can exist for a particular group in the public sector context. Findings to support this will be presented later in this chapter and discussed further in Chapter 6.

Secondly, Freeman's process did not allow enough flexibility to gather and incorporate other meaningful information that was important for understanding the stakeholder relationships. The agreed scope for the analysis was the Executive Members' strategic stakeholder relationships (discussed in Chapter 4) and considering significant time constraints at the Executive level, the Project Team wanted to utilise the Executive Members' time as best they could by gathering as much information as possible while they were engaged in the identification process. Adhering fully to Freeman's four step rational level process would not meet these needs of the Project Team.

An example of information that the Project Team decided was important to gather, which applying Freeman's (1984) framework does not typically account for, was the strategic goal that the stakeholder relationship contributed to achieving. That is, 
each strategic goal has specific outcomes to achieve and the Project Team wanted to know which stakeholder relationships were instrumental in achieving those outcomes. This was what made a stakeholder relationship either strategic or nonstrategic. Understanding which strategic goal the stakeholder relationship contributes to is a key input to developing and implementing relationship strategies. This is because the relationship approach will be developed to ensure it successfully delivers the strategic goal outcomes; thus enabling the organisation to continue moving towards its strategic direction or vision. Therefore, this information was important for improving the rigour in planning relationships with stakeholders.

This led to the finding that when conducting stakeholder analysis within an organisation, it is usually being done to satisfy wider organisation objectives and therefore, the information gathering requirements must be defined within that context so that all required information is gathered. This finding is further elaborated on in Chapter 6.

Another reason that Freeman's (1984) framework was not deemed to be suitable was that it assumes the Rational Level process can be worked through methodically and logically from start to finish to generate a consistent and comprehensive list of stakeholders and other related information. While it was acknowledged that developing a stakeholder map, identifying specific stakeholders and their stakes (Steps $1-3$ of Freeman's Framework) was all relevant information that would likely come out of the identification process, the Project Team thought that it was more logical to identify the specific stakeholders and their stakes first so that they could then be grouped/categorised by stake before generating a stakeholder network map. This would produce a more meaningful stakeholder map that could be used as the basis for further stakeholder management. The differences between the "meaningfulness" of the maps that arise from the two processes is illustrated by comparing the stakeholder maps in Section 5.2.2 with Freeman's generic stakeholder map referred to in Chapter 2 (Figure 2.2). 
Step 4 of Freeman's (1984) analytical framework is to depict an organisation's stakeholders on a two dimensional grid of power versus stake. Power refers to a stakeholder's ability to use resources to make an event actually happen, represented by three points of interests along a continuum - formal/voting, economic or political. Stake refers to the type of interest the stakeholder has in the organisation because it affects them in some way (Freeman, 1984). The Project Team decided that developing a power versus stake grid was not a meaningful form of stakeholder analysis for the public sector context. The dimensions of power and stake do not accurately reflect the complexity of the hugely varying interests found in public sector organisations, and attempts to pigeon-hole stakeholders into these three categories would not be especially useful; or would it provide meaningful information by which to further develop effective strategies for working with identified stakeholders.

For example, the stake dimension was developed based upon a traditional 'marketplace' theory perspective that reflect the differing stakes of owners, customers and suppliers, and government in a commercial/private sector context (Freeman, 1984). These categories of stakeholders do not directly translate in the public sector context, where owners are the government and there are many different groups of customers who receive DOC's products and services for free through public value (e.g. general public, sports and recreational groups) and those who pay for the use of DOC land (energy companies, concessionaires). Additionally, this dimension does not account for the interest/stake of a significant stakeholder group that volunteers its resources for public good. Some of these different stakeholder aspects are discussed in more detail in the next section.

Similarly, for the power dimension, Freeman's (1984) framework refers to the formal voting power of owners to appoint directors and support management decisions; the economic power of customers and suppliers who choose to invest, purchase products and services, switch to other organisations, raise prices or withhold supply; and government's political power through passing legislation and writing new regulations. As described above, the lines become blurred between 
formal/voting and political power in the public sector context, and economic power is not as prominent in what is essentially a monopoly environment.

In summary, and in line with Freeman's (1984) discussion of the limitations of the stakeholder analysis framework, the modern organisation in both the private and public sector context is a lot more complicated than the management concepts and principles that Freeman's initial tools have been based upon. The framework, as typically presented, is over simplified to provide a basis on which to develop generalised stakeholder management approaches and each individual organisation should adjust the analysis process to suit the organisation's specific environment.

As a result, the Project Team determined and agreed what the required stakeholder information to be gathered would be and developed a suitable information gathering and analysis process that they perceived would maximise engagement with the Executive Members. Below (Figure 5.1) is an outline of the key steps in the process that were followed to achieve the activities as described in Section 4.6 and subsequently achieve the research objectives. Some of these steps have already been described in Chapter 4, and references to these will be made where applicable. 


\section{Stakeholder Identification Process}

1) Determined research scope

2) Agreed definition of strategic stakeholder

3) Agreed information requirements

Refer to Chapter 4, Section 4.6.1 that describes information gathered for my thesis objectives stakeholder name, stake / interest, DIA classification. A lot of the information gathered related to the wider project objectives that were outside the scope of my thesis.

4) Developed and distributed questionnaire for stakeholder identification

Based upon the required information agreed in Step 1, the Project Team developed and distributed a questionnaire to the Executive Members for them to identify all their stakeholder relationships in relation to which strategic goal the relationship contributed to.

5) Completed document analysis for additional stakeholder identification

A document analysis was undertaken while Executive Members completed the questionnaire over a $6-7$ week period.

6) Completed first phase of data collation and analysis

Input data and created a pivot table so data could be analysed in any form according to information gathered. Workshop with Project Team to finalise stakeholders and related information.

7) Conducted one-on-one interviews with Executive Members

Discussed stakeholder lists, particularly to clarify which ones were strategic stakeholders, identify their stake, eliminate any duplications, cross check stakeholders I had identified during the document analysis. Initial feedback on process.

8) Completed second phase of data collation and analysis

Consolidated information from all Executive Member interviews into one table to ensure each stakeholder was only represented once.

9) Preparation for Executive Team presentation

Drew stakeholder maps to represent various contexts (see findings below)

10) Presentation to Executive Team

Confirmed stakeholders and groupings, and received responses about the process and use of stakeholder networking theory in strategic planning.

11) Completed final phase of data collation and analysis

Figure 5.1. Stakeholder Identification Process for DOC 


\subsubsection{Types of Stakeholders}

Following the one-on-one interviews, each Executive Members' list of strategic stakeholders was consolidated. The initial results of the stakeholder identification questionnairereported that the nine Executive Members had relationships with 144 different strategic stakeholders. After discussing the results and clarifying the nature of the relationships in one-on-one interviews with Executive Members, this number was reduced to 66 stakeholders. Reducing stakeholder numbers was done by removing duplicates where more than one Executive Member reported the same stakeholder (each stakeholder was allocated to one Executive Member who was designated as the lead for that relationship). This was predominantly important for the wider project objectives around relationship management, but it also assisted my thesis objectives by having a more clearly defined list. It also took into account whether the stakeholder was strategic or non-strategic as discussed in Section 4.6.1.

It had been assumed that a strategic stakeholder was one that had been identified as having a collaborative or partnership relationship. However, when discussed further in the one-on-one interviews, it was found that strategic relationships could also exist with stakeholders considered to be in the other categories (Coexistence, Cooperation, or Networking). For example, one Executive Member categorised an existing relationship as 'cooperation' because the relationship was characterised by an acknowledgement of each others issues / interests and they worked together on some project level tasks, but it was not a formal commitment based on the more developed relationship category of collaboration. However, the Executive Member still considered the relationship to be strategic because of the future opportunities that could arise from the current level of engagement. Similarly, another Executive Member reported a 'networking' relationship as strategic based on the nature of information being shared and the potential for it to contribute to DOC's strategic interests. Despite a lower level of engagement and no joint decision making with the stakeholder, the information being shared was around a strategic issue that could become critical for DOC. This illustrates the dynamism associated with stakeholder relationships. 
Executive Members identified between five and 12 strategic stakeholders each to comprise the final set of 66 stakeholders. The variation in stakeholder numbers reported was due to differences in the size and scale of responsibilities across the nine Executive roles and was also affected by the degree to which each area of the organisation was involved in contributing to the key strategic changes/shifts that constitute DOC's strategic direction.

Due to confidentiality agreements for my thesis research, the specific stakeholders cannot be named. Therefore, once the consolidated list of stakeholders had been agreed by the Executive Team, I grouped each stakeholder by similar interests for use in the stakeholder network maps depicted here. The general groups to which the specific stakeholders belong have been listed below in Table 5.1.

\begin{tabular}{|l|l|l|}
\hline Corporate Sponsors & Government Agencies (Delivery Partners) & National Conservation Forums \\
\hline Business Partners & Government (Governance) & National Conservation Organisations \\
\hline Concessionaires & International Conservation Organisation & National Volunteer Organisations \\
\hline Community Volunteer Groups & International Knowledge Forums & Regional Councils \\
\hline Cultural Groups & Maori Organisations & Research Groups \\
\hline Education Groups & Media Groups & Sport and Recreation Organisations \\
\hline Energy Companies & National Conservation Authorities & Tourism Organisations \\
\hline
\end{tabular}

Table 5.1. DOC's Generic Groups of Stakeholders

The variation in this list provides an indication of the diverse range of stakeholder groups that DOC engages with at a strategic level. There are differences in interests across each of the groups, but each group consists of stakeholders that possess similar interests. Below are some examples of the interests of selected stakeholder groups:

1) Concessionaires are those that negotiate for the use of conservation estate to make a profit.

2) Conservation Groups are those that lobby government for the protection of a conservation aspect (e.g. plants, animals, cultural heritage, land, waterways etc.) 
3) Education groups are those that educate the general public in relation to the diverse range of conservation topics

4) National Authorities are organisations that are authorised and have a legal responsibility to manage an aspect of conservation under government legislation

5) Sports and Recreational Groups are those who use conservation estate for sport and enjoyment e.g. fishing, skiing, hunting, hiking etc.

While the stakeholder groups are presented as discrete categories, they are not necessarily mutually exclusive, which highlights a problem with applying Freeman's generic framework. For example, energy companies are also concessionaires, but they are recorded as a separate group because they have a potentially differentiating interest in emerging conservation topics; and therefore should be considered in both contexts. Likewise, some organisations have dual roles, such as conducting conservation research or education and also acting as a lobby group in the protection of conservation. Therefore, they would be in both the National Conservation Group and Research Group. This is the same for those Concessionaires who are also Tourism Organisations, such as ski fields.

Another example of how Freeman's (1984) framework of stakeholder identification proved too generic for this context is seen by examining the complexity of what Freeman broadly labels the 'Government' stakeholder group. In the private sector context, government has a clearly defined reference to the passing of legislation, and writing new rules and regulations (Freeman, 1984). However, in the public sector context, there are multiple and complex interests across the Government stakeholders which would not be reflected by using the simple label of 'Government'. The difference in this context has been reported by separating this group into 'Government Agencies (Delivery Partners)' who are those stakeholders that work with DOC in the delivery of conservation outcomes; and 'Government (Governance)' who are those stakeholders that provide direction and expectations (e.g. Minister of Conservation), pass legislation, set wider government goals, monitor progress of DOC, control budget processes (e.g. Treasury), and implement state service frameworks (e.g. State Services Commission) etc. At times, though, even these groupings might prove too broad and not homogeneous. 


\subsubsection{Stakeholder Network Mapping}

Identifying the names of the strategic stakeholders was the first step toward drawing the stakeholder networks maps. The second step was to understand the relationships between these stakeholders so they could be represented as connecting links on the maps. These relationships were determined through discussion with the Executive Members during their one-on-one interviews and through general knowledge of the Project Team members.

In determining the links/connections between DOC's stakeholders, it was found that relationships exist for a specific purpose around a specific issue and while stakeholders might have a relationship around one issue, this does not necessarily mean that the relationship will exist for every issue. For example, an Energy Company, an Iwi group, a Regional Council and a Conservation Group might all be linked through a series of relationships regarding development of a wind farm. However, if another issue arose in that same area, for example, about a new hiking trail, then only some of those stakeholders might be connected and relationships would be based around a different purpose.

Therefore, it was found that when drawing stakeholder network maps, the context in which the map is being drawn must be clearly defined in order to determine what stakeholders are involved and where a relationship exists. This will ensure that the stakeholder maps provide a meaningful and accurate reflection of the networking links between stakeholders in a given context.

The findings from the DOC context revealed that different maps could be drawn to represent stakeholder relationship networks across a wide range of contexts and situations, including strategic issues, project teams, divisions of the business, or even around one specific stakeholder. Additionally, each map that is developed offers a range of information and insight specific to that situation. Examples of the stakeholder network maps that were drawn in relation to various DOC situations are presented below with a brief description of the conclusions that can be drawn from each map. Further discussion of the maps will occur in Chapter 6, elaborating on the practical implications and how they can be used to make informed management decisions. Due to the confidentiality agreements mentioned above, the specific 
stakeholder names in each map have been replaced with the relevant generic names presented in Table 5.1. I recognise this turns these into generic stakeholder maps as opposed to more specific stakeholder maps that were found to be more useful.

\section{Stakeholder Map 1 - Conservation Initiative in an Area of New Zealand}

This first map (Figure 5.2) presents the network of stakeholder relationships involved in a large scale conservation initiative within a specific DOC conservancy area of New Zealand. The initiative was in the beginning stages of getting underway so the purpose of this network was to identify those relationships in this context that were already existing (illustrated by solid lines) and also those relationships that did not currently exist (illustrated by dotted lines) but were considered to have potential benefits for successfully delivering the objectives of the initiative. Additionally, one of the divisions within DOC head office was trying to understand the different avenues for engaging into the conservation initiative (illustrated by numbers 1, 2 and 3). The colour of the lines represent smaller sub-networks of stakeholders that are closely linked within the wider network. The intention is also to simplify the map and make it easier for the eye to look at by breaking up the network.

Stakeholders depicted in this context consist of those from different areas of DOC including Conservancies, two of DOC's head office divisions (as described in Section 4.4.1), a specific team within one of those divisions, and two conservation funds managed within that same division. Other stakeholders named in the map are external to DOC, including local community and iwi groups, farmers within that area, the regional council, a government agency, and an energy company. These were the major players in this 'conservation initiative' context.

A key conclusion that can be drawn from the network is that there are five key relationships that do not already exist (dotted lines) that would be beneficial for achieving objectives related to this initiative. Firstly, while a relationship between $X Y Z$ Conservancy and the multiple $i w i$ groups in the area already exists, it was not a particularly strong relationship for various historical reasons. The map demonstrated that XYZ Conservancy could leverage their established relationship with local 
community and DOC Division Team's relationship with local community to build their own relationship with the local marae, which could provide an opportunity for $X Y Z$ Conservancy to utilise the link between the local marae and iwi to strengthen their relationship with the local iwi groups. Further, this could lead to XYZ Conservancy playing a facilitating role to broker a relationship between iwi and the Regional Council, which would assist in meeting the objectives of the conservation initiative.

A similar conclusion can be drawn regarding the opportunity for XYZ Conservancy and Other Conservancies around New Zealand to develop a relationship with the Energy Company by leveraging existing relationships with the Regional Council and $A B C$ Conservancy who already have a relationship with the same energy company. The same logic through lines of influence can be used to explain the opportunity for $X Y Z$ Conservancy to develop a relationship with farmers.

The DOC division and two teams within that division (black circles depicted on the left side of the map) were also keen to understand how they could engage with the initiative from a Head Office perspective. The map illustrated that the Division had five lines for potential engagement; three directly to $X Y Z$ Conservancythrough different parts of the DOC division, one to the local community, and one to the farmers in that area. 
CHAPTER 5: FINDINGS

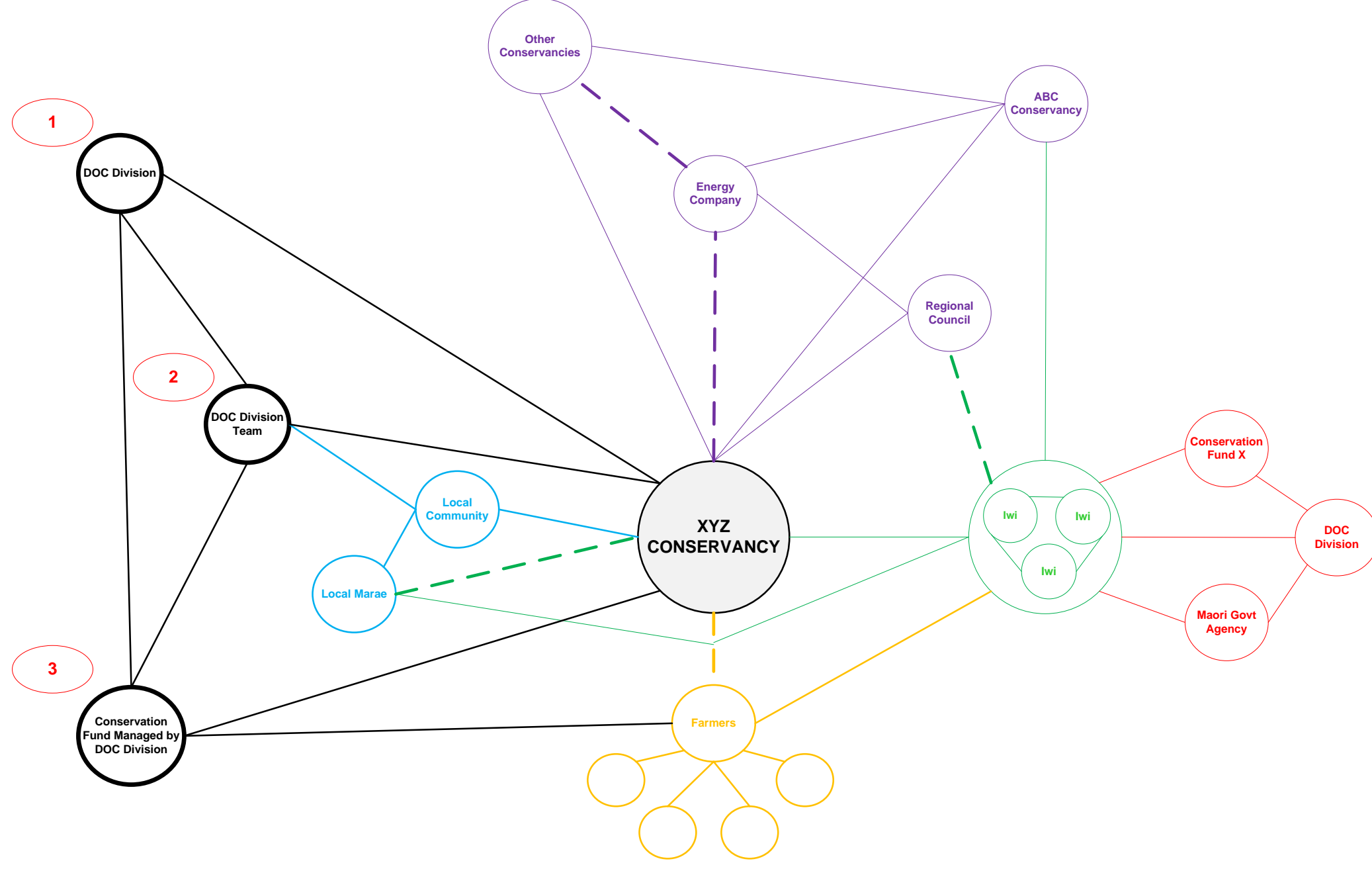

Figure 5.2. Stakeholder Network Map 1 - Large scale conservation initiative in a region of New Zealand 
Stakeholder Network Map 2 - Engagement between DOC and one specific stakeholder

This stakeholder network map (Figure 5.3) illustrates seven of DOC's eight divisions and the Director General (eight separate circles) and the roles within each division (smaller circles inside the eight circles) that engage with the specific Government Agency stakeholder shown on the left. It was recognised by DOC that the relationship with this stakeholder was not progressing well, particularly in reference to maintaining a successful working relationship in the instance where both organisations had conservation interests on the same topic. There was thought to be a lot more potential for the relationship to achieve conservation outcomes. Therefore, the purpose of this network map was to understand how many of DOC's eight divisions, and how many roles within those divisions, were engaging with this stakeholder so that DOC could try to create some consistency in the way they communicated and interacted with the stakeholder.

The divisions have been numbered and within each division, the roles have been labelled as a general manager, manager, or a team; depending on who is responsible for the engagement. It can be determined from the stakeholder network map that all seven divisions and the Director General have a relationship with the stakeholder and within six of the seven divisions; there are multiple roles that have individual relationships with the Government Agency stakeholder. Further, within DOC itself, there are potentially 28 different lines of communication between the seven divisions and the Director General, assuming each division communicates with each other regarding the relationship with the Government Agency Stakeholder. The number of linkages between the multiple roles across each division was not able to be determined, but it is acknowledged that such linkages exist.

The map very clearly shows the complexity of the relationship between DOC and the Government Agency stakeholder, and the significant effort required to ensure consistent messages and relationship management given the numerous existing lines of communication. Specifically, it highlights links that could potentially be eliminated to increase consistency and on the other hand, also illustrates links that could be strengthened. 


\section{CHAPTER 5: FINDINGS}

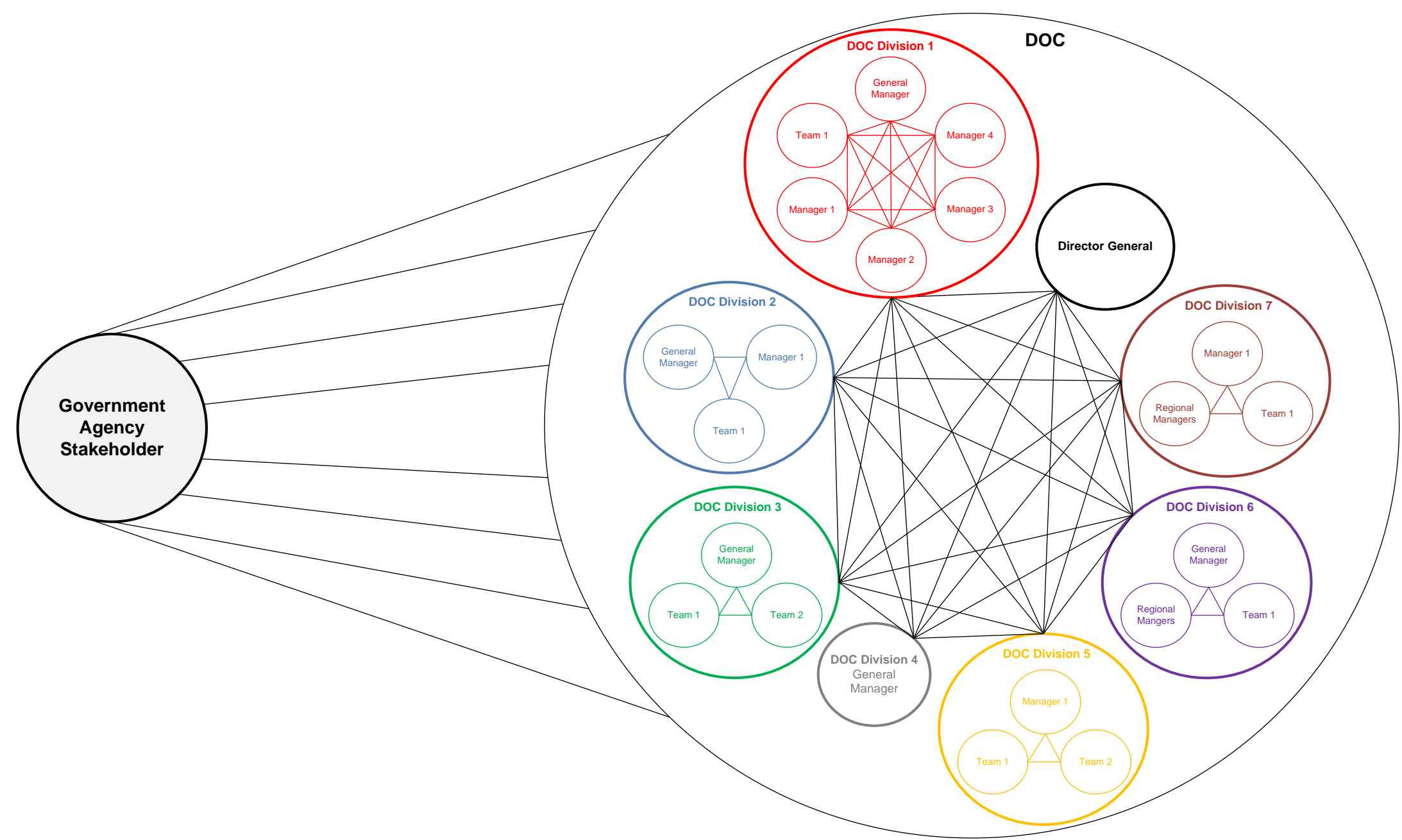

Figure 5.3. Stakeholder Network Map 2 - Network of engagement between DOC and one specific stakeholder 


\section{$\underline{\text { Stakeholder Network Map } 3 \text { - Growing engagement with target markets }}$}

The third map (Figure 5.4) was drawn to identify the existing and potential strategic relationships for one of DOC's divisions to grow engagement with some of the organisation's selected target markets. Particular focus was around a National Conservation Forum that was perceived to not be utilised to its full potential for delivering conservation benefits. As above, the existing relationships are illustrated by solid lines and potential relationships are illustrated by dotted lines.

The DOC Division is connected to the National Conservation Forum by 1 dotted line, indicating potential for a beneficial relationship; and by nine solid lines because it also has separate relationships with each of the nine organisations outside of the forum. As can be determined from the map, a strong relationship with the National Conservation Forum would provide an opportunity to reach four of DOC's identified target markets(Target Market 2, 3, 4, and 5). It would also assist in developing a much desired relationship between the National Authorityand both DOC and the Tourism Organisation. This would bridge a gap between DOC and the Authority Boards and Conservators, which is a strategically important relationship for DOC in reaching the significantly sized Target Market 1 . 
CHAPTER 5: FINDINGS

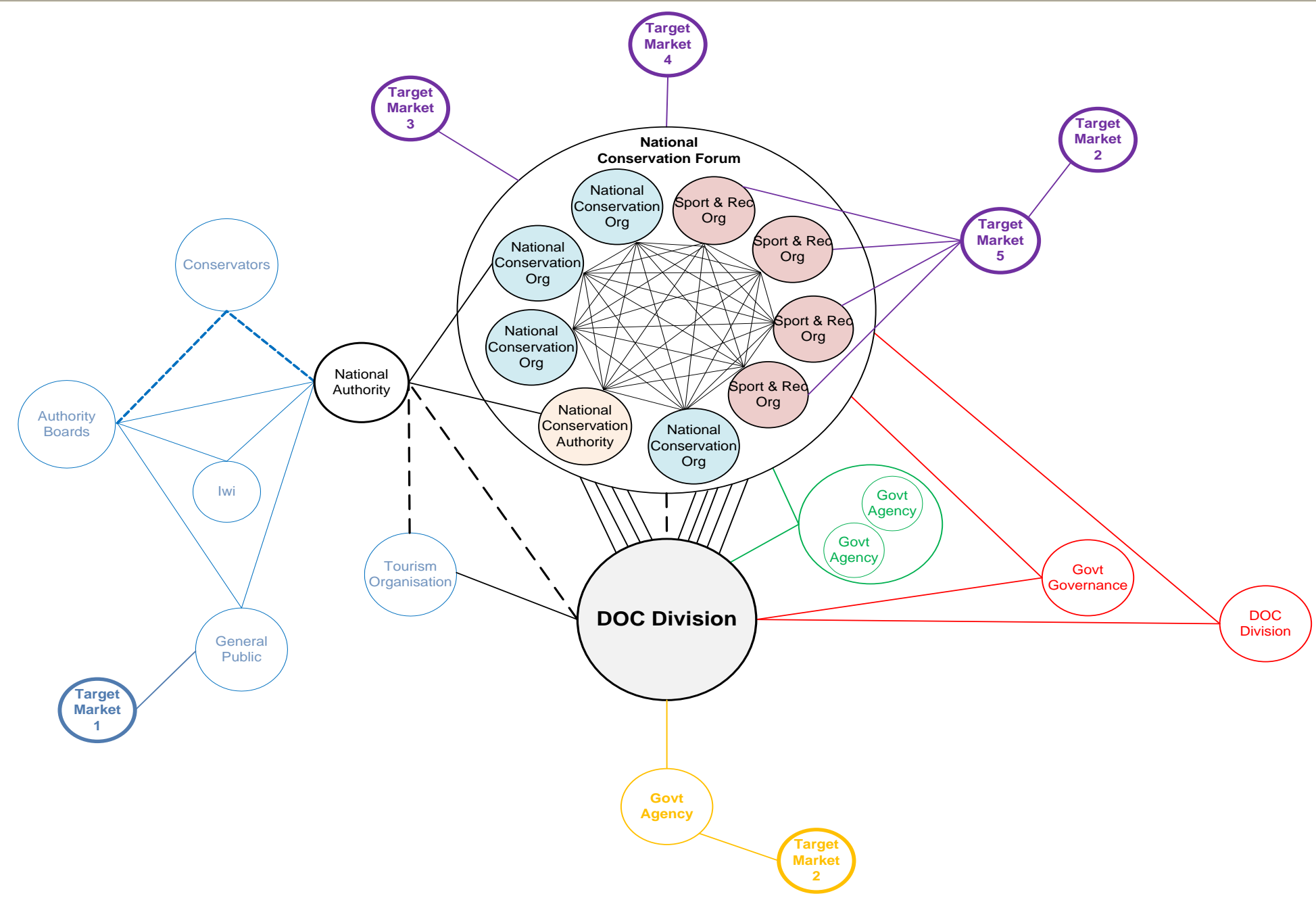

Figure 5.4. Stakeholder Network Map 3 - Growing engagement with target markets in one division of DOC 


\section{Stakeholder Network Map 4 - Project Team network of key players}

This fourth map (Figure 5.5) was drawn for the Project Team to illustrate the key relationships and lines of engagement required to successfully deliver the project objectives. The context shows how stakeholder network mapping can be used for internal organisational contexts as well as external relationships.

The colours of the map represent the smaller sub-networks of the Executive Team, roles within the division, other government agencies that are also pursuing relationship management projects, conservancies being used as pilot projects and other related stakeholders.

Compared with the previous maps, it represents a stakeholder network at a much more individual level where the majority of the circles represent individual employees and their personal relationships with others inside DOC. This is opposed to network maps that depict relationships across different organisations. There are a couple of different organisations named (green circles), but when the map was being drawn by the project team, specific employees were identified in those organisations where existing contacts could be utilised.

The most significant conclusion for the Project Team in drawing this map was recognising the number of communication lines between the Executive Members. There is a total of 35 potential lines of communication, which illustrates significant risk of different messages and understanding about the project (Chinese whispers). This highlighted the need for us to develop an effective communications plan to ensure consist messaging and communications with each Executive Member.

Another conclusion that could be determined was understanding how the pilot conservancies linked into the Executive Team and the need to manage those relationships carefully to ensure consistency of messages between the Executive Members and their conservancy, and between the Executive Member and the Project team. This was important because the Executive member was key to championing our work with the conservancies and could impact the quality of our engagement. 
CHAPTER 5: FINDINGS

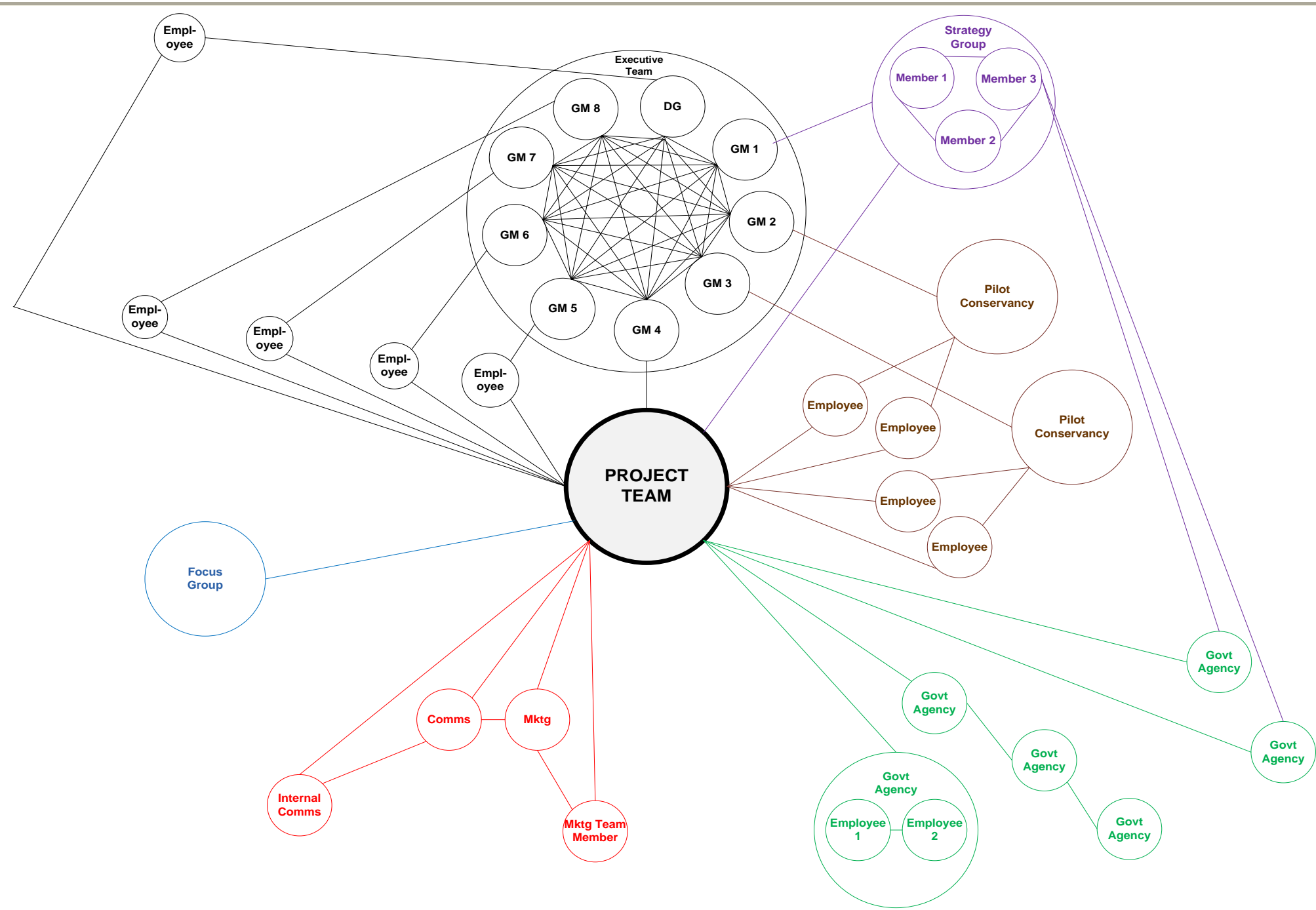

Figure 5.5. Stakeholder Network Map 4 - Growing engagement with target markets in one division of DOC 


\subsection{Ministry of Agriculture and Forestry Biosecurity New Zealand}

\subsubsection{Identification of Stakeholders}

As described in Section 4.6.2, the identification of stakeholders for MAF BNZ followed a different process and resulted in different findings than DOC. The approach was to hold a series of focus groups with the three group managers and identify the key stakeholders for that group to engage with in the development of a new strategic plan. The findings relating to the process and the types of stakeholdersidentified will be discussed in the following two subsections.

\subsubsection{Stakeholder Identification Process}

The stakeholder identification process for MAF BNZ started after the DOC process. Therefore, drawing on the DOC context learning, it was decided not to use Freeman's (1984) rational level analysis to identify stakeholders. The key steps in the process are outlined below. It is necessary to note that the process is a variation of that used with DOC as it had to account for the differences between the two organisational contexts.

The primary factor was the difference in the size and scale of the two contexts. The DOC context was looking at all strategic relationships across the whole organisation, involving participation of the nine Executive Members. In contrast, MAF BNZ context was looking at the stakeholders to engage with in developing the strategic plan for one group, the Pest Management Group, in the Biosecurity part of the organisation. Therefore, the scope and scale were significantly different and a tighter more restricted process using focus groups could be designed for the smaller number of participants in MAF BNZ and the narrower context.

Additionally, the process developed for MAF BNZ was not constrained by the requirements and objectives of the aforementioned organisational project in DOC that was being driven from the Executive Team. This meant that the process did not have to be designed to achieve multiple objectives, again allowing for a more manageable and efficient process using focus groups. The process followed is outlined below in Figure 5.6. The findings relate to the process followed and the use of stakeholder networking theory in strategic planning are discussed further in Section 5.4 . 


\section{Stakeholder Identification Process}

1) Information requirements

Determined the information to be gathered against the research objectives.

2) Focus group for phase one information gathering

Held a focus group with three managers from the unit I was researching to understand what the team delivered and begin initial stakeholder identification.

3) Document analysis

Document analysis of a broad range of organisation and team documents to identify additional stakeholders.

4) Data collation and analysis

Collation of stakeholder names identified from first focus group and document analysis

5) Focus group for phase two information gathering

Second focus group to:

a. confirm list with managers

b. identify any additional stakeholders

c. check whether stakeholders identified through document analysis process should be included

d. discuss the concept and use of stakeholder network maps

e. discuss the relationships and linkages between stakeholders

6) Collation and analysis

Consolidation and analysis of additional information

7) Stakeholder network mapping

First attempt to develop stakeholder network maps with available information

8) Focus group for phase three information gathering

Third focus group to:

a. discuss the outcome of the stakeholder network mapping exercise

b. gain feedback on the process followed and usefulness of stakeholder network mapping as a technique to assist strategic planning

9) Final collation and analysis

Figure 5.6. Stakeholder Identification Process for MAF BNZ. 


\subsubsection{Types of Stakeholders}

After consolidating the stakeholder information gathered from the first two focus groups and document analysis, the initial results reported that the MAF BNZ group had 48 key stakeholders that they considered to be important to engage with in the development of a strategic plan. Stakeholder relationships are at the group level and were not attributed to individual roles. To maintain confidentiality, I have categorised them into 12 generic groups, each representing specific stakeholders with predominantly the same interests. These are listed below in Table 5.2.

\begin{tabular}{|l|l|}
\hline Environmental Lobby Groups & Primary Production Organisations \\
\hline General Public & Regional Authorities \\
\hline Government Agencies (Delivery Partners) & Regional Councils \\
\hline Government (Governance) & Sport and Recreational Groups \\
\hline Industry Organisations & Territorial Local Authorities \\
\hline Media Groups & Utilities Providers \\
\hline
\end{tabular}

Table 5.2. MAF BNZ's Generic Groups of Stakeholders

While the number of specific stakeholders was not significantly less than DOC's, there is a noticeable difference in the number of groups they could be categorised under, with DOC having 21 groups and MAF BNZ having only 12. This is likely to be because the boundary for identifying DOC's stakeholders was for the nine Executive Members across the whole organisation, while for MAF BNZ I was only looking at one team that had a defined focus of pest management within New Zealand.

Another reason for the significant difference is that the key driver for MAF BNZ undergoing stakeholder identification and mapping was to generate input for the development of a strategic plan, as opposed to the delivery of the plan, which would likely require engagement with a greater number of stakeholders. 


\subsubsection{Stakeholder Network Mapping}

Having identified the stakeholders that were deemed important to engage with in the development of a new strategic plan for the MAF BNZ group, I intended to draw relevant stakeholder network maps, as I did for DOC, based on the relationships identified in the second focus group. However, it was found that because the stakeholders had not been identified in the context of a specific issue, the linkages that had been identified by the focus group were variable depending on the issue that was being considered.

The stakeholders had been identified in terms of who MAF BNZ should engage with around developing a strategic plan, but stakeholders did not have relationships between themselves regarding this issue; their linkages related to and varied across a variety of strategic issues. Therefore, meaningful links to represent a network of stakeholder relationships could not be made in this context.

For example, Regional Councils, Environmental Lobby Groups, General Public, Media, and Sport and Recreational Groups would be strongly linked around a specific issue such as didymo pest management, but not around pest management in the primary production context or containers and cargo context. Stakeholder links in these two areas would show various connections between Environmental Lobby Groups, Government Agencies, Industry Organisations, Media Groups, Primary Production Organisations, and Regional Authorities.

The inapplicability of developing stakeholder network maps in the context of strategic plan development will be further discussed in Chapter 6, with suggestions of other ways it could be usefully applied in the strategic planning process. 


\subsection{Management Issues in the Application of Stakeholder Networking Theory}

The findings in this section relate to the management issues that arose during the process of applying stakeholder network theory in two large public sector organisations. This refers to the process described in Chapter 4 and Section 5.2.1.1 for DOC and Section 5.3.1.1 for MAF BNZ. Findings were identified during interviews, Project Team meetings, and the Executive Team workshop in DOC; and focus groups in MAF BNZ as described in Section 4.6.

As mentioned in Chapter 4, it was important to gather information from all the participants' perspectives because not all participants were involved in every activity during the process and mapping exercise. Table 5.3 below summarises the different participants and the activities they were involved in.

\begin{tabular}{|c|c|c|}
\hline \multicolumn{2}{|c|}{ Participants } & Activities involved in \\
\hline DOC & MAF BNZ & \\
\hline $\begin{array}{l}\text { Project Team } \\
\text { (including } \\
\text { myself) }\end{array}$ & $\begin{array}{l}\text { Researcher } \\
\text { (myself) }\end{array}$ & $\begin{array}{l}\text { Developers and Conductors of the Process } \\
\text { - Developed process and definitions for } \\
\text { conducting stakeholder networking process } \\
\text { - Developed questionnaires and conducted } \\
\text { interviews to gather specified information } \\
\text { - Collated and analysed information } \\
\text { - Drew stakeholder network maps } \\
\text { - Prepared and presented information back to } \\
\text { recipients }\end{array}$ \\
\hline Executive Team & $\begin{array}{l}\text { Focus Group } \\
(3 \\
\text { Managers) }\end{array}$ & $\begin{array}{l}\text { Recipients of the Process } \\
\text { - Completed questionnaires and attended } \\
\text { interviews / focus group sessions to identify } \\
\text { stakeholders and related stakeholder } \\
\text { information } \\
\text { - Attended final session to review outputs of } \\
\text { stakeholder networking process }\end{array}$ \\
\hline
\end{tabular}

Table 5.3. Summary of Participants and Activities. 
With two discrete groups of participants, slightly different questions were asked to provide the relevant findings for this objective. Firstly, the questions I posed to the Project Team and myself (developers and conductors of the process) were;

1) What were the key issues that arose during development and conducting of the stakeholder networking process?

2) What could be done differently to improve these issues in the future?

Secondly, the other participants (recipients of the process) were asked to respond to these questions;

1) What insights do you have on the process that has been followed to identify your stakeholder relationships?

2) Do you have any recommendations on how the process could be improved or done differently?

Therefore, the issues that arose from the perspective of those developing and conducting the stakeholder networking process were identified; as well as those who were recipients of the process. As indicated, this also includes my own experiences. This coverage ensured that a comprehensive view of the whole process and encompassing activities was represented in the findings.

It should be noted that because these management issues were raised and emerged in interactive sessions, and were discussed / modified at the time, it is not always possible to attribute them to a specific individual; either a team member, manager, Executive Member, or myself. Although, I was able to separate the findings into the two groups of participants described above. 1) recipients of the process - i.e. the DOC Executive Team and the MAF BNZ managers in the focus group; and 2) those who developed and conducted the process - the Project Team in the case of DOC and myself for MAF BNZ. This separation illustrates the differences between the two perspectives and provides some insight as to who reported the findings. 
Table 5.4 below provides a summary of the key findings relating to the management issues, which are then elaborated below. It is noteworthy that more of these findings came from the 'developers and conductors of the process' because they were more heavily involved in the process activities than the other participants, which can be determined from Table 5.3 above.

\begin{tabular}{|c|c|c|c|}
\hline $\begin{array}{l}\text { Who Provided } \\
\text { the Response? }\end{array}$ & Management Issue Category & DOC & MAF \\
\hline \multirow{2}{*}{$\begin{array}{l}\text { Recipients of the } \\
\text { Process }\end{array}$} & Rigorousness of Process & & \\
\hline & Method of Stakeholder Identification & & \\
\hline \multirow{9}{*}{$\begin{array}{l}\text { Developers and } \\
\text { Conductors of the } \\
\text { Process }\end{array}$} & Buy-in and acceptance of business owners ${ }^{2}$ & & \\
\hline & Extensive relationships to consider & & \\
\hline & $\begin{array}{l}\text { Direction and requirements from the } \\
\text { business owners }\end{array}$ & & \\
\hline & $\begin{array}{l}\text { Suitable process for the organisation } \\
\text { context }\end{array}$ & & \\
\hline & $\begin{array}{l}\text { Engagement with business owners } \\
\text { throughout the process }\end{array}$ & & \\
\hline & $\begin{array}{l}\text { Time commitment of participants to be } \\
\text { involved in the process }\end{array}$ & & \\
\hline & $\begin{array}{l}\text { Data management techniques to cope with } \\
\text { extensive information }\end{array}$ & & \\
\hline & $\begin{array}{l}\text { External perspective only for stakeholder } \\
\text { network maps }\end{array}$ & & \\
\hline & $\begin{array}{l}\text { Ownership and continuation of process for } \\
\text { practical use in the business }\end{array}$ & & \\
\hline
\end{tabular}

Table 5.4. Summary of management issues in applying the process for stakeholder networking theory.

\footnotetext{
${ }^{2}$ The term "business owner" might seem inappropriate in relation to public sector organisations because they are not typically referred to as 'businesses'. However, this term is commonly used in project methodology to describe those people in any organisation, regardless of whether it is profit driven or not-for-profit, who have initiated the work and who will use the outputs once it has been completed (i.e. they own the outputs because they are being developed for their use). Therefore, henceforth in this thesis, the term 'business owners' refers to these respective people within DOC and MAF BNZ.
} 


\subsubsection{Recipients of the Process}

\section{1) Rigorousness of Process}

All participants reported that the process for applying stakeholder networking theory was well developed and structured for achieving the purposes of identifying stakeholders. This finding was particularly strong from the MAF BNZ participants because the process solely focussed on my own research objectives as opposed to multiple other Project objectives in the DOC context; that resulted from my research being conducted within a wider relationships project. This difference in perspective is illustrated by comparing the nature of the following two quotes;

The process has been easy to participate in and has resulted in a comprehensive list of our stakeholders and an understanding of their interest in our group's activities... (MAF BNZ Manager).

It has been a good opportunity for us to have an in depth discussion about the group's stakeholders, and timely given we are thinking about who to engage in the development of our strategic plan (MAF BNZ Manager).

The stakeholder identification process has obviously been developed with a lot of consideration by the Project Team and has been comprehensive in its coverage. However, it has sometimes felt like we are trying to achieve too many objectives through this one process and we lose sight of the basics (DOC Executive Member).

The other objectives that were a key focus for the Relationships Project were around relationship management such as, clarifying the strategic issues for which relationship management was important, which Executive Members were responsible for these strategic areas, agreeing who should be accountable for leading the relationships, what those relationships should try to achieve, etc. 
Therefore, the process had to factor in information gathering around these objectives, discussing them during interviews and the final Executive Team workshop, and producing project deliverables that effectively met these objectives. As a consequence, it was a lot more in depth and time consuming than the process followed at MAF BNZ, as reflected by the quotes above.

\section{2) Method of Stakeholder Identification}

One of the differences between the processes used for the two organisations was the method for initially identifying stakeholders. For DOC, this occurred by requesting the Executive Team to complete a questionnaire (that was accompanied by written instructions) about their stakeholder relationships and then following up with a oneon-one interview for further discussion. However, for MAF BNZ, stakeholders were identified in a focus group environment with the three selected managers and me brainstorming and generating a list. My role as the researcher was to guide the session and record the information they were reporting.

The way in which the DOC participants completed the questionnaire suggested that they did not easily understand the written instructions because they interpreted them in different ways. For example, four Executive Members identified their individual relationships, three identified relationships from the perspective of their wider division, and two identified strategic relationships for the organisation as a whole. Additionally, there were a number of gaps in the questionnaires where fields had been left blank. It became apparent to the Project Team that the brief provided before distributing the questionnaires, and the written instructions that accompanied them, were not adequate for ensuring consistent understanding and interpretation. Their responses to the "management issues" question supported the Project Team's suspicion that there had been some confusion with the instructions and interpretation;

I wasn't sure whether I was supposed to identify the stakeholder relationships from the perspective of my own relationships, all the relationships held within my group, or what I thought were the whole organisation's strategic relationship” (DOC Executive Member) 
While I thought the questionnaire was good for allowing us time to consider our strategic relationships, it might have been helpful to discuss and identify them as a group so that we could agree which ones were strategic at the outset (DOC Executive Member)

This was in contrast to the positive responses received from the MAF BNZ participants who reported that the focus group identification method (the opposite method to that used at DOC) was an efficient use of their time and they also felt confident in the answers they were providing because they had an opportunity for discussing stakeholders as a team before confirming them for my research. Additionally, it was reported that having the researcher there was useful to check their understanding of the information I was seeking and to provide clarification where required.

Being able to discuss and identify the strategic stakeholders together has been a good use of our time. Firstly, we needed to do this exercise anyway, and also if we had done it on our own and then discussed it together at a later time, we would likely spend a lot of time presenting and rationalising our thoughts before reaching agreement.

It has been valuable in terms of testing our common understanding of strategic stakeholders across our group in an informal way.

It was good to have you present in the focus group to ensure we stayed on track to meet your research objectives, particularly as we understand from your information sheet that you need specific information. 


\subsubsection{Developers and Conductors of the Process}

As stated above, the following findings are those raised by the people who developed and conducted the stakeholder networking process. For DOC, this was the Project Team, which included me. Findings for this section emerged out of various Project Team meetings and group discussions throughout the duration of the project, although we discussed and confirmed them at two specific points. The first was at the conclusion of the one-on-one interviews with Executive Members, and the second was at the end of the process following the Executive Team workshop. The discussions focussed on clarifying our thoughts and formulating them on the whiteboard to be coherent.

For MAF BNZ, the developer and conductor of the process was just me. In this instance, I reflected on the issues that arose during the application of stakeholder networking theory at the end of the process, following the final focus group session. I made general written notes and summarised them at a later point when writing up the findings.

As a result of my approach to gathering this information, the points below are extractions and summaries of group meetings and my written notes. Therefore, specific quotes are not available as for the previous section.

As indicated on the summary table above (Table 5.4), most management issues were identified in both DOC and MAF BNZ and only one was only raised in one organisation. This is elaborated further in the finding tables below by reporting the 'key issues' raised in each organisation separately. For example, if a box is left blank, it means that that issue was not raised for that organisation. If both boxes are complete, then a similar issue was raised in both organisations and the recommended 'improvement' will address both of them. 


\begin{tabular}{|c|c|c|}
\hline \multicolumn{3}{|c|}{ 1) Buy in and acceptance of the business owners } \\
\hline Key Issue(s) & DOC & MAF BNZ \\
\hline & $\begin{array}{l}\text { There was not a consistent } \\
\text { understanding across the Executive } \\
\text { Team (business owner) of the need } \\
\text { and benefits of the Relationships } \\
\text { Projects at the outset, and therefore } \\
\text { acceptance and buy-in from } \\
\text { Executive Members was mixed. }\end{array}$ & $\begin{array}{l}\text { The benefits of the stakeholder } \\
\text { networking process were not } \\
\text { understood at the beginning, which } \\
\text { impacted the drive and commitment } \\
\text { to completing the process. }\end{array}$ \\
\hline Improvement & 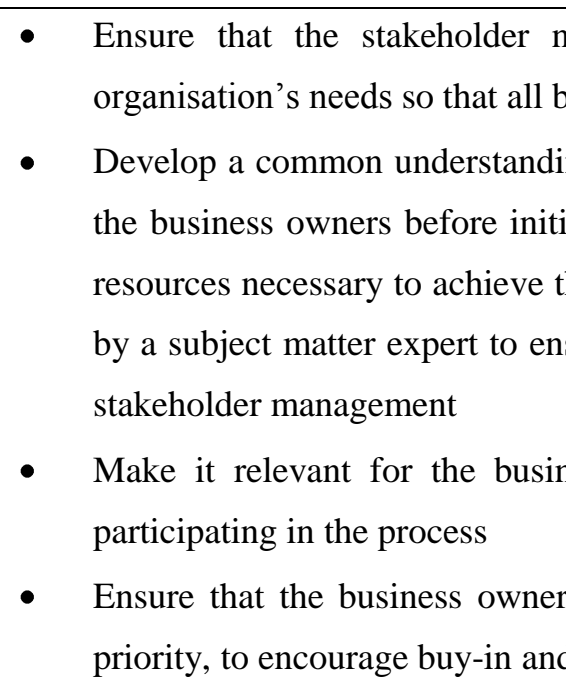 & $\begin{array}{l}\text { tworking process is aligned to the } \\
\text { siness owners can see a need for it } \\
\mathrm{g} \text { of the outcomes and benefits across } \\
\text { ting the process. Invest the time and } \\
\text { is, even if it requires some facilitation } \\
\text { ure a comprehensive understanding of } \\
\text { ss owners so they are interested in } \\
\text { agree the process is an organisation } \\
\text { commitment by everyone }\end{array}$ \\
\hline
\end{tabular}

\begin{tabular}{|c|c|c|}
\hline Key Issue(s) & $\begin{array}{l}\text { DOC } \\
\text { A large organisation of this nature } \\
\text { has an extensive range of } \\
\text { stakeholder relationships to } \\
\text { consider, making it a significant task } \\
\text { and difficult to know where to } \\
\text { begin. }\end{array}$ & $\begin{array}{l}\text { MAF BNZ } \\
\text { Same as DOC finding - extensive } \\
\text { relationships to consider. }\end{array}$ \\
\hline Improvement & \multicolumn{2}{|c|}{$\begin{array}{l}\text { - Restrict the scope to a clearly defined group of stakeholder } \\
\text { relationships and apply the process to that group only to begin with. } \\
\text { Then apply the same process to another group of relationships until all } \\
\text { of them have been covered; i.e. avoid looking at relationships across } \\
\text { the whole organisation in one go to make it manageable } \\
\text { - Agree definitions of the stakeholder group to ensure everybody } \\
\text { involved has a consistent understanding of the types of stakeholder } \\
\text { relationships being identified and analysed; this will help deter scope } \\
\text { creep through the duration of the process }\end{array}$} \\
\hline
\end{tabular}




\begin{tabular}{|c|c|c|}
\hline \multicolumn{3}{|c|}{ 3) Direction and requirements from the business owners } \\
\hline Key Issue(s) & $\begin{array}{l}\text { DOC } \\
\text { A clearly defined set of the } \\
\text { requirements or end point for the } \\
\text { Relationships Project was not } \\
\text { established, which led to scope creep } \\
\text { as Project objectives continued to be } \\
\text { debated through lengthy } \\
\text { discussionsand adjusted as new } \\
\text { requirements were identified } \\
\text { throughout the process. This also } \\
\text { impacted on engagement levels. }\end{array}$ & MAF BNZ \\
\hline Improvement & 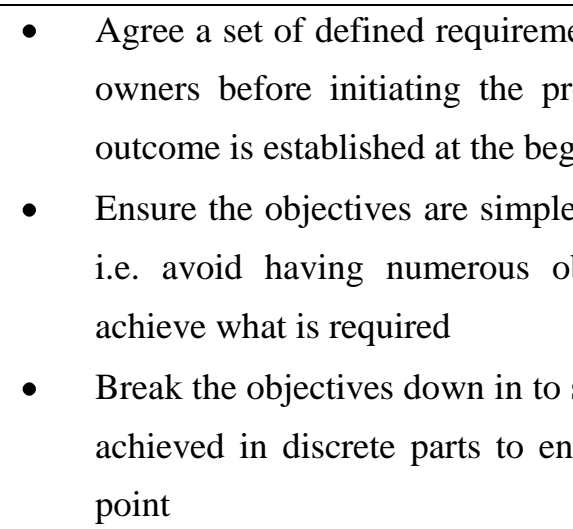 & $\begin{array}{l}\text { factors with the business } \\
\text { hg a clear direction and } \\
\text { process } \\
\text { requirements efficiently } \\
\text { only set objectives to } \\
\text { able activities that can be } \\
\text { progress toward the end }\end{array}$ \\
\hline
\end{tabular}

\begin{tabular}{|c|c|c|}
\hline The Key Issue(s) & $\begin{array}{l}\text { DOC } \\
\text { The generic process intended to be } \\
\text { used for stakeholder identification } \\
\text { was not appropriate for the } \\
\text { organisation's needs and information } \\
\text { requirements. A relevant and } \\
\text { appropriate process for DOC had to } \\
\text { be developed. }\end{array}$ & $\begin{array}{l}\text { MAF BNZ } \\
\text { Same as DOC finding - generic } \\
\text { process did not suit the context and a } \\
\text { more relevant process had to be } \\
\text { developed to suit the information } \\
\text { requirements and that was } \\
\text { appropriate for the people and } \\
\text { working style of MAF BNZ. }\end{array}$ \\
\hline $\begin{array}{l}\text { The } \\
\text { Improvement }\end{array}$ & \multicolumn{2}{|c|}{$\begin{array}{l}\text { - While a predetermined approach could be used as a base from which to } \\
\text { develop a stakeholder networking process, it may need to be adapted to } \\
\text { suit the specific needs and requirements of the organisation context in } \\
\text { which it is being applied e.g. the organisational culture, the types of } \\
\text { personalities involved, information requirements etc. } \\
\text { - Ensure the objectives and outputs of the process are fully understood } \\
\text { before developing the process, to ensure it will meet all its } \\
\text { requirements and success factors }\end{array}$} \\
\hline
\end{tabular}




\section{5) Engagement with Business Owners throughout the process}

\begin{tabular}{|c|c|c|}
\hline The Key Issue(s) & $\begin{array}{l}\text { DOC } \\
\text { Different levels of understanding about } \\
\text { stakeholder relationships and varying } \\
\text { degrees of buy-in from the Executive } \\
\text { Members meant that they were not all } \\
\text { on the same page throughout the } \\
\text { process. A lot of time had to be spent } \\
\text { bringing people along, reacquainting } \\
\text { them with the objectives, describing } \\
\text { what was trying to be achieved and } \\
\text { why, and understanding the benefits. }\end{array}$ & $\begin{array}{l}\text { MAF BNZ } \\
\text { It was difficult to create } \\
\text { momentum between focus group } \\
\text { sessions and keep the Managers } \\
\text { engaged in the process, } \\
\text { particularly because the benefits or } \\
\text { the reward of their time } \\
\text { commitment was not absolutely } \\
\text { clear. }\end{array}$ \\
\hline & \multicolumn{2}{|c|}{$\begin{array}{l}\text { - Develop a communications plan at the beginning of the process to } \\
\text { keep key audiences and stakeholders engaged throughout the } \\
\text { process, particularly if long periods of time elapse between } \\
\text { meetings, focus groups etc. } \\
\text { - Ensure effective, relevant, consistent and regular messages are } \\
\text { communicated to maintain momentum and move people along } \\
\text { together } \\
\text { - Reiteration of the benefits of the process and how the outcomes will } \\
\text { help participants to achieve their goals and objectives } \\
\text { - Develop an "elevator" speech so that a consistent message about the } \\
\text { process can be communicated concisely and effectively in } 30 \\
\text { seconds. }\end{array}$} \\
\hline
\end{tabular}

6) Time commitment of participants to be involved in the process

\begin{tabular}{|c|c|c|}
\hline \multirow{2}{*}{ The Key Issue(s) } & \multicolumn{2}{|r|}{ MAF BNZ } \\
\hline & $\begin{array}{l}\text { Conducting the process was time } \\
\text { consuming due to the need to } \\
\text { accommodate Executive Members' } \\
\text { other commitments. Busy schedules } \\
\text { also created a desire for the benefits } \\
\text { / outcomes without having to be } \\
\text { involved in the process, which } \\
\text { impacted engagement levels and } \\
\text { ownership of the final outcomes } \\
\text { when it came time to } \\
\text { implementation. }\end{array}$ & $\begin{array}{l}\text { The time required to attend focus } \\
\text { groups had to be scheduled in around } \\
\text { the Managers other work } \\
\text { commitments, which impacted the } \\
\text { timeframe of the process. This was } \\
\text { not a significant issue compared with } \\
\text { DOC because the group was much } \\
\text { smaller (only } 3 \text { MAF BNZ } \\
\text { Managers) so coordinating diaries } \\
\text { was easier. }\end{array}$ \\
\hline $\begin{array}{l}\text { The } \\
\text { Improvement }\end{array}$ & \multicolumn{2}{|c|}{ 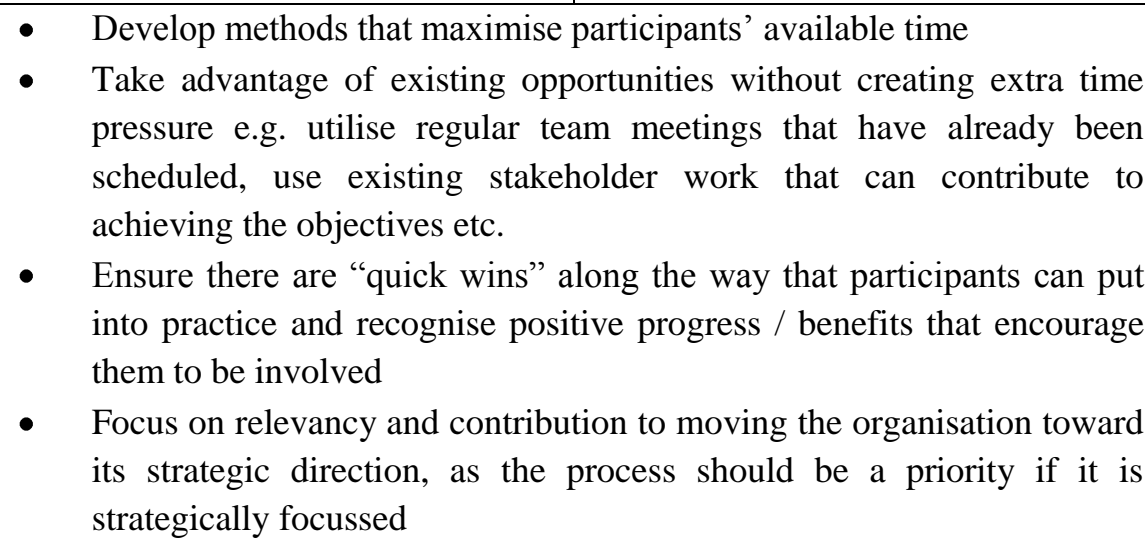 } \\
\hline
\end{tabular}




\begin{tabular}{|l|l|l|}
\hline 7) Data management techniques to cope with extensive information \\
\hline The Key Issue(s) & $\begin{array}{c}\text { DOC } \\
\text { Due to the number of participants } \\
\text { involved in the process, there was a } \\
\text { huge amount of data gathered that } \\
\text { had to be captured and managed. }\end{array}$ & $\begin{array}{l}\text { While the amount of information } \\
\text { being captured was not as significant } \\
\text { as for DOC, it was still an issue as to } \\
\text { how data from the various sources } \\
\text { was captured and managed to ensure } \\
\text { aspects were not lost. }\end{array}$ \\
\hline $\begin{array}{l}\text { Improvement } \\
\text { The }\end{array}$ & $\begin{array}{l}\text { Prior to commencing information gathering, ensure there is a } \\
\text { systematic approach for recording information and so that it can be } \\
\text { easily collated, analysed and reported back to participants. } \\
\text { Key consideration could be given to different capturing techniques } \\
\text { from different sources e.g. document analysis, interviews, focus } \\
\text { groups, meetings etc; how information will be stored once it has been } \\
\text { captured and prior to collation. }\end{array}$ \\
\hline
\end{tabular}

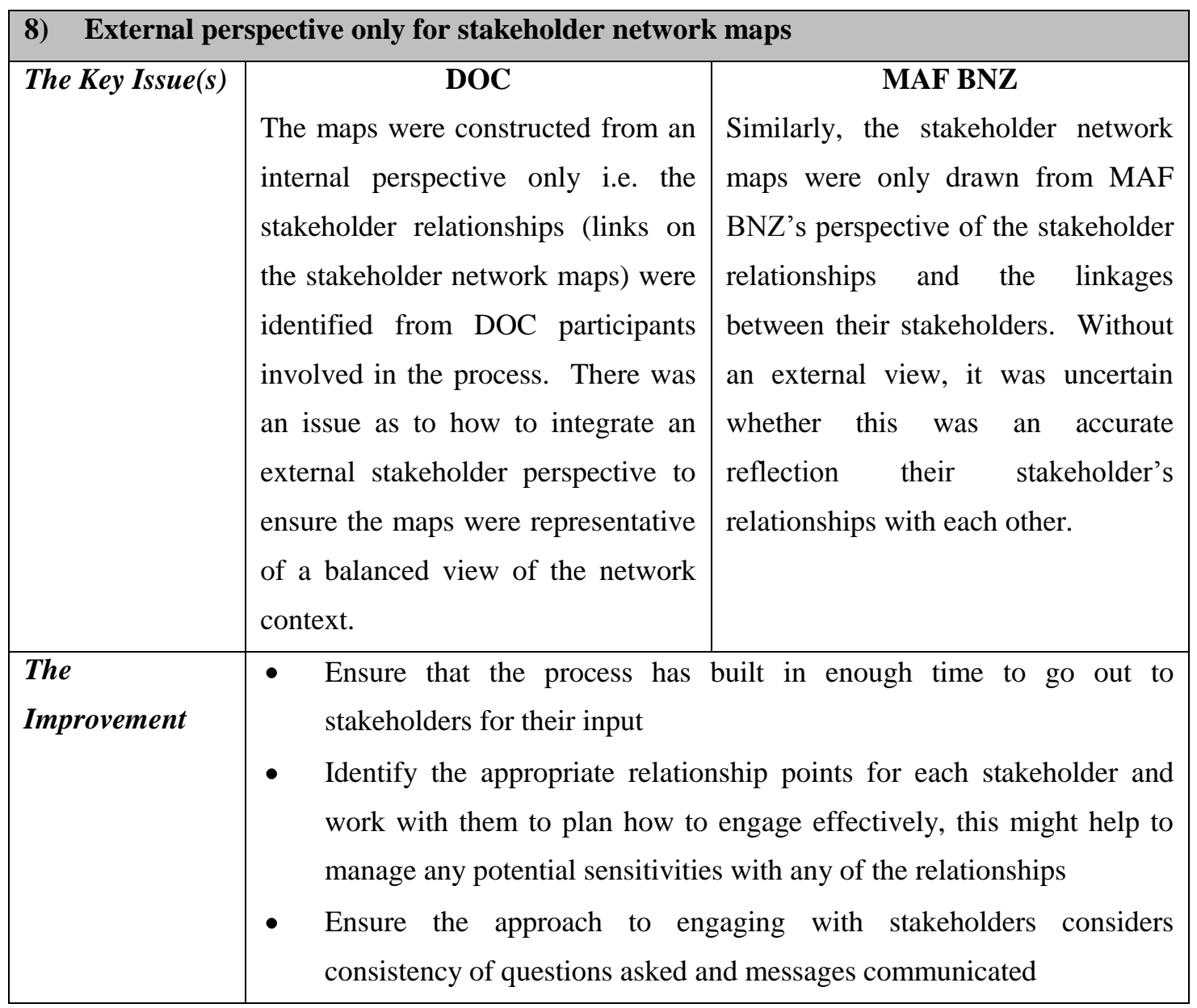




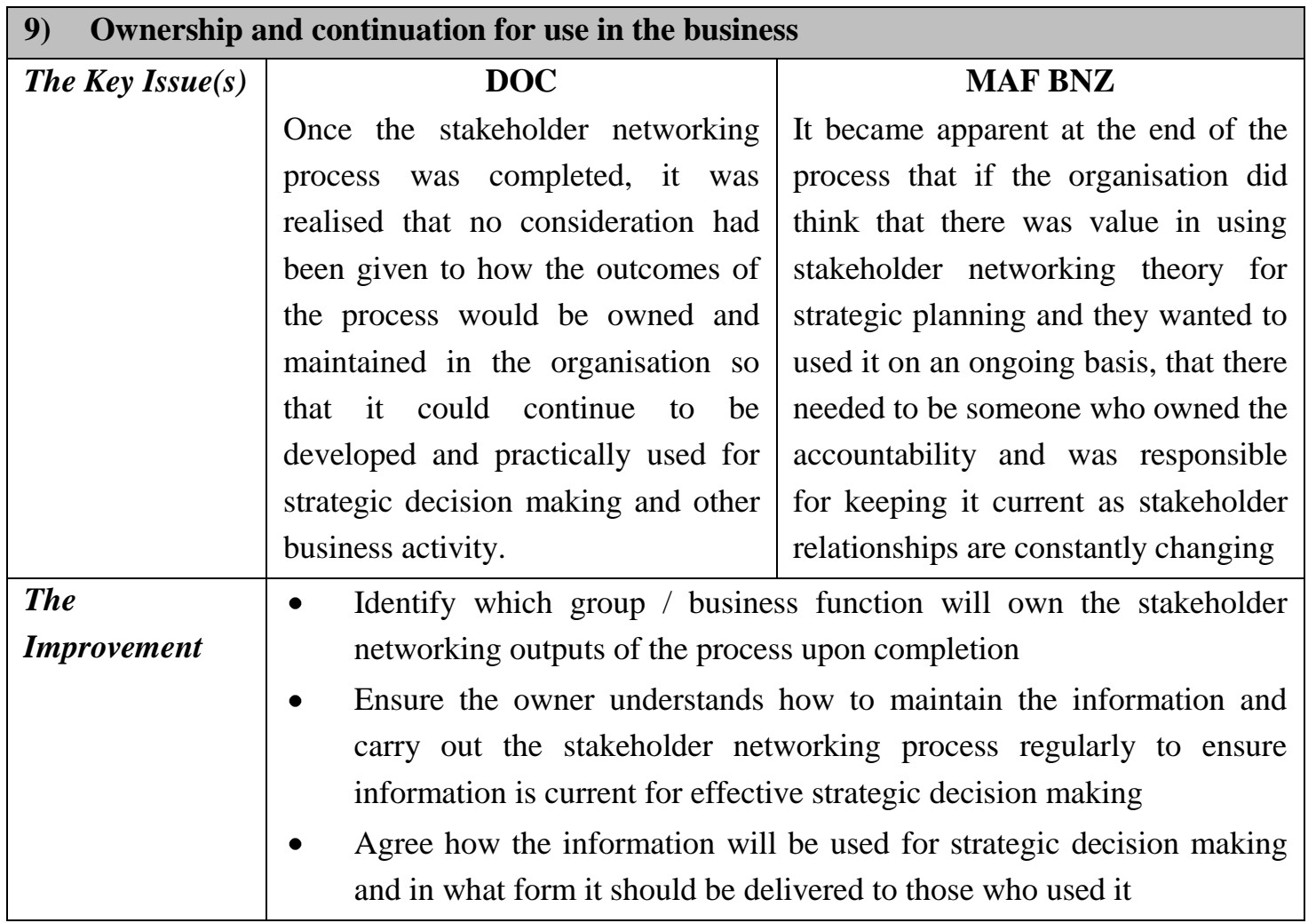

\subsection{The Use of Stakeholder Networking Theory for Strategic Planning}

The findings in this section relate to the usefulness of stakeholder network mapping for strategic planning. Data was gathered at the end of the stakeholder network process in both organisations, after the network maps had been developed and presented to the participants.

Although there were no final network maps presented for MAF BNZ (refer to section 5.3.2), temporary maps were drawn by myself and illustrated for discussion with the focus group to show how they were not so applicable in this context. This resulted in a general discussion about how they could be useful in other aspects of strategic planning. Therefore, the findings were gathered from the 3 Managers drawing on the temporary maps, and me.

In DOC, stakeholder network maps were drawn by me with input from the Project Team. They were then presented to the Executive Team at the final strategic stakeholder relationships workshop as finished maps for them to review and provide feedback. The Project Team also gave responses regarding the usefulness of stakeholder network mapping for strategic planning. 
The discussions that generated these findings in both MAF BNZ and DOC were prompted by the following question;

"How have you found this exercise of mapping your organisation's strategic stakeholder relationships useful for strategic planning?"

The findings that came out can be naturally grouped into two aspects. Firstly, there were discussions about usefulness related to the process of considering and identifying strategic stakeholder relationships. Secondly, there were discussions about the usefulness of the network maps themselves i.e. within a given strategic context, looking at stakeholder relationships in the form of a network map and understanding the networking concepts that have implications for strategic planning.

Finally, it is important to note that the findings that came out of all the discussions with MAF BNZ and DOC (the Executive Team and the Project Team) were similar in nature, so they have been reported together and are not always attributed to a particular organisation or participant.

\subsubsection{Usefulness of the Process of Stakeholder Networking}

When participants were asked about the usefulness of the stakeholder networking process for strategic planning, a common theme was that it was more than the output (network maps) that was helpful; it was the other benefits that occurred along the way. The following quote from one DOC Executive Member sums this up quite succinctly;

It's not just the network maps that are helpful for strategic planning, the map is just one output, but it's the process that has additional, yet less obvious benefits; such as promoting conversations between managers and teams, and bringing relationships into the way we think about things.

In regard to this theme, the following three uses / benefits of conducting the process of stakeholder networking were found. 


\section{1) Ensures adequate relationships to deliver strategic direction}

The benefit that was first discussed in both organisations was that it got them thinking about what the organisations' strategic priorities were and what relationships they had in each of those areas that helped to deliver the related strategic goals. This first step was a 'light bulb' moment for some participants as they became aware of areas of the strategic direction that did not have sufficient relationships to deliver the goals. Thus, they were prompted to think about what relationships they might need to focus on developing.

Likewise, it also worked in reverse. There were some stakeholders that were consistently identified by participants, but they did not appear to add significant value to achieving the organisations' strategic goals and direction. Therefore, it had to be questioned whether it was in fact a strategic relationship. This also encouraged a degree of efficiency in the organisations' approach to relationship management.

In summary, the process benefitted the organisations as it helped them to identify gaps and opportunities for developing their strategic relationships and ultimately achieving their strategic goals. One participant summarised this point by saying;

It gives clear guidance as to what we should be doing in terms of strategic relationship building that is in line with our strategic direction.

\section{2) Encourages conscious relationship management and strategic conversations}

Due to limited opportunities for participants to all get together and have good quality discussions about relationship management, one of the key findings was that this process encouraged each individual to think about the organisations' strategic priorities and its relationship landscape, which then led to being able to have constructive strategic conversations in the group sessions (i.e. focus group session in MAF BNZ; and the strategic stakeholder relationships workshop in DOC). The process created the right environment for this to occur. 
Both organisations also reported that going through the stakeholder networking process forced them to think consciously about how they manage their strategic relationships as opposed to this being something they do ad hoc. One participant commented;

People think "relationships are all ok. We've been doing it for years". But it's usually a beer and a chat or a reactive thing. This isn't good enough if we are to really progress the organisation and start seeing tangible results from our strategic relationships.Also, this approach is not conducive to resolving conflict or developing a new relationship if there hasn't been a prior relationship.

There was also general consensus around the process being useful for bringing to the foreground some key relationship issues with stakeholders that threatened the ability for both organisations to achieve their strategic goals. With the process highlighting these relationship risks, participants reported that they began to think about how the relationships can be developed and improved. One DOC Executive Member explained this benefit by saying;

Now that we know where the areas of concern are, we can focus on these relationships and gain clarity around how best to manage them.

Not only did it initiate discussions and a response to reducing high risk relationships, but it also raised awareness for both organisations as to the number of the relationships held and how they could deal with this increasing number and variety of stakeholders. In summary, it was reported as an;

Excellent opportunity to refine our thinking and has fulfilled a need to understand our key relationships and be smarter about how we go about business. 


\section{3) Inventory of relationships}

It was found that another benefit of conducting this process was the resulting inventory of relationships that was developed with all the related information gathered. This was first time that this sort of resource had been developed where the information was held in a central point and could be viewed all at once.

In particular, it highlighted where there was more than one relationship point for each stakeholder, which could potentially create inconsistent relationship management approach across stakeholders. It also helped to clarify people's role in managing the strategic relationships and improved the efficiency in which this was happening.

This finding was more prominent for DOC than for MAF BNZ as it involved a larger sample size and the number of relationships was more extensive. The three MAF BNZ Managers were all in the same group, so regular communication about stakeholder relationship management was easier.

\subsubsection{Usefulness of Stakeholder Network Maps}

The second group of findings that participants reported in response to the question about the usefulness of stakeholder networking for strategic planning related to the benefits that were obtained as a result of the stakeholder network maps. The following four uses / benefits were identified.

\section{1) Setting the context around strategic issues}

Overall, there was general consensus from all participants in both organisations that a primary benefit of stakeholder network mapping was that it crystallises the context around strategic issues in a way that words never could; and that it provides something tangible that people can easily relate to when discussing the opportunities for relationship strategies. It was alsosaid to be an excellent tool for visual people.

Additionally, due to stakeholder network maps not being drawn successfully in the context of MAF BNZ, the discussion led to other uses of stakeholder network 
mapping for strategic planning. One finding was that it would be beneficial to develop a stakeholder network map for each strategic issue outlined in the strategic plan in order to better under the stakeholder landscape and context surrounding that issue. This would assist in identifying the important stakeholders for that context and the key relationships required to manage and respond to that particular issue.

Strategic issues included in the strategic plan are those that have been prioritised for the organisation to develop a response to as well as to meet specified targets and outcomes that will indicate whether they are effectively responding to that issue. It was said that mapping out the stakeholder network would set the context for that issue and would assist in identifying opportunities for developing response strategies, such as those discussed below.

\section{2) Identifies opportunities for developing relationship strategies}

In line with the interpretations of the stakeholder network maps above, participants reported that mapping the network view of a given context could make valuable contributions to identifying potential opportunities for developing relationship strategies.

For example, it was noted that public sector organisations have a strong focus on growing engagement with the public and its other key stakeholder groups, and network maps can be used to highlight opportunities for leveraging existing relationships to expand organisations' reach to target audiences. The general theme of this discussion was around developing strategies based on relationship building and identifying circles of influence within the networks that organisations could utilise to achieve their strategic goals.

In the case of our organisation in the public sector, this is not about market share and profits, but it is about reaching the public and creating awareness of what we are trying to achieve so that our stakeholders will work with us to achieve the same goals for public good. 
An example of this is Stakeholder Map 3 (figure 5.4) where DOC talked about developing growth strategies that relied on strengthening and utilising existing relationships with those organisations that show links to the various 'Target Markets'. This is also evident in Stakeholder Map 4 (figure 5.5), which shows how relationships can be used to champion and communicate messages that need to reach further through the organisation.

Another way in which participants reported network maps can be used to identify opportunities for strategy development was that they illustrate where beneficial relationships do not exist. That is, maps highlight where organisations do not have relationships with stakeholders within the network, and if that relationship could be advantageous in meeting the strategic goals within that context, then it prompts organisations to think about developing a strategy to build that relationship. This was highlighted in Stakeholder Map 1 (Figure 5.2), where the XYZ conservancy did not have a relationship with the energy company, which they determined would be very valuable in successfully delivering the outcomes of the conservation initiative in that context.

Participants also reported that stakeholder network maps were useful for highlighting where targeted and planned relationship strategies were required. This was because the multiple links shown on the network maps made them think about the concepts and principles of networking and appreciate the extensive and complicated lines of communication that are possible in a network of stakeholders. This led to consensus that stakeholder network mapping could assist in determining which strategic stakeholders needed planned relationship strategies to ensure the relationship is managed in a way that actually contributes to the achievement of the organisation's strategic goals. Stakeholder Map 2 (figure 5.3) was particularly instrumental for this finding, emphasising the need for consistency messaging and relationship management. 


\section{3) Enables strategic prioritisation}

Participants reported that the stakeholder network maps were beneficial because they illustrated opportunities for strategic prioritisation decisions within that given context. Through the process of identifying relationship strategies, as described above, organisations can then determine which stakeholder relationships are the important ones to focus on in terms of acting on those strategies.

Additionally, it was reported that the network view allowed participants to more clearly see the systemic impact, or flow on effect, of making changes to the network, i.e. it is easier to understand the impact of developing new relationships, improving existing relationships, and/or ending ineffective relationships. With these impacts in mind, it is possible to make informed decisions about which relationships are strategically important, and are therefore a strategic priority so as to ensure that these relationships have adequate coverage and resources to sustain them. An example of this is in Stakeholder Map 1 and 3 (Figure 5.2, 5.4) where the dotted lines show how these contexts could benefit from developing the dotted line relationships.

Conversely, it was also reported that it is unrealistic to have direct relationships with all stakeholders involved in a given context, so the network maps were useful for illustrating where the focal organisation does not have to have a direct relationship but can instead utilise an existing relationship to access another stakeholder. Thus, it is possible to make further strategic prioritisation decisions as to relationships that are not a priority for achieving strategic objectives in that context, and make efficiency gains.

It is also a reality for organisations that they cannot invest resources in every strategic initiative, so participants also reported that by comparing network maps they could assess where the organisation would get the biggest benefits from investment in relationships. This would also allow them to make prioritisation decisions between strategic initiatives. 


\subsection{Chapter Summary}

This chapter has presented the results gathered from MAF BNZ and DOC by following the research process outlined in Chapter 4. These have been reported against the three research objectives, providing the foundation for further elaboration and discussion in Chapter 6.

Apart from findings related to the process of stakeholder network mapping and the outcome of the stakeholder network maps, the findings for the usefulness of stakeholder network mapping for strategic planning and the management issues that arise during application of the process were predominantly the same for both MAF BNZ and DOC.

This suggests that there is a degree of generalisation and some useful lessons to be considered for other public sector organisations thinking of applying stakeholder network mapping. These will now be discussed in Chapter 6. 


\section{CHAPTER 6}

\section{DISCUSSION}

\subsection{Introduction to Chapter}

During my experience as a strategic management consultant in the public sector, it has become apparent that New Zealand public sector organisations are under increasing pressure to meet broadening demand for social products and services; while at the same time, ensuring public value through the most efficient utilisation of resources. This pressure has continued to heighten since the National Government was elected at the end of 2008, driving public sector organisations to think about how they will respond to these environmental challenges without creating additional pressure on public sector funds. Finance Minister Bill English's recent budget announcement confirms this (Stuff article, March 2010):

We've given the public service leadership 12 months lead time to think about how they are going to deal with a much smaller increase, and have signalled to them...they won't be getting new money for probably three to five years...In most cases, public services will need to drop activities that are not effective and work out how to move money from the back office to the front line.

The question that this thesis sought to investigate is whether the theory of stakeholder networking can contribute to strategic planning in the public sector to assist such organisations in developing stronger partnerships and collaboration with stakeholders that will meet the aforementioned challenges. In taking a practical perspective to this research, the thesis was also designed to identify the management issues associated with applying stakeholder networking theory in public sector organisations so that it could make some useful contributions to management practice.

This chapter serves as a combined discussion and conclusion of the key findings from Chapter 5 and presents the generalisations that can be made from this study of the application of stakeholder networking theory for strategic planning in the public sector. The discussion has been separated into two sections. The first section 
proposes a framework to guide public sector organisations through the generic steps of applying stakeholder networking theory. The second section is a discussion of the usefulness of stakeholder networking theory for strategic planning in the public sector. These two sections are concluded with a brief summation of the key discussion points before the implications and limitations are presented and the thesis is rounded out with some concluding remarks.

\subsection{A Framework for the Application of Stakeholder Networking Theory}

Chapters 2 and 3 highlighted a gap in stakeholder and strategic management research that indicated the potential use of stakeholder networking theory to assist managers with strategic planning in the public sector; and which provided practical guidance on how to apply this theory. To fill this research gap, two of the three research objectives for this thesis were to 1) determine the applicability of stakeholder networking theory in the public sector, and 2) understand the management issues that arise during the practical application of stakeholder networking theory in the public sector. The findings presented in Section 5.2 and 5.3 demonstrate that stakeholder networking theory, which was originally developed in the private sector context, appears applicable in the public sector and the process for doing this in two public organisation contexts was presented. However, Section 5.4 illustrated a range of management issues and considerations for public organisations when applying stakeholder networking theory in the public sector.

Drawing on these key findings and having thought about how these 'application issues' could be overcome, the following nine step 'Stakeholder Network Framework' (figure 6.1) is proposed as a good practice approach to applying stakeholder networking theory in the public sector. In practice, it is likely there will be a dedicated person or team of people responsible for conducting the process. The Framework is designed to be used by such a person or team in order to produce a successful outcome. Each step of the Framework and the inter-dependencies between the elements are discussed below. 
Step 1: Defining the Context

Gain acceptance / direction from business owners

Define scope and objectives

Initiate project team

d) Identify audience for communication

a) Review the Process

b) Track usage of the information

c) Maintain the information

Step 8: Present Information

a) Report back to business owners

b) Put into action

c) Share learning across the business

Step 7: Analyse and Prepare Information

a) Draw conclusions from the analysis

b) Identify implications of the networks

c) Agree how to present the information

Step 6: Collation and Network Maps

Collate the information

b) Map the stakeholder networks

Step 2: Confirm Stakeholder Definition

a) Refer back to and confirm the stakeholder context

b) Clearly define which stakeholders are in and out of scope

Step 3: Review Current State

a) Identify existing information sources

b) Review and analyse existing information

\section{Step 4: Planning}

a) Define information requirements

b) Design information gathering process

c) Test the process and incorporate feedback

Step 5: Collect Information

Conduct information gathering inline with agreed plan

Figure 6.1. Proposed 'Stakeholder Network Framework'

\section{The Stakeholder Network Framework}

In line with the key finding that the process for applying stakeholder networking theory in an organisation must be flexible and adaptable to suit the context in which it is being applied, the proposed Stakeholder Network Framework is purposefully high level and has been designed as a guideline to the broad steps/process that a person/team might go through in applying stakeholder networking theory. It is up to the individual organisation to conduct each step in the way that suits their context in order to get the maximum benefit. Therefore, even though the framework is generic in a sense, it has attempted to include the required triggers to allow for adaptation and a context-specific application to occur.

Creating this flexibility for the application of stakeholder networking theory is particularly important to enable stakeholder networks to be mapped and analysed in 
a range of different organisation contexts. For example, an organisation might be looking at stakeholders in the context of "which stakeholders are central to a particular strategic issue'; or 'who the key stakeholders are for a certain group within the organisation'; for a certain Manager; or for a particular project. Therefore, having a flexible framework that is not prescriptive,means that it can be applied in a greater variety of organisational contexts, for a range of stakeholder purposes.

\section{Step 1 - Defining the Context}

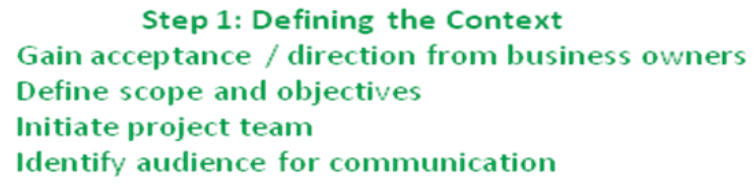

One of the key findings in this research arose from the success in mapping stakeholder networks for the different contexts within DOC, but not so successfully in the case of MAF BNZ. This was attributed to not having identified a context specific issue for MAF BNZ, but instead, identifying stakeholders that were deemed important in the development of a new strategic plan. This research context did not allow for as meaningful links to be determined and mapped because the relationships altered depending on the strategic issue. It is noteworthy that this is not to say stakeholder analysis of a general nature is not relevant when determining who to involve in the development of a strategic plan (because it is a requirement described by Bryson (2004) in his strategic planning process). More so, it was that stakeholder networking theory in particular did not add any value in this situation because of the reasons previously described. Two key implications arise from this finding, which have been factored into the Framework by suggesting they be conducted as Step 1 .

Firstly, it emphasises the need for the business owners to provide clear direction and guidance of the outcomes expected from the stakeholder networking process at the outset. These outcomes may be broad or narrow, depending on how clear the business owners' expectations are, but should at least articulate what they want to achieve with the outputs to ensure the process can deliver those. It is important this occurs first as it is the fundamental input to subsequent steps, in particular, Step 2, 4 and 5 . 
Secondly, the inapplicability of stakeholder networking theory in the MAF BNZ context illustrates the importance of having a clearly defined issue around which to conduct the process. This is essential for putting a boundary around an otherwise complex and diverse pool of stakeholders that could be mapped and analysed multiple different ways. As demonstrated in Chapter 3, compared to private sector organisations which tend to operate with a more singular set of objectives and less pluralistic demands (i.e. they have fewer stakeholders with significant power who can dictate to them (Jarzabkowski \& Fenton, 2006)); the complexity and diversity of stakeholders in the public sector is significantly greater due to the broader range of concerns and public interest that these organisations have to consider (McAdam et al., 2005; Davenport \& Leitch, 2007). This difference is emphasised by Freeman's (1984) use of generic names to describe stakeholders for private sector organisations, compared to the variety of names that had to be used to group DOC and MAF BNZ's range of stakeholders by similar interests (Tables 5.1\&5.2). Even then, some stakeholders will fit into multiple groups because they have different interests depending on the context that is being considered i.e. stakeholders might be grouped into a broad generic class and networked in one way, but that same generic group might then be less homogeneous in another context.

The need for successful application of stakeholder networking theory to be around a particular issue is consistent with the majority of stakeholder networking research examples reviewed during the course of this thesis (e.g. Jennings \& Ewalt. 1998; Sipple, 1999; Provan \& Milward, 2001; Miskel \& Song, 2004; Cronin \& Jackson, 2004; Mahon et al., 2004; Timur, 2005; Vandekerckhove\&Dentchev, 2005; Musso, et al., 2006; Shannon \& Walker, 2006; Stokes, 2006; Gomes \& Gomes, 2008; Mrosek, A $\beta$ mann, Kies, Allen \& Schulte, 2010). This is further supported by Achterkamp and Vos (2007) whoconfirm the contribution of critical systems thinking (CST), in the form of 'boundary critique', as a means for stakeholder identification. They state (Midgley, 2003, cited in Achterkamp \& Vos, 2007, p 3);

boundaries define both, in a coherent way, what issues are to be included or excluded and who is to be involved dealing with these issues. 
Therefore, moving beyond customary stakeholder analysis methods that traditionally focus on identifying stakeholders of a whole organisation (Achterkamp \& Vos, 2007) this Framework proposes that the purpose of the process and the issue(s) for which to develop stakeholder network maps, should be defined at the beginning to effectively direct the stakeholder networking process. This will hopefully simplify some of the complexity of the stakeholder landscape by creating a clear boundary around the pool of stakeholders that are of primary interest.

An additional benefit of defining the context and outcomes with the business owners upon initiation of the project is that in doing so, they are inevitably "buying into" the process and the end outputs. A key success factor to effective delivery in organisations is ensuring the owners are engaged in the process so that they develop a good understanding of the subject matter, the benefits it will deliver, and how it will be used. This will increase the chance that upon delivery, they willingly accept the outputs and use as recommended; ensuring that the investment and the knowledge base developed in completing such a project does not get lost, and that the information is kept current and made available and accessible for use across the organisation.

The context will also determine the target audience and key people to engage with throughout the process. This will likely extend beyond the business owners to those who will use the outputs of the process upon completion. A key finding presented in Chapter 5 was that the business owners and others involved in the process do not necessarily have expert knowledge in the subject of stakeholder networking, and therefore, the process can turn into an enlightening journey where the project team is educating people and passing on subject matter knowledge and skills. Organisations might also experience push back and should take into account that the journey can sometimes feel like a hard sell in trying to get people to buy into the outcomes and benefits of the process. Therefore, it is recommended that organisations develop a communication strategy for the duration of the project as part of Step 1, to ensure careful consideration is given to engaging people and managing any push back, in order to successfully deliver the project objectives. 
$\underline{\text { Step } 2-\text { Confirm the Stakeholder Definition }}$

Step 2: Confirm Stakeholder Definition

a) Refer back to and confirm the

stakeholder context

b) Clearly define which stakeholders are

in and out of scope

Considering the context and purpose, the next step is to develop a clear definition of the stakeholders that will be in and out of scope for the process. This should occur prior to any form of information gathering to ensure that all subsequent steps are primarily focussed on the defined issue and stakeholder definition, otherwise there could be a mis-investment of resources in activities that are not contributing to the defined outcomes of the process. The need to confirm the stakeholder definition early on in the process is supported by Mrosek et al. (2010) who report a similar finding in their framework for stakeholder analysis in the German forestry industry.

Thinking back to the variety of stakeholder definitions reviewed in Chapter 2 (e.g. Freeman, 1984; Goodpastor, 1991; Argandona, 1992; Hill \& Jones, 1992; Clarson, 1995; Donaldson \& Preston, 1995; Mitchell et al, 1997; Frooman, 1999) there are many different ways to identify a stakeholder for inclusion and it is still an area of stakeholder management that is continually explored (Parmer et al., 2010). This suggests that the person/people conducting the process need to define the stakeholders for inclusion based on the relevancy for the organisation and the purpose for which stakeholders are being networked. In the case of DOC, the definition adopted was;

[a stakeholder] relationship that is actively managed to support the Department in delivering the strategic direction. Therefore, if the relationship does not exist in a strong/proactive form, then the Department will fail in moving toward the strategic direction, and in delivering the outcomes and goals.

In the case of MAF BNZ, the definition was less explicit, but it was still based on the fundamental principle of those stakeholders who are critical to achieving goals (in 
this instance it was those stakeholders who are critical for involving in strategic plan development). Both of these definitions are similar to those who view stakeholders based on their role as either 'the affected' or 'the involved' (Freeman, 1984; Goodpastor, 1991; Frooman, 1999; Achterkamp \& Vos, 2007). Frooman (1999) refers to this as the strategic versus moral split, and the emphasis on one or the other could vary depending on the organisation and the issue.

\section{$\underline{\text { Step } 3 \text { - Review the Current State }}$}

\footnotetext{
Step 3: Review Current State

a) Identify existing information sources

b) Review and analyse existing information
}

While the reasons behind this step did not arise as a specific finding, it is good practice to consider in developing a comprehensive framework. Part b) is predominantly about considering information sources that might already exist within the organisation, which could contribute to stakeholder identification or stakeholder network mapping in the given context. This is an important step in practice because it is inefficient to repeat work that has already been completed and it can also provide useful insights into what has and has not worked in the past for similar work. This is consistent with research that supports the use of existing knowledge to support the generation of new organisational knowledge (Nonaka, 1994)

Additionally, all organisations have a varying degree of memory and it is important to at least understand what has come before so that people have confidence that the process will not repeat previous failed attempts at the same exercise or reinvent the wheel (Swan, Newell, Scarbrough \& Hislop, 1997). Furthermore, gathering information is time consuming and can lead to frustration for those involved if it has been previously asked for. 
Step 4 - Planning and Step 5 - Collect Information

Step 4: Planning

a) Define information requirements

b) Design information gathering process

c) Test the process and incorporate feedback
Step 5: Collect Information

Conduct information gathering inline with agreed plan

These two steps are closely linked in that Step 4 plans the information requirements, designs the information gathering process, and tests this with a cross section of people from the organisation to ensure it is sound;then Step 5 carries out the process as planned. As mentioned in Step 1, there is strong linkage between having a clearly defined context in which stakeholders are to be identified and analysed and being able to effectively determine the information requirements. This has been reflected in the sequence of the Framework, where the context and expectations are set up front with the business owners (Step 1), the stakeholder definition is confirmed (Step 2), and there is an understanding of what information already exists and where there are information gaps (Step 3). All of which lead to the ability to determine what information is required to be gathered and the best approach for achieving that (Step 4) so that the necessary details are gathered and the stakeholder networks can be mapped effectively.

To demonstrate this interdependency between setting the context (Step 1) and determining the information requirements and information gathering process (Step 4); if the business owners' primary objective of conducting stakeholder networking is to improve consistent relationship management with strategic stakeholders, then they will likely want to know who in the organisation has a relationship with their strategic stakeholders. Thus, the information gathering process will be internally focussed and seek to gather relationship contact points across the organisation from employees. On the other hand, if the business owners want to know who the key stakeholders are that are involved in the organisation's primary strategic issues and where effort should be targeted to improve strategic relationships, then the information requirements will be different and the gathering approach will likely focus on stakeholders outside the organisation to understand who they have relationships with, the nature of those relationships, and what strategic opportunities exist. 
Therefore, ensuring the context is defined at the outset will increase the likelihood of gathering the right information, hence avoiding the possibility of information gaps, which can be a tendency if the requirements are not properly defined prior to information gathering.

Due to the limited research available on the application of stakeholder networking theory in practice, it is difficult to compare and contrast the reported interdependencies in a Framework of this nature. However, Mrosek et al. (2010) who recently developed a stakeholder analysis framework, which incorporates stakeholder networking as one of three modules, devotes a large chunk of the methods section to defining the context of the framework, and reviewing and clarifying the definition of stakeholders in that context to enable stakeholder identification. This suggests support for clarifying these two things at the outset, as proposed by this Framework.

As suggested by the different levels of satisfaction between DOC and MAF BNZ regarding the use of questionnaires and interviews as opposed to focus groups, the information gathering process is an important consideration to ensure it is effective and appropriate for the organisation's culture and employees as all organisations are different. Some organisations lend themselves to electronic approaches, questionnaires with limited personal contact; while others might prefer face-to-face interaction in a one-on-one environment or in a group. It was evident through participant responses that questionnaires can be open to different interpretations, even if they are sent out with written instructions. This could be because people do not have a common understanding of the context in which stakeholders are being identified or the purpose of the stakeholder analysis. Additionally, depending on whether people have been involved in an exercise of this nature before, there could be different levels of experience and understanding of the type of information required.

Whatever the reason, the findings suggest that methods such as focus groups or oneon-one meetings, where people can seek clarification at the time, are likely to be more effective. This might be particularly pertinent in the public sector where the 
number of stakeholders is typically greater in a given context and the potential for greater variation in responses is higher. Additionally, as the complexity of the stakeholder context being mapped increases, the information and the number of people to engage with (inside and outside the organisation) is likely to broaden. This could also contribute to greater variation in responses.

\section{$\underline{\text { Step } 6 \text { - Collation and Network Maps }}$}

\section{Step 6: Collation and Network Maps \\ Collate the information \\ b) Map the stakeholder networks}

There were no specific findings that arose from the research relating to this area of the Framework. However, this step is crucial for collating all gathered information in order to draw the stakeholder network(s) It is worth noting that the ease in which the information can be collated is dependent upon the previous steps being completed comprehensively.

Collating the information could be done around each defined issue; pulling together the relevant stakeholders, a view of the interrelationships between stakeholders, and any other information that is selected to be displayed on the network map. Having smaller groups of information might make potentially large amounts of information easier to manage.

If the previous steps are achieved in line with the determined information requirements (Step 4) then identifying the links between stakeholders should be relatively straightforwardand the networks should accurately reflect the stakeholder relationships within the defined context. As the network maps are the end result that is visually presented, they should be drawn clearly to enable easy interpretation in the next step. 
$\underline{\text { Step } 7 \text { - Analyse and Prepare Information / Step } 8 \text { - Present Information }}$

Step 7: Analyse and Prepare Information

a) Draw conclusions from the analysis

b) Identify implications of the networks

c) Agree how to present the

information

Step 8: Present Information

Report back to business owners

Put into action

Share learning across the business

The most important aspect of preparing and presenting the information is analysing the networks, which involves interpretation, drawing conclusions, identification of strategic opportunities, and identification of any other practical implications that can be determined.

As presented in Chapter 2 and 3, network analysis is commonly achieved by using the network principles of density and centrality, which an organisation may or may not choose to employ. In the case of this research, it was decided by the Project Team in DOC and myself as the researcher in MAF BNZ, not to utilise these principles. This was because stakeholder networking theory was a new concept for both organisations and none of the participants had any previous experience in technical networking aspects. Therefore, in the interests of keeping the presentation relatively simple and to ensure participants were not overcome and turned off by too much detail, network principles were not adopted. Instead, general relationship language was used to explain the networks and identify various strategic opportunities as illustrated through the network descriptions in Chapter 5.

Interestingly, this did not appear to detract from the robustness of the presentation because participants naturally began to interpret and discuss opportunities evident in the networks, in line with the concepts of centrality and density, unknowingly. This highlights part c) of Step 7, which is to agree how to present the information back to the business owners, emphasising the need to ensure that the way information is presented should be suitable for the particular audience. 
To ensure the benefits of the stakeholder networks are effectively communicated to the business owners, this thesis emphasises the need to identify opportunities that will assist an organisation in achieving its strategic goals and ultimately move toward its strategic direction. Additionally, opportunities should be practical so that they can be put into action. This could improve the business owners' acceptanceof the opportunities as the value of implementation is more easily recognisable.

The last two parts of Step 8 (b and c) emphasise the need to actually use the information and outputs once they have been completed and presented. The person/people conducting the stakeholder networking process should encourage business owners to agree which of the identified strategic opportunities they want to implement and/or the way in which they will use the information to inform other strategic activities. This is to ensure that the organisation receives the benefit of investing in the process.

Finally, sharing the lessons learnt and the outputs of the process across the different parts of the organisation can contribute to helping others deliver successful projects and furthermore, there might be people (other than the business owners) who could benefit from utilising the outputs in their day-to-day management functions.

\section{$\underline{\text { Step } 9 \text { - Track the Outcomes }}$}

Step 9: Track the Outcomes

a) Review the Process

b) Track usage of the information

c) Maintain the information

Tracking the outcomes is a key step to round out the stakeholder networking process. The first part (part a) is to review the process, in particular to determine whether the outcomes have been effective in meeting the defined objectives.This could offer useful insights and improvements for conducting the stakeholder networking process in the future and for the application of other organisation processes/projects. 
Part b) refers to a common challenge that many management consultants have witnessed in the work place, which is that initiatives/projects often lose momentum once they have been completed in organisations. This could result in,firstly, the outputs not being used as they could be; and secondly, the information not being maintained or kept current. Given the significant investment required to undertake the process, it would be an inefficient use of public resources to not keep the work current if it will continue to inform decision making and strategic activity. Therefore, the Framework proposes that by tracking the usage of the information, organisations can ensure that 1) maximum benefit is gained across the organisation from the investment; 2) the information is contributing and adding value to the organisation; and 3) improvements can be made to the process to meet changing organisation requirements.

Finally, the third part of this step recommends that the information is kept current for the organisation. Instead of being a one-off process, it would ideally occur regularly in order to have up-to-date stakeholder relationship information that can be used as a key management input. This is recommended in line with the literature discussed in Chapter 2 regarding the dynamic nature of stakeholders, which illustrates that stakeholders are not static. Instead, their position can change from issue to issue, and the nature of these issues can also change over time (Mitchell et al., 1997; Husted, 2000; Kochan \& Rubinstein, 2000; Elias et al., 2002; Mahon \& Waddock, 1992; Davenport \& Leitch, 2005). Therefore, organisations should regularly refresh the network perspectives to ensure they keep abreast of changes within the various stakeholder landscapes and strategic issues. Attention could focus on new stakeholder relationship opportunities and the development of new strategic issues.

In conclusion, the Stakeholder Network Framework has been proposed as a generic approach for the application of stakeholder networking theory in practice. It is generic in nature so as not to be prescriptive as this might prevent its applicability across a variety of organisation settings. However, its flexible nature still allows for organisations to incorporate context-specific elements that are particular to their organisations by encouraging the person/people conducting the process to complete each step as appropriate for their organisation. 


\subsection{The Use of Stakeholder Networking for Strategic Planning in the Public Sector}

The third research objective was to investigate the use of stakeholder networking theory for strategic planning in the public sector. As presented in Chapter 5, a total of six uses were reported in the context of this research, of which, three uses were in relation to going through the process of applying stakeholder networking theory, and three uses were in relation to the usefulness of the stakeholder network maps.

In summary, stakeholder networking theory was reported to be useful for strategic planning for the following reasons;

\section{Process of Applying Stakeholder Networking Theory}

1) Ensures adequate relationships to deliver the organisation's strategic direction

2) Encourages conscious relationship management and strategic conversations

3) Develops an inventory of strategic relationships that could be used as a central source of information for relationship management on an ongoing basis

\section{$\underline{\text { Stakeholder Network Maps }}$}

4) Setting the context around strategic issues

5) Identifies opportunities for developing relationship strategies

6) Enables strategic prioritisation

The discussion here will focus on the last three findings because they are exclusive to the networking aspect of stakeholder networking theory, as opposed to the first three findings, which relate to the application of any stakeholder theory (because stakeholders must first be identified for any stakeholder exercise). Additionally, the findings will be discussed in relation to Bryson's (2004) strategic planning process for public organisations, focussing on which steps of the process stakeholder networking theory can contribute to; and also comparing and contrasting the findings with other relevant research introduced in Chapter 2 and 3. 
As presented in Chapter 3, Bryson (2004) described the need for certain stakeholder information and input across the steps of a strategic planning process, to ensure organisations plan effectively to meet stakeholder expectations. Refer back to Section 3.2 for a description of the stakeholder inputs. The stakeholder requirements at each step were primarily about understanding who the key stakeholders are, their needs and expectations, their primary interests in terms of what the organisation focuses on within the internal and external environment, and using them to propose and test potential strategies.

However, the findings of this thesis do not support a stakeholder networking approach to provide or assist with gathering the stakeholder information or input Bryson (2004) describes. This is because the application of any general stakeholder management approach would achieve these fundamental requirements of identifying and understanding stakeholders, and these are not unique to stakeholder networking theory.

In saying that, the findings show that stakeholder networking theory can contribute to Bryson's (2004) strategic planning process in two additional ways, not previously identified or discussed. The first use is in developing a stakeholder network for each strategic issue once they have been identified i.e. at the completion of Step 5. In line with findings reported by participants, stakeholder networks are found to be useful for visually representing the context around strategic issues, particularly because they crystallise a context making it meaningful and easy to understand (a purpose for which words would be insufficient, lengthy and inadequate). This relates to finding number 4 above and is consistent with Fassin (2008) who outlines some benefits of graphical representations, including helping people to comprehend their environments, and that they simplify and aggregate complex information that would otherwise be difficult to make sense of. Vandekerckhove and Dentchev (2005) also report that stakeholder networking enables stakeholders to better understand the involvement of all parties in relation to a particular issue, increasing knowledge about those stakeholders' expectations and how they behave. This has interesting implications for organisations that are not used to, or are in the early stages of shifting toward a more transparent and collaborative stakeholder environment, 
because it could initiate opportunities or stakeholder reactions that the organisation is not yet prepared to respond to.

The second use of stakeholder networking theory for strategic planning relates to Bryson's (2004) Step 6 - 'Formulate Strategies to Manage Issues'. Here, he talks about the need to obtain strategy proposals from key stakeholders and then test strategies with them to ensure they will meet stakeholder needs. The findings from this thesis (numbers 5 and 6) suggest that stakeholder networking theory can also be used for this strategy development step, but in a different way than what Bryson (2004) describes. Firstly, stakeholder network maps provide a means to identify all relevant stakeholders for each strategic issue mapping them through a network view of connections based on established relationships. Timur (2005) presented a similar finding in an urban tourism context, saying that stakeholder networking offers a useful tool for identifying those involved and the basic structure of how tourism functions in cities.

Additionally, once the network has been developed, it is possible to identify opportunities for potential relationship strategies that effectively contribute to organisations' responses to those strategic issues. For example, participants talked about identifying opportunities for expanding reach to target audiences, improving existing relationships to use as leverage for gaining access to important stakeholders, or eliminating ineffective relationships that were consuming unnecessary resources which could be invested with greater benefit elsewhere. The use of stakeholder networking theory to assist in identifying strategic opportunities is consistent with other findings that also illustrate strategic benefits, e.g. assessing strategic alliances (Gulati, 1998, 1999; Gulati et al., 2000) and helping entrepreneurs to identify new business opportunities (Vandekerckhove \& Dentchev, 2005). Of particular similarity to the types of strategic opportunities identified in this thesis, Vandekerckhove and Dentchev (2005) report the ability to identify important partners for achieving specified goals in relation to particular issues. Similarly, participants recognised opportunities for developing stronger relationships and potential partnerships, particularly when they believed that sitting on the outer of the network was not beneficial in that context. This emphasises the benefits and 
usefulness of stakeholder networking theory for strategic opportunity identification, and given that similar findings are not limited to public or private organisations, this suggests that the benefits can be generalised across various organisation contexts.

Another example of a strategic opportunity that was identified through the application of stakeholder networking was the ability to prioritise the important strategic relationships compared with those that were unlikely to make a significant contribution in responding to the strategic issue. This was because the visual network links made it easier for participants to recognise the impacts of relationship management activities (i.e. developing new relationships; ceasing existing relationships; or improving relationships through targeted effort etc). Similarly, stakeholder networking theory has previously been found to help identify the most important, important and unimportant stakeholders within a given context (Timur, 2005). This is consistent with research that has reported the ability of stakeholder networking theory to pinpoint strongly influential stakeholders within contexts, enabling organisations to prioritise investment for targeting those stakeholders to achieve specified outcomes e.g. to influence policy changes (Miskel \& Song, 2004); to target thought leaders and influence the perception of stakeholders across the network (Mahon et al., 2004); or manage the demands and influence from highly powerful stakeholders (Gomes \& Gomes, 2008).

This thesis suggests that the benefit of prioritisation also results in the more efficient use of public resources because it means that organisations are better informed to invest their resources in relationships that contribute the most value, and thus free up other resources to be used elsewhere. Other research also supports the finding that stakeholder networking theory results in more the efficient use of resources but the focus has predominantly been in relation to service delivery i.e. looking at networks in action (Levine \& White, 1961;Jennings \& Ewalt, 1998; Sipple, 1999; Provan \& Milward, 2001;Musso et al., 2006). While network delivery aspects were beyond the scope of this thesis, it could be likely that implementing strategies identified through stakeholder networks result in greater resource efficiency, particularly if strategies rely on coordination and collaboration with other stakeholders in the network. This could be a useful area for future research to investigate. 
In summary, looking at the research findings in relation to Bryson's (2004) public sector strategic planning process, it can be determined that stakeholder networking theory should be able to contribute to strategic planning in the public sector. This is consistent with those who have previously reported similar benefits of stakeholder networking theory, suggesting it can be added to the group of tools that assist in integrating a stakeholder perspective into strategic planning (Arnstein, 1969, cited in Green \& Hunton-Clarke, 2003; Scholes, 2001; Bryson, 2004; Davenport \& Leitch, 2005; Plant, 2006). Additionally, in conjunction with the proposed Framework, the findings go beyond simply supporting the use of stakeholder networking theory for strategic planning; they provide practical advice for organisations on how to apply it.

\subsection{Implications for Managerial Practice}

Due to the emphasis on the practical nature of my research, most of the findings of this thesis are implications for managerial practice. Even so, this section will highlight some of those key implications and discuss these more explicitly within the context of organisations' practical realities.

\section{Managing the Application of Stakeholder Networking Theory in an Organisation}

This section is dedicated to the lessons and considerations for managers when applying stakeholder networking theory in their organisations. Firstly, when the decision is made to apply stakeholder networking theory, it is likely the business owners will want to achieve additional objectives to do with relationship management to maximise the process, and these will also need to be factored in. This was the case with DOC where the application of stakeholder networking theory was only one aspect of an overarching relationships project. This emphasises the need to complete Step 1 of the Framework before commencing the process, to ensure clear context and expectations. It also highlights that organisations should not limit themselves to prescriptive processes, but instead, adopt flexible processes that allow adaptation to suit their specific needs. This is why the Stakeholder Networking Framework has been designed in this way. 
Another aspect to note when applying stakeholder networking theory is the time consuming nature of the exercise, which may increase even further depending on the number of project objectives. This makes it even more important that the context, expectations and objectives are clearly defined so that efforts can be targeted to meet project objectives and avoid spending time on other unrelated activities.

Also considering the time consuming nature of applying stakeholder networking theory, managers should determine whether the organisation has capacity to properly engage into the process so that the objectives are effectively met and the resulting outcomes can be used by the organisation to add value. It is common for organisations to have a lot of initiatives underway and prioritisation can be challenging, which often results in employees being too stretched and not having enough capacity to commit the quality time required to deliver objectives of all these initiatives. Therefore, managers could consider reprioritising some initiatives to free up people's time to ensure there is enough capacity, or think about delaying the project to a time when the organisation is better able to deliver. It is likely that this will depend on the leadership team's urgency and commitment to have the project outcomes for strategic decision making.

This raises the next point; the success of the project will likely be impacted by the buy-in and commitment from the leadership team to undertake the process. There could be a situation where some of the leadership team understand the need and are committed, but others are not. This will require those conducting the process to think about how they getall leadership members on board to ensure that, upon completion of the project, the outcomes are actually used. This can often be perceived as somewhat of a "sell job", so it is helpful to have the benefits of the process clearly articulated. As well as leadership buy-in, there might be other people across the organisation who could utilise the end outputs and if they are not on board, then the success of the process will also be threatened. To summarise, having sufficient commitment from the leadership team and wider organisation is key for successful implementation of stakeholder networking theory. 
In terms of obtaining buy-in and commitment to the project, it is not only the leadership team that need to be on board, it is also other members of the organisation that are required to be involved in the process. Due to the aforementioned challenge of multiple initiatives occurring in an organisation at any one time, it is sometimes difficult to keep people engaged and get their commitment to attend meetings and complete exercises within set timeframes. This can result in delays and extended timelines for project deliverables, which is a practical reality in a large busy organisation. This can be avoided by developing a communications plan, as discussed in Step 1 of the framework, with targeted key messages to ensure people do not lose sight of their involvement in the process, even if there is limited activity across long periods of time.

Success of stakeholder networking application is also partly dependent on the person/people conducting the process having the required skills and capability to complete each step effectively. This presents a challenge to managers adopting the Framework in practice if the employee skills and capability required to follow the process, do not exist internally. Organisations might want to then think about contracting someone externally to lead the process, while at the same timebuild up internal capability so the organisation can run the process on a long term sustainable basis. Otherwise, training should occur prior to initiating the process to ensure success.

\section{Developing and Interpreting Stakeholder Network Maps}

Managers should be aware that developing stakeholder network maps will likely be complicated, particularly in the public sector where it has been demonstrated that the stakeholder landscape consists of multiple interests and is especially diverse and complex (Ring \& Perry, 1985; Davenport \& Leitch, 2005; McAdam et al., 2005). Identifying every relationship link between stakeholders could be difficult as it will rely on having good enough knowledge and/or relationships with all stakeholders in the network to gather this information. In reality, this could be challenging and unrealistic, potentially resulting in some parts of the network being constructed solely from the perspective of the organisation. Thus, it is unlikely that stakeholder 
network will be $100 \%$ accurate at any given point in time. Additionally, networks do not show certain stakeholder dynamics or relationship management circumstances that might exist within the context of the network. For example, stakeholder networking literature talks about mobilisation of organisation-organisation links, but in reality, links are often mobilised through individual-individual ties because of relationship capability. At the generic level, the stakeholder networks do not reflect the complexity of these organisational relationships realistically or the ability of organisations to easily influence, build or change relationships.

Based on these two factors, managers could think about complementing interpretation of stakeholder networks with other knowledge and information about stakeholder relationships and the strategic issue when identifying strategic opportunities and prioritising stakeholders.

\section{Stakeholder Network Maps Inform Decision Making}

Another practical implication when applying stakeholder networking theory, which has been previously discussed, is that once stakeholder networks have been developed, they should be used by the organisation. I have seen, during previous consulting experience, that organisations too often invest a lot of time and resource into projects and then do not use the outputs in their day-to-day management activities to create organisation value. It is emphasised that stakeholder networking theory can practically contribute to strategic planning and should be used to this effect to ensure benefits of the investment are realised.

\section{Organisational Approach to Relationship Management}

According to Vandekerckhove and Dentchev (2005), it is also necessary to consider the ethical implications of strategic activity that arises from a stakeholder network perspective. It is suggested that shifting from the hub-model to a network perspective implies an organisational mindset shift from conflict and power to one of shared expectations, trust and collaboration. In line with this, this thesis recommends that managers integrating a network view consider any potential 
changes to the way they approach their stakeholders during relationship management activities. For example, are there any changes to the type of language used when communicating with stakeholders? Are there any different or conflicting messages being communicated about the way the organisation will operate in the future? How might these messages be perceived by key stakeholders? Are we implying any shifts in power? Are we threatening the position of any key strategic relationships by implementing any identified strategic opportunities?

Therefore, managers will need to think about the implications on other stakeholders in the network and how they manage this to ensure relationships are not damaged and to avoid any unintentional impacts.

\section{Generalisability for other Organisation Contexts}

Given the context specific nature of the Framework proposed, arguing for broad generalisability of the results of the research is not appropriate. However, the findings from the public sector managers studied and their perceptions of stakeholder networking as applied, suggests there it offers more scope for such organisations to better understand their stakeholders and manage their interactions through a stakeholder networking approach. Specifically, for planning activities, this might alloworganisations to achieve greater clarity of the stakeholder landscape surrounding their key strategic issues, enabling more informed strategy development through the recognition of strategic relationship opportunities, and strategic prioritisation.

Due to these benefits being reasonably generic and relevant for strategic planning in any organisational setting, it also suggests that the findings could be generalised to contexts outside of the public sector, including other non-profit organisations and private sector. 


\subsection{Implications for Future Research}

This thesis has supported the application of stakeholder networking theory in the public sector, presenting a framework that could assist managers to apply the theory in practice and highlighting ways it can help strategic planning. However, there are more opportunities for further exploration in this field, particularly because there is limited research about the benefits of stakeholder networking theory for strategic management, and which provides practical support for managers.

Firstly, the most apparent area for attention is to investigate the applicability of the proposed Stakeholder Networking Framework in a range of different organisations, in both public and private sectors, to determine whether it is a valid approach for managers wanting to apply stakeholder networking theory in practice. This would either support or argue against the generalisability of the proposed framework across organisations.

Future research could also explore more closely whether theuses of stakeholder networking theory for Bryson's (2004) strategic planning process, reported here, are found in other public sector organisations. There might also be other uses for strategic planning that were not identified, but which could add further support to the usefulness of stakeholder networking for strategic planning. Research could target the areas of stakeholder integration that Bryson (2004) describes to determine whether stakeholder networking theory could in fact be used for those purposes.

Extending the use of stakeholder networking theory to other organisation management practices could also contribute to the stakeholder literature. For example, it might be that stakeholder networking theory could provide a means to analyse internal organisation relationships i.e. to identify where communication channels might be broken or effective collaboration between different organisational divisions is not occurring. Internal organisation relationships are equally important for contributing to a well performing organisation, so there is an opportunity for future research to investigate the potential for stakeholder networking theory to improve these as well. 
A significant finding from this research was about the importance of mapping a stakeholder network around a specific issue or a clearly defined context because relationships between stakeholders change depending on the issue. This notion of the 'issue' was mentioned in Chapter 2 in relation to stakeholder dynamics and is supported by other researchers who explore the changing nature of stakeholder relationships and issues (Freeman, 1984; Mitchell et al., 1997; Husted, 2000; Kochan \& Rubinstein, 2000; Elias et al., 2002; Davenport \& Leitch, 2005). However, while some research has briefly touched on the idea of the 'issue', there is limited research that looks into the practical implications of stakeholder networking theory within the boundaries of particular 'issues'. Therefore, there is an opportunity for future research to explore the benefits of using 'boundaries' and 'issues' for the application of stakeholder networking theory. This would also contribute another dimension to the unresolved issue of stakeholder identification, which is continually discussed by researchers as demonstrated in the literature review of Chapter 2.

This research was very much focussed on the planning aspects of strategy, but the subsequent focus of strategic management once the planning stage is complete is strategy implementation or deployment stage (Bryson, 2004). That is, once strategies have been developed, managers must then put those strategies into action. Therefore, there is an opportunity for research to extend beyond the theoretical aspects of stakeholder networking and look at how managers might mobiliselinks or develop strategic relationships they have identified from the stakeholder networks. And whether these identified opportunities actually create organisation value in reality? There might be regularly identified opportunities from stakeholder network maps that are more effective for achieving strategic goals, such as targeting stakeholders that are centrally located in the network with a lot of connections. Existing research by Saxena and Ilbery (2008) has found that the creation of networks does not necessarily result in empowerment for all concerned and that desired outcomes can be hindered by complex issues of participation and inclusion. This suggests there are challenges in the practical realties of realising networking opportunities, emphasising the potential contribution future research. 
Equally, as with any organisation's reality, there could be dynamics and circumstances that might create complexities in implementing identified strategies; such as, poor stakeholder relationships due to historical issues, significant differences in goals and interests between an organisation and its stakeholders, lack of relationship management capability and skills to effectively implement and manage relationship strategies. Interesting research questions that might arise from this include, under what conditions can organisations commence strategic actions to realise network opportunities? What is the sequence of strategic actions that needs to occur to realise these opportunities? What relationship management capability and skills do employees need to have to affect these network opportunities? What is the role of an organisation's leadership in initiating and successfully realising network opportunities?

In terms of following through on strategies identified from stakeholder network maps, there might also be some theories that could support managers to implement strategies in practice. For example, Payne and Calton (2004) have investigated the use of multi-stakeholder dialogues to encourage learning across networks, for relationship building within network environments, and to assist organisations in responding to social pressure from stakeholders in their network. Future research could look at combining theories such as this 'multi-stakeholder dialogues' to determine whether there is value for managers in using these when implementing strategic relationship opportunities.

It would also be interesting to do a longitudinal study to compare and contrast an organisation's various stakeholder networks from when they were first mapped to a time after implementation of identified strategic opportunities. For instance, referring back to DOC's Stakeholder Network Map 1 (Section 5.5.2), if DOC decided to action the relationship opportunities identified (i.e. the ones with dotted lines), a longitudinal study could map the stakeholder network around the same issue in 2 years time and analyse changes to the network structure as a result of strategy implementation. Further, they could track progress against DOC's strategic goals for this issue to determine whether implementing the strategic opportunities contributed 
to achieving those goals. This would add support to the benefits of stakeholder networking theory for strategic planning and achieving strategic goals.

In summary, there is a wide range of research opportunities for the future which would contribute to developing a greater collection of literature to either support or critique the use of stakeholder networking theory for strategic planning, in both the public and private sector. In a broader sense, there is continued debate and discussion around the kind of entity "stakeholder theory" really is (Parmar et al., 2010). It is questioned whether there is really enough definition and clarity around the stakeholder concept for it to even be considered a theory, or whether its purpose is more about being a general management theory that contributes value through its ability to serve different purposes? For the philosophical pragmatists (Parmar et al., 2010) and the management practitioner alike, future research in this field will contribute to answering some of these questions and hopefully provide some lessons that organisations can adopt to create value for their stakeholders.

\subsection{Limitations}

While research limitations were sought to be overcome in designing and implementing this research, limitations are inevitable when conducting research. It is prudent to acknowledge these so that the findings can be interpreted meaningfully and future research can consider these. Limitations relating to the research design were discussed in Section 4.9, which included sample size, constraints on the availability of information, and stakeholder networks being developed from an internal perspective only. Some of these are discussed further below, as well as some are new limitations.

Firstly, as determined in Chapters 2 and 3, many possible research options were available due to limited research about stakeholder networking theory and strategic planning. However, the scope of a Masters thesis restricts the research focus to limited aspects only, so while stakeholder networking theory might be useful for strategic planning in the public sector in other ways, I cannot comment on these potential benefits. Hence, the discussion of opportunities for future research above. 
A second limitation of this research, which was also raised in Chapter 4, is the sample size of only two public sector organisations. While it was for practical reasons that I selected two organisations (to be able to carry out the participation research design within the thesis timeframe) it still raises question as to the generalisability of the research findings and whether different findings might have arisen if more than two organisations had been investigated. This was acknowledgedabove, while also noting potential comparisons which provide a solid base for further research to support the findings. Regarding whether more than two organisations would produce different findings, it is possible that some findings could have been further strengthened and some might have been unique to these two organisations only. Further research would offer clarification.

A third limitation was the research framework itself, being action research that was participatory in nature.Due to this, I was involved in the three main aspects of this research and contributed to the findings for these. There were two primary implications that arose from this. Firstly, because the research framework required me to be intrusive and heavily involved, the sample of the two organisations was chosen based on relationships already existing through previous consulting activities. This might be more difficult for other researchers to replicate, as gaining such access to organisations is not easily achieved.

Secondly, it is possible that my involvement in conducting and being part of the research had implications for the application of stakeholder networking theory and impacted the findings. This is because the findings were a result of my involvement in designing the application process, facilitation skills when meeting with participants, and my ability to draw useful stakeholder network maps that accurately reflected the contexts described to me. Thus, the findings could change depending on the skills and approach taken by the researcher. This limitation was not as prominent for DOC because I was part of a team and there were more people involved that could contribute different skills and balance any major influence I was having. However, for MAF BNZ, it was only me, as the researcher, who developed and conducted the process. Therefore, the findings relating to the research areas from this perspective were limited to my responses only and therefore might not have been as varied as the multi perspectives gathered from within DOC. 
These implications of the participatory research were again highlighted by the lack of issues that the 'recipients' of the process identified, which was because they were not involved in as many activities of the application process as the developers and conductors of the process. This did not discredit the findings because responses from the people involved in designing and using the process were also gathered.

A fourth limitation relates to the generation of stakeholder network maps from an organisation's internal perspective, as previously discussed. One argument for identifying stakeholder relationships internally is to avoid mobilising links and setting unintentional relationship expectations with stakeholders prior to relationship prioritisation. However, moving from an inward focus to a multi-perspective stakeholder network map provides a much richer representation of reality to use as the basis for strategic stakeholder relationship decision making. If gathering information from multiple stakeholder perspectives can be achieved in a neutral way without creating unintended implications for future stakeholder relationships, then it would be beneficial for researchers and organisations.

A fifth limitation is also to do with the stakeholder network maps. As with all situations that take a 'snapshot in time', the stakeholder network can only be considered a representation of reality at a particular point in time and does not necessarily reflect the full complexity and dynamics of the stakeholder relationships in the network. For example, the maps illustrated in Chapter 5 represent all stakeholders as being of equal importance, but in reality this might not be true. Some relationships might be more important than others for strategic reasons, such as their level of influence within that context or due to political reasons, etc. I was unable to get this far in developing the maps due to time constraints and trying to achieve multiple other project objectives outside the scope of my thesis, but future researchers could think about reflecting these differences through visual means such as, the sizes of the bubbles, the thickness of network lines, or colour coding. This limitation has also been recognised by other researchers, such as Fassin (2008), but equally, he says that maps are social constructions that simplify and reduce reality to make it easily understood so that meaningful interpretations can be drawn. 
In summary, this research was not conducted without limitation, but through recognising and acknowledging these, it is hoped that the findings can be interpreted as they are intended and some meaningful lessons adopted for both stakeholder literature and managers in practice.

\subsection{Concluding Remarks}

This thesis was initiated to determine whether stakeholder networking theory could offer a new and beneficial approach to New Zealand public sector organisations' strategic planning efforts.

After conducting research in line with the research design set out in Chapter 4 and reporting the findings in Chapter 5, this thesis has argued that stakeholder networking theory can be applied in the public sector to assist managers in some aspects of the strategic planning process. Issues that arose in the application of stakeholder networking theory were identified and have been factored into the design ofthe proposed Stakeholder Networking Framework. This is a 9 step framework and its purpose is to guide managers through the successful application of stakeholder networking theory in practice. However, it is not prescriptive; it is designed to be flexible so that managers can conduct each step in a way that suits the needs and objectives of their organisation.

The uses of stakeholder networking theory for strategic planning in the public sector were also identified by comparing the findings to Bryson's (2004) strategic planning process for the public sector. Broadly, the key uses for strategic planning were found to come after strategic issues had been identified and included the ability of stakeholder network maps to visually represent the strategic stakeholder context around the issues;to provide a means for identifying strategic relationship opportunities that might contribute to the achievement of strategic goals in that context; and to assist managers in prioritising which stakeholders are important and influential in relation to the strategic opportunities and goals. 
In order to carry out this research and produce these findings, I adopted an involvement type research approachthat resulted in practical implications for the organisations I was researching, known as action research. Typically, this is characterised by the researcher's heavy involvement in the research process, often blurring the boundaries between researcher, participant and practitioner. In my case, my involvement was intrusive, becoming part of a project team in one organisation and being provided with a desk and access to internal resources at the other organisation.

There are common difficulties and challenges with this type of approach which I also experienced during my research, including its time consuming nature due to the in depth research approach; the challenge of becoming part of the organisations and having my thesis timeframes threatened by the everyday constraints faced by large organisations of that nature; balancing the needs and objectives of the organisations with my thesis objectives because these were not always the same; and gathering and managing large quantities of information.

However, while recognising all of this, research of a qualitative nature often encounters these challenges and by being transparent about these factors, the findings can be interpreted accordingly. Also, one of the key principles of action research is that it is about implementing change that leads to the production of knowledge (O'Leary, 2004) and the fact that I was so involved within the organisations allowed this transfer of knowledge to occur more strongly and effectively than if I had been sitting on the periphery at arm's length from the organisations. I even noticed a difference in the effectiveness of this knowledge transfer between DOC and MAF BNZ as I was more integrated with DOC, which enabled the transfer of knowledge to happen more easily than in MAF BNZ, where my involvement with participants was not as frequent.

Additionally, this thesis was conducting research in a field that has limited literature available, so its primary purpose was exploratory and to gather rich information, which has hopefully provided a good foundation for suggested future research to conduct more empirical research to support and/or critique the findings. In the 
meantime, there are lessons and implications that can be considered by managers in both private and not-for-profit organisations, which could assist their stakeholder management and strategic planning practices.

The relevance for public sector managers of this Stakeholder Networking Framework and the reported uses of stakeholder networking theory for strategic planning, consists of a practical approach for applying stakeholder networking theory, which can lead to greater clarity around strategic issues and the identification of strategic relationship opportunities to achieve strategic goals. Further, if managers commit to the circular nature of the Framework and keep the networking outputs current for the organisation to use, then managers could continue to realise the strategic benefits in the long term.

However, it should be noted that if organisations fail to recognise the dynamic nature of strategic issues and stakeholder relationships and do not repeat the process regularly, the stakeholder networks will change and the opportunities previously identified will no longer be relevant. Thus, if it is a one off process, the benefits are most likely limited.

Coming at this research from my perspective as a strategic management consultant who had recognised a need for an approach to incorporate a stakeholder perspective into strategic planning in the public sector, it was my aim to produce a thesis with strong practical considerations. It is now my hope that the learning I have experienced during my involvement type research with these two organisations, may prove to be beneficial for others seeking such a pragmatic approach for management practice; and to researchers looking for new ways to expand the body ofknowledge that continues to define the possibilities of stakeholder theory for creating organisational value. 


\section{REFERENCES}

Achterkamp, M. \& Vos, J. (2007). Critically identifying stakeholders: Evaluating boundary critique as a vehicle for stakeholder identification. Systems Research and Behavioural Science, 24, 3-14.

Albert, S., Ashforth, B. \& Dutton, J. (2000). Organisational identity and identification: Charting new waters and building new bridges. Academy of Management Review, 25(1), 13-17.

Alford, J. (2001). The implications of 'publicness' for strategic management theory. In Johnson, G. \& Scholes, K (Eds.), Exploring Public Sector Strategy (p 1 16). Pearson, Essex, UK.

Ambler, T. \& Wilson, A. (1995). Problems of stakeholder theory. Business Ethics, $4(1), 30-35$.

Andriof, J. \& Waddock, S. (2002). Unfolding stakeholder engagement. In Andriof J, Waddock S, Husted B, \& Sutherland Rahman S (eds), Unfolding stakeholder thinking: Theory, responsibility and engagement. Sheffield: Greenleaf Publishing, 19-42.

Andriof, J., Waddock, S., Husted, B. \& Rahman, S. (2002). Unfolding stakeholder thinking: Theory, responsibility and engagement. Sheffield: Greenleaf Publishing, 19-42.

Argandona, A. (1998). The stakeholder theory and the common good. Journal of Business Ethics, 17, 1093-1102.

Argenti, J. (1993). Your organisation: What is it for? McGraw Hill, New York.

Barnard, C. (1984). The function of the executive. Cambridge: Harvard University Press.

Berry, G. (2003). Organising against multinational corporate power in cancer ally The activist community as primary stakeholder. Organisation and Environment, 16(1), 3-33.

Bingham, L., Nabatchi, T., \& O’Leary, R. (2005). The new governance: Practices and processes for stakeholder and citizen participation in the work of government. Public Administration Review, 65(5), 547-558.

Blair, M. (1998). For whom should corporations be run?: An economic rationale for stakeholder management. Long Range Planning, 31(2), 195-200

Bovaird, T. (2005). Public governance: balancing stakeholder power in a network society. International Review of Administrative Sciences, 71(2), 217-226. 
Brugha, R. \& Varvasovszky, Z. (2000). Stakeholder analysis: A review. Health Policy and Planning, 15(3), 239-246.

Bryson, J. (1988). A strategic planning process for public and non-profit organisations. Long Range Planning, 21(1), 73-81.

Bryson ,J., Cunningham, G., \& Lokkesmoe, K. (2002). What to do when stakeholders matter: The case of problem formulation for the African American men project of Hennepin County, Minnesota. Public Administration Review, 62(5), 568-584.

Bryson, J. (2004). What to do when stakeholders matter: Stakeholder identification and analysis techniques. Public Management Review, 6(1), 21-53.

Bryson, J. (2004). Strategic planning for public and non-profit organisations: A guide to strengthening and sustaining organisation achievement ( $3^{\text {rd }}$ Edition). United States of America: Jossey-Bass.

Bryson, J., Ackermann, F., \& Eden, C. (2007). Putting the resource-based view of strategy and distinctive competencies to work in public organisations. Public Administration Review, 67(4), 702-717.

Buysse, K. \& Verbeke, A. (2003). Proactive environmental strategies: A stakeholder management perspective. Strategic Management Journal, 24(5), 453-470.

Canada's Performance 2006-2007. (2006). Canada Government. Retrieved from http://www.tbs-sct.gc.ca/media/nr-cp/2007/1122-eng.asp.

Carrington, P., Scott, J., \& Wasserman, S. (eds) (2005). Models and methods in social network analysis. Cambridge: Cambridge University Press.

Cavana, R., Delahale, B., \& Sekaran, U. (2001). Applied business research. John Wiley \& Sons Australia Ltd: Queensland.

Clarkson, M., Starik, M., Cochran, P., \& Thomas, M. et al. (1994). The Toronto conference: Reflections on stakeholder theory. Business and Society, 33(1), 82-131.

Clarkson, M. (1995). A stakeholder framework for analysing and evaluating corporate social performance. Academy of Management Review, 20(1), 92112.

Connecting Government: Whole of Government responses to Australia's priority challenges. (2004). Retrieved from http://www.apsc.gov.au/mac/connectinggovernment.pdf

Creswell, J. (1998). Qualitative inquiry and research design: Choosing among five traditions. Thousand Oaks, California: Sage Publications. 
Cronin, K. \& Jackson, L. (2004). Hands across the water: Developing dialogue between stakeholders in the New Zealand biotechnology debate. Wellington: Victoria University of Wellington.

Cross, R., Liedtka, J., \& Weiss, L. (2005). A practical guide to social networks. Harvard Business Review, March.

Davenport, S. \& Leitch, S. (2005). Circuits of power in practice: Strategic ambiguity as delegation of authority. Organisation Studies, 26(11), 16031623.

Denis, J., Langley, A., \& Rouleau, L. (2007). Strategizing in pluralistic contexts: Rethinking theoretical frames. Human Relations, 60(1), 179-215.

De Nooy, W., Mrvar, A., \& Batagelj, V. (2005). Exploratory social network analysis with Pajek. Cambridge: Cambridge University Press.

Denzin, N. \& Lincoln, Y. (2003). Strategies of qualitative inquiry. Thousand Oaks, California: Sage Publications.

Department of Internal Affairs relationship continuum,

De Wit, B. \& Meyer, R. (2002). Strategy synthesis: Resolving strategy paradoxes to create competitive advantage. United Kingdom: Thompson Learning.

Donaldson, T. \& Preston, L. (1995). The stakeholder theory of the corporation: Concepts, evidence and implications. The Academy of Management Review, 20(1), 65-91.

Driscoll, C. \& Starik, M. (2004). The primordial stakeholder: Advancing the conceptual consideration of stakeholder status for the natural environment. Journal of Business Ethics, 49, 55-73.

Dunham, L., Freeman, E. \& Liedtka, J. (2006). Enhancing stakeholder practice: A particularised exploration of community. Business Ethics Quarterly, 16(1), 23-42.

E-government Strategy Update. (December 2001). Networking Government in New Zealand. Retrieved from http://www.e.govt.nz/plone/archive/aboutegovt/programme/e-gov-strategy-dec-01.

Elias, A., Cavana, R., \& Jackson, L. (2002). Stakeholder analysis for R\&D project management. R\&D Management, 32(4), 301-310.

Elias, A., Jackson, L., \& Cavana, R. (2004). Changing positions and interests of stakeholders in environmental conflict: A New Zealand transport infrastructure case. Asia Pacific Viewpoint, 45(1), 87-104. 
Eppink, J. \& de Waal, S. (2001). Global influences on the public sector. In Johnson, G. \& Scholes, K (Eds.), Exploring Public Sector Strategy, (p 38 55). Pearson, Essex, UK.

Fassin, Y. (2008). Imperfections and shortcomings of the stakeholder model's graphical representation. Journal of Business Ethics, 80, 879-888.

Ferlie, E., Ashburner, L., Fitzgerlad, L., \& Pettigrew, A. (1996). The new public management in action. London: Oxford University Press.

Freeman, E. (1984). Strategic management: A stakeholder approach. Boston MA: Pitman.

Freeman, E. (1994). The politics of stakeholder theory: Some future directions. Business Ethics Quarterly, 4, 409-421.

Freeman, E. \& Liedtka, J. (1991). Corporate social responsibility: A critical approach. Business Horizons, Jul/Aug91, 34(4), 92-98.

Freeman, E. \& Liedtka, J. (1997). Stakeholder capitalism and the value chain. European Management Journal, 15(3), 286-296.

Friedman, A. \& Miles, S. (2006). Stakeholders: Theory and Practice. Oxford University Press, New York.

Frooman, J. (1999). Stakeholder influence strategies. The Academy of Management Review, 24(2), 191-205.

Frooman, J. \& Murrell, A. (2005). Stakeholder influence strategies: The roles of structural and demographic determinants. Business Society, 44(1), 3-31.

Gilbert, N. (Ed). (2001). Researching social life ( $2^{\text {nd }}$ Ed). London: Sage Publications Inc.

Gioia, D. (1999). Practicability, paradigms, and problems in stakeholder theorizing. Academy of Management Review, 24(2), 228-232.

Glynn, M., Barr, P., \& Dacin, M. (2000). Pluralism and the problem of variety. Academy of Management Review, 25(4), 726-734.

Gomes, R. \& Gomes, L. (2008). Who is supposed to be regarded as a stakeholder for public organisations in developing countries? Evidence from an empirical investigation in Brazilian municipalities. Public Management Review, (2), 263-275.

Goodpastor, K. (1991). Business ethics and stakeholder analysis. Business Ethics Quarterly, 1, 53-71. 
Grafe-Buckens, A. \& Hinton, A. (1998). Engaging the stakeholders: Corporate views and current trends. Business Strategy and the Environment, 7, 124133.

Green, S. (1998). Strategic management initiatives in the Civil Service: a crosscultural comparison. International Journal of Public Sector Management, 11(7), 536-552.

Green, A. \& Hunton-Clarke, L. (2003). A typology of stakeholder participation for company environmental decision-making. Business Strategy and the Environment, 12(5), 292-299.

Gregory, A. (2003). The ethics of engagement in the UK public sector: A case in point. Journal of Communication Management, 8(1), 83-94.

Guffey, M. (2003). Collaborative networks: The initial design strongly influences the outcome. The Public Manager, 32(2), 42-44.

Gulati, R. (1998). Alliances and networks. Strategic Management Journal, 19(4), 293-317.

Gulati, R. (1999). Network location and learning: The influence of network resources and firm capabilities on alliance formation. Strategic Management Journal, 20(5), 397-420.

Gulati, R., Nohria, N., \& Zaheer, A. (2000). Strategic networks. Strategic management Journal, 21(3), 203-215.

Hall, J. \& Vrendenburg, H. (2005). Managing stakeholder ambiguity. MIT Sloan Management Review, 47(1), 11-13.

Harrison, J. \& Freeman, E. (1999). Stakeholders, social responsibility, and performance: Empirical evidence and theoretical perspectives. Academy of Management Journal, 42(5), 479-485.

Harrison, J. \& St John, C. (1996). Managing and partnering with external stakeholders. Academy of Management Executive, 10(2), 46-60.

Harting, T., Marmeling, S., \& Venkataraman, S. (2006). Innovative stakeholder relations: When "ethics pays" (and when it doesn't). Business Ethics Quarterly, 16(1), 43-68.

Hill, C. \& Jones, T. (1992). Stakeholder-agency theory. The Journal of Management Studies, 29(2), 131-154.

Hillman, A. \& Keim, G. (2001). Shareholder value, stakeholder management, and social issues: What's the bottom line? Strategic Management Journal, 22, 125-139. 
Howard, E. (1998, March 27). Keeping ahead of the green regulators. Financial Times. London: UK, p 8.

Husted, B. (2000). A contingency theory of corporate social performance. Business Society, 39(1), 24-48.

Jack, S. (2005). The Role, Use and Activation of Strong and Weak Network Ties: A Qualitative Analysis. Journal of Management Studies, 42(6), 1233-1251.

Jarzabkowski, P. \& Fenton, E. (2006). Strategising and organising in pluralistic contexts. Long Range planning, 39(6), 631-648.

Jawahar, I. \& McLaughlin, G. (2001). Toward a descriptive stakeholder theory: An organisational life cycle approach. Academy of Management Review, 26, 397-414.

Jennings, E. \& Ewalt, J. (1998). Interorganizational coordination, administrative consolidation, and policy performance. Public Administration Review, 58(5), 417-428.

Johnson, G., Scholes, K. \& Whittington, R. (2005). Exploring Corporate Strategy: text and cases $\left(5^{\text {th }}\right.$ Edition). London: Prentice Hall.

Joldersma, C. \& Winter, V. (2002). Strategic management in hybrid organisations. Public Management Review, 4(1), 83-99.

Jonker, J. \& Foster, D. (2002). Stakeholder excellence? Framing the evolution and complexity of a stakeholder perspective of the firm. Corporate Social Responsibility and Environment Management, 9, 187-195.

Kaplan, R. \& Norton, D. (2001). The strategy-focused organisation: How balanced scorecard companies thrive in the new business environment. United States of America: Harvard Business School Publishing Corporation.

Kochan T. \& Rubinstein, S. (2000). Towards a stakeholder theory of the firm: The Saturn partnership. Organisation Science, 11, 367-386.

Lawless, M. \& Moore, R. (1989). Interorganisational systems in public service delivery: A new application of the dynamic network framework. Human Relations, 42(12), 1167-1184.

Leitch, S. \& Davenport, S. (2003). Strategic ambiguityin communicating public sector change. Journal of Communication Management, 7(2), 129-139.

Leitch, S. \& Davenport, S. (2007). Strategic ambiguity as a discourse practice: the role of keywords in the discourse on 'sustainable' biotechnology. Discourse Studies, 9(1), 43-61. 
Levine, S. \& White, P. (1961). Exchange as a conceptual framework for the study of interorganizational relationships. Administrative Science Quarterly, 5(4), 583-601.

Llewellyn, S. \& Tappin, E. (2003). Strategy in the public sector: Management in the wilderness. Journal of Management Studies, 40(4), 955-982.

Madsen, H. \& Ulhoi, J. (2001). Integrating environmental and stakeholder management. Business Strategy and the Environment, 10, 77-88.

MAF BNZ Pest Management Group Annual Plan 2007/2008. (2007). Ministry of Agriculture and Forestry Biosecurity New Zealand.

MAF BNZ Profile (no date). Ministry of Agriculture and Forestry Biosecurity New Zealand.

MAF BNZ Strategic Plan (2006). Ministry of Agriculture and Forestry Biosecurity New Zealand.

Mahon, J., Heugens, P., \& Lamertz, K. (2003). Social networks and non-market strategy. Journal of Public Affairs, 4(2), 170-189.

Mahon, J. \& Waddock, S. (1992). Strategic issues management; An integration of issue life cycle perspectives. Business and Society, 31, 19-32.

Malvey, D., Fottler, M., \& Slovensky, D. (2002). Evaluating stakeholder management performance using a stakeholder report card: The next step in theory and practice. Health Care Management Review, 27(2), 66-79.

Marsden, P. (2005). Recent developments in network measurement. In P. Carrington, J. Scott, \& S. Wasserman (Eds), Models and methods in social network analysis. Cambridge: Cambridge University Press, 8-30.

McAdam, R., Hazlett, S., \& Casey, C. (2005) Performance management in the UK public sector: Addressing multiple stakeholder complexity. The International Journal of Public Sector Management, 18(3), 256-273.

McNiff, J. \& Whitehead, J. (2002). Action research: Principles and practice $\left(2^{\text {nd }}\right.$ ed.). London, RoutledgeFalmer.

Miles, M. \& Huberman, A. (1994). Qualitative Data Analysis (2nd Edition). Thousand Oaks, California: Sage Publications.

Miller, E., Buys, E., \& Summerville, J. (2007). Quantifying the Social Dimension of Triple Bottom Line: Development of a Framework and Indicators to Assess the Social Impact of Organisations. International Journal of Business Governance and Ethics, 3(3), 223-237. 
Ministry of Fisheries Stakeholder Consultation Process. (no date). Retrieved from http://www.fish.govt.nz/NR/rdonlyres/804C2063-4023-46BE-BD98-

4D3BD69FBFC2/0/consultation_standard.pdf.

Mintberg, H. (1996). Managing government, governing management. Harvard Business Review, May - June.

Miskel, C. \& Song, M. (2004). Passing reading first: Prominence and processes in an elite policy network. Educational Evaluation and Policy Analysis, 26(2), 89-109.

Mitchell, R., Agle, B., \& Wood, D. (1997). Toward a theory of stakeholder identification and salience: Defining the principle of who and what really counts. Academy of Management Review, 22(4), 853-886.

Moore, M. (2003). The public value scorecard A rejoinder and an alternative to "strategic performance measurement and management in non-profit organisations" by Robert Kaplan. Hauser Center for Nonprofit Organisations Working Paper No. $18 . \quad$ Retrieved from http://ssrn.com/abstract=402880.

Mrosek, T., Aßmann, M., Kies, U., Allen, S., \& Schulte, A. (2010). A framework for stakeholder analysis of forest and wood-based industry clusters - Case study at the State of North Rhine-Westphalia, Germany. The Open Forest Science Journal, 3, 23-37.

Musso, J., Weare, C., Oztas, N., \& Loges, W. (2005). Neighbourhood governance reform and networks of community power in Los Angeles. American Review of Public Administration, 36(1), 79-97.

National Population Projections: 2006 (base) - 2061. (2006). Statistics New Zealand. Retrieved from http://www.stats.govt.nz/browse_for_stats/population/estimates_and_projecti ons/NationalPopulationProjections_HOTP06-61/Technical\%20Notes.aspx.

Neville, B. \& Menguc, B. (2006). Stakeholder multiplicity: Toward an understanding of the interactions between stakeholders. Journal of Business Ethics, 66, 377-391.

Nohria, N. \& Eccles, R. (1992). Networks and organisations: Structure, form and action. Boston: Harvard Business School Press.

Nonaka, I. (1994). A dynamic theory of organisational knowledge creation. Organization Science, 5(1), 14-37.

Norman, R. (2003). Obedient servants? Management freedoms and accountabilities in the New Zealand public sector. Wellington: Victoria University Press. 
Norman, R. (2006). New governance, new dilemmas: Post-reform issues in New Zealand's public sector. Policy Quarterly, 2(3), 24 - 31.

O'Leary, Z. (2004). The essential guide to doing research. Sage Publications Inc: London.

O’Toole, L. (1997). Treating networks seriously: Practical and research-based agendas in public administration. Public Administration Review, 57(1), 4552 .

Palmer, B., Freeman, E., Harrison, J., Wicks, A., Purnell, L., \& de Colle, S. (2010). Stakeholder theory: State of the Art. Academy of Management Annals, 4(1), 403-445.

Payne, S. \& Calton, J. (2004). Exploring research potentials and applications for multi-stakeholder learning dialogues. Journal of Business Ethics, 55, 71-78.

Perrini, F. \& Tencati, A. (2006). Sustainability and stakeholder management: the need for new corporate performance evaluation and reporting systems. Business Strategy and the Environment, 15(5), 296-308.

Plant, T. (2006). Public sector strategic planning: An emergent approach. Performance Improvement, 45(5), 5-6.

Post, J., Preston, L., \& Sachs, S. (2002). Managing the extended enterprise: The new stakeholder view. California Management Review, 45(1), 6-28.

Preble, J. (2005). Toward a comprehensive model of stakeholder management. Business and Society Review, 110(4), 407-431

Provan, K. \& Milward, H. (2001). Do networks really work? A framework for evaluating public-sector organisational networks. Public Administration Review, 61(4), 414-424.

Putting Pen to Paper - Profiles. (2007, July). Department of Internal Affairs.

Ramirez, R. (2001). Understanding the approaches for accommodating multiple stakeholders' interests. International Journal of Agricultural Resources, Governance and Ecology, 1(3-4), 264-285.

Reason, P. \& Bradbury, H. (Eds.). (2001). Handbook of action research: Participative inquiry and practice. London: Sage Publications Ltd.

Ring, P. \& Perry, J. (1985). Strategic management in public and private organisations: Implications of distinctive contexts and constraints. Academy of Management Review, 10(2), 276-286.

Rowley, T. (1997). Moving beyond dyadic ties: A network theory of stakeholder influences. Academy of Management Review, 22(4), 887-910. 
Rowley, T. \& Moldoveanu, M. (2003). When will stakeholder groups act? An interest and identity-based model of stakeholder group mobilization. Academy of Management Review, 28(2), 204-219.

Salkind, N. (Ed.) (2010). Encyclopaedia of research design. Thousand Oaks, California: Sage Publications Inc.

Sanderson, I. (1996). Evaluation, learning and the effectiveness of public services: Towards a quality of public service model. International Journal of Public Sector Management, 9(5/6), 90-108.

Saxena, G. \& Ilbery, B. (2008). Integrated rural tourism - A border case study. Annals of Tourism Research, 35(1), 233-254.

Schick, A. (1996). The spirit of reform: Managing the New Zealand state sector in a time of change. Wellington, New Zealand: State Services Commission.

Scholes, K. (2001). Stakeholder mapping: A practical tool for public sector managers. In Johnson, G. \& Scholes, K (Eds.), Exploring Public Sector Strategy (p 165-184). Pearson, Essex, UK.

Scott, J. (1991). Social network analysis: A handbook. London: Sage Publications.

Shannon, P. \& Walker, P. (2006). Community development and control in a statelocal partnership in Aotearoa New Zealand. Community Development Journal, 41(4), 506-520.

Sipple, J. (1999). Institutional constraints on business involvement in K-12 education policy. American Education Research Journal, 36(3), 447-488.

Silverman, D. (2006). Interpreting qualitative data ( $3^{\text {rd }}$ Edition). London: Sage Publications.

Skok, J. (1989). Toward a definition of strategic management for the public sector. The American Review of Public Administration, 19(2), 133-147.

Statement of Government intentions for an improved community-government relationship. (December 2001). Office of Community and Voluntary Sector, p1-2. Retrieved from http://www.ocvs.govt.nz/documents/publications/policies/governmentintentions.pdf.

State Services Commission (2005). 'Whole-of-government' definition. Retrieved from http://www.ssc.govt.nz/glossary.

State Services Development Goals. (2007). Retrieved from http://www.ssc.govt.nz/display/document.asp?DocID=6368. 
Steurer, R., Langer, M., Konrad, A., \& Martinuzzi, A. (2005). Corporations, stakeholders, and sustainable development I: A theoretical exploration of business-society relations. Journal of Business Ethics, 61(3), 263-281.

Steurer, R. (2006). Mapping stakeholder theory anew: From the 'stakeholder theory of the firm' to three perspectives on business-society relations. Business Strategy and the Environment, 15, 55-69.

Stokes, R. (2006). Network-based strategy making for events tourism. European Journal of Marketing, 40(5/6), 682-695.

Stoney, C. (1998). Lifting the lid on strategic management: A sociological narrative. Journal of Radical Organisational Theory, 4(1), 1-34.

Soney, C. (2001). Strategic management or strategic Taylorism? A case study into change within a UK local authority. International Journal of Public Sector Management, 14(1), 27-42.

Stuff article (2010, 12 March). Public sector on notice for budget. Retrieved from http://www.stuff.co.nz/national/politics/3439334/Public-sector-on-notice-forBudget.

Svendsen, A. \& Laberge, M. (2005). Convening stakeholder networks: A new way of thinking, being and engaging. Journal of Corporate Citizenship, 19, 91104.

Swan, J., Newell, S., Scarbrough, H., \& Hislop, D. (1997). Knowledge management and innovation; Networks and networking. Journal of Knowledge Management, 3(4), 262-275

Thiel, S. \& Leeuw, F. (2002). The performance paradox in the public sector. Public Performance \& Management Review, 25(3), 267-281

Timur, S. (2005). A network perspective of stakeholder relationships in the context of sustainable urban tourism (Ph.D dissertation). Canada, University of Calgary, Publication Number: AATNR05655.

Trisurat, Y. (2006). Community-based wetland management in Northern Thailand. International Journal of Environmental, Cultural, Economic and Social Responsibility, 2(1), 49-63.

Vandekerckhove, W. \& Dentchev, N. (2005). A network perspective on stakeholder management: Facilitating entrepreneurs in the discovery of opportunities. Journal of Business Ethics, 60(3), 221-232.

Vigoda, E. (2002). From responsiveness to collaboration: Governance, citizens, and the next generation of public administration. Public Administration Review, 62(5), 527-540. 
Wasserman, S. \& Faust, K. (1994). Social network analysis: Methods and applications. Cambridge: Cambridge University Press.

Wellman, B. \& Berkowitz, S. (1988). Social structures: A network approach. New York: Cambridge University Press.

Wells, R., Lee, S., McClure, J., Baronner, L., \& Davis, L. (2004). Strategy development in small hospitals: Stakeholder management in constrained circumstances. Health Care Management Review, 29(3), 218-228.

Yates, D. (1991). Management in public and private organisations: Similarities and differences. In Ott, Hyde \& Shafritz (Eds.). Public management: The essential readings (p 39-58). Chicago: Lyceum Books.

Ziervogel, G. \& Downing, T. (2004). Stakeholder networks: Improving seasonal climate forecasts. Climatic Change, 65(1-2), 73-101. 


\title{
APPENDIX 1a \\ Research Information Sheet for DOC
}

\author{
TE WHARE WÃNANGA O TE OPOKO O TE IKA A MAUI

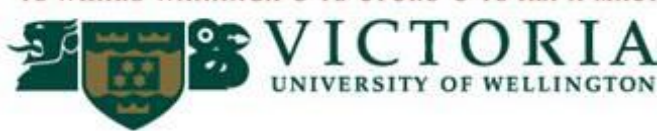 \\ Louise Proctor \\ MCA Masters Thesis in Management \\ Victoria University of Wellington
}

\section{INFORMATION SHEET \\ MAF BIOSECURITY NEW ZEALAND}

\section{The Practical Application of Stakeholder Networking Theory in the New Zealand Public Sector}

\section{The Researcher}

I, Louise Proctor, am the sole researcher for this thesis, which I am conducting to complete a Master of Commerce and Administration (MCA) from Victoria University of Wellington. I have also been an employee of Gemtech Solutions, working in the Strategic Management practice, who have current professional services engagements with DOC. The thesis research is independent and is not being conducted for the use of either Gemtech or DOC.

\section{Overview}

This thesis is centered around a particular stakeholder theory proposed by Rowley (1997) called "stakeholder networking", which was originally developed from a private sector perspective. It is the aim of this research to investigate whether stakeholder networking theory is applicable in the public sector space and how it can be used to enhance the strategic planning process.

The motivation for this research has arisen from recognising that the public sector operates with a different underlying purpose and structure of governance compared with the private sector. Additionally, the new whole-of-government approach is creating increasing expectations for Government organisations to work together.

Consequently, the multiplicity of stakeholder interests influencing public sector organisations and the pressure to incorporate stakeholders in the strategic planning process makes stakeholder alignment and collaboration imperative to the success of a public sector organisation.

To further narrow the research focus, the Environment Sector has been selected for consideration. This is due to increasing social awareness of environmental issues such as climate change, sustainability, tourism and trade, which are expanding the number of stakeholders for engagement. 


\section{Research Gap}

While previous studies have researched stakeholder alignment and collaboration in the public sector, there has been no practical application of this particular stakeholder networking theory.

Further, stakeholder networking theory was originally proposed as a means of predicting how organisations respond to the simultaneous influence of multiple stakeholders, but it has not been researched in terms of how it can be used to enhance the strategic planning process.

\section{Research Objectives}

1) Develop stakeholder networks of two public sector organisations in the Environment Sector.

2) Analyse the different characteristics between stakeholder networks of organisations that are at different stages of the strategic planning process.

3) Describe how stakeholder networking theory can enhance the strategic planning process.

4) Understand the management issues that arise in the practical application of stakeholder networking theory in the public sector.

\section{Interaction with you}

\section{$\underline{\text { Data Collection }}$}

- To gain a full view of DOC's stakeholders and develop a visual stakeholder network according to the theory, I will research within DOC and ask people about the names of stakeholders; how to segment them; the nature of the relationships; and the relationships between stakeholders.

- In order to gather information from the stakeholder's perspective, I will also interview people from DOC's key stakeholders groups who have knowledge about the type of relationship between their organisation and DOC.

\section{Voluntary Participation}

- Your participation in the interviews for this thesis is voluntary. Ethics approval is a standard requirement for such research and has been obtained from the VUW Human Ethics Committee.

\section{Consent and Confidentiality}

- A research agreement will be signed in order to gain informed consent. Here, you are provided with the opportunity to consent to having the interview recorded.

- All information collected during this research will remain confidential. Only the researcher and her university supervisor will have access to information obtained.

- All information from the interviews will be reported in an aggregate and summary form that does not specifically identify individuals.

- Interview notes, recordings and similar materials will be stored securely and destroyed within 1 year of the completion of the research. 
Use of Information

- Information gathered during this research will be used to write my thesis.

- Depending on the results generated from this research, the findings could be used for academic or non-academic presentations and/or reports. However, this will be done to maintain confidentiality as no statements will be attributed to individuals.

- Information relating to individual interviews and a summary of the findings is available upon request. Some summary feedback will be provided to your organisation.

\section{Contact Information}

\begin{tabular}{|c|c|c|c|}
\hline Researcher & $\begin{array}{l}\text { Louise Proctor } \\
\text { Victoria Management School } \\
\text { Victoria University of Wellington } \\
\text { PO Box } 600 \\
\text { Wellington } \\
\text { Email: louise.proctor@vuw.ac.nz } \\
\text { Mobile: } 021581521\end{array}$ & Supervisor & $\begin{array}{l}\text { Urs Daellenbach } \\
\text { Victoria Management School } \\
\text { Victoria University of Wellington } \\
\text { PO Box } 600 \\
\text { Wellington } \\
\text { Email: Urs.Daellenbach@ vuw.ac.nz } \\
\text { Work: } 4635732\end{array}$ \\
\hline
\end{tabular}




\title{
APPENDIX 1b
}

\section{Research Information Sheet for MAF BNZ}

\section{Louise Proctor}

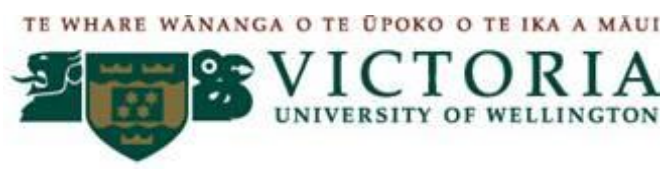

\author{
MCA Masters Thesis in Management \\ Victoria University of Wellington
}

INFORMATION SHEET

MAF BIOSECURITY NEW ZEALAND

\section{The Practical Application of Stakeholder Networking Theory in the New Zealand Public Sector}

\section{The Researcher}

I, Louise Proctor, am the sole researcher for this thesis, which I am conducting to complete a Master of Commerce and Administration (MCA) from Victoria University of Wellington. I have also been an employee of Gemtech Solutions, working in the Strategic Management practice, who have current professional services engagements with MAF BNZ. The thesis research is independent and is not being conducted for the use of either Gemtech or MAF Biosecurity

\section{Overview}

This thesis is centered around a particular stakeholder theory proposed by Rowley (1997) called "stakeholder networking", which was originally developed from a private sector perspective. It is the aim of this research to investigate whether stakeholder networking theory is applicable in the public sector space and how it can be used to enhance the strategic planning process.

The motivation for this research has arisen from recognising that the public sector operates with a different underlying purpose and structure of governance compared with the private sector. Additionally, the new whole-of-government approach is creating increasing expectations for Government organisations to work together.

Consequently, the multiplicity of stakeholder interests influencing public sector organisations and the pressure to incorporate stakeholders in the strategic planning process makes stakeholder alignment and collaboration imperative to the success of a public sector organisation.

To further narrow the research focus, the Environment Sector has been selected for consideration. This is due to increasing social awareness of environmental issues such as climate change, sustainability, tourism and trade, which are expanding the number of stakeholders for engagement. 


\section{Research Gap}

While previous studies have researched stakeholder alignment and collaboration in the public sector, there has been no practical application of this particular stakeholder networking theory.

Further, stakeholder networking theory was originally proposed as a means of predicting how organisations respond to the simultaneous influence of multiple stakeholders, but it has not been researched in terms of how it can be used to enhance the strategic planning process.

\section{Research Objectives}

1) Develop stakeholder networks of two public sector organisations in the Environment Sector.

2) Analyse the different characteristics between stakeholder networks of organisations that are at different stages of the strategic planning process.

3) Describe how stakeholder networking theory can enhance the strategic planning process.

4) Understand the management issues that arise in the practical application of stakeholder networking theory in the public sector.

\section{Interaction with you}

\section{$\underline{\text { Data Collection }}$}

- To gain a full view of MAF BNZ's stakeholders and develop a visual stakeholder network according to the theory, I will research within MAF BNZ and ask people about the names of stakeholders; how to segment them; the nature of the relationships; and the relationships between stakeholders.

- In order to gather information from the stakeholder's perspective, I will also interview people from MAF BNZ's key stakeholders groups who have knowledge about the type of relationship between their organisation and MAF BNZ.

\section{Voluntary Participation}

- Your participation in the interviews for this thesis is voluntary. Ethics approval is a standard requirement for such research and has been obtained from the VUW Human Ethics Committee.

\section{Consent and Confidentiality}

- A research agreement will be signed in order to gain informed consent. Here, you are provided with the opportunity to consent to having the interview recorded.

- All information collected during this research will remain confidential. Only the researcher and her university supervisor will have access to information obtained.

- All information from the interviews will be reported in an aggregate and summary form that does not specifically identify individuals.

- Interview notes, recordings and similar materials will be stored securely and destroyed within 1 year of the completion of the research. 
Use of Information

- Information gathered during this research will be used to write my thesis.

- Depending on the results generated from this research, the findings could be used for academic or non-academic presentations and/or reports. However, this will be done to maintain confidentiality as no statements will be attributed to individuals.

- Information relating to individual interviews and a summary of the findings is available upon request. Some summary feedback will be provided to your organisation.

\section{Contact Information}

\begin{tabular}{|c|c|c|c|}
\hline Researcher & $\begin{array}{l}\text { Louise Proctor } \\
\text { Victoria Management School } \\
\text { Victoria University of Wellington } \\
\text { PO Box } 600 \\
\text { Wellington } \\
\text { Email: louise.proctor@vuw.ac.nz } \\
\text { Mobile: } 021581521\end{array}$ & Supervisor & $\begin{array}{l}\text { Urs Daellenbach } \\
\text { Victoria Management School } \\
\text { Victoria University of Wellington } \\
\text { PO Box } 600 \\
\text { Wellington } \\
\text { Email: Urs.Daellenbach@ vuw.ac.nz } \\
\text { Work: } 4635732\end{array}$ \\
\hline
\end{tabular}




\section{APPENDIX 2}

\section{Interview Schedule for DOC and MAF BNZ}

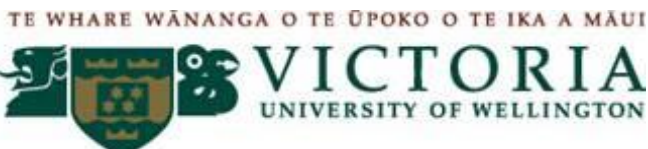

\section{INTERVIEW SCHEDULE} INTER VIEWS WITH DOC AND MAF BNZ

The Practical Application of Stakeholder Networking Theory

in the New Zealand Public Sector

\section{General sensitivities}

- Be aware of the timing of the interview due to being in their workplace.

- Use prompt questions to tease out answers and be receptive to hearing responses that do not necessarily fit in with my expectations.

\section{General Introduction}

- Name

- Overview of thesis and motivation

- What I aim to get from you

2. Gain Approval (introduction and approval, 5 minutes)

- Hand over information sheet

- Briefly draw attention to key points.

- Hand over research agreement and get them to sign.

3. Warm-up/background (about 5-10 minutes)

Ask about their role within DOC / MAF BNZ:

- How long have you been working with DOC / MAF BNZ?

- What is your role within DOC / MAF BNZ?

- Are you closely involved with the stakeholder alignment and collaboration processes?

\section{STAKEHOLDER ALIGNMENT AND COLLABORATION WITHIN DOC / MAF BNZ}

1. Do you think that DOC / MAF BNZ are typically good at their efforts in stakeholder alignment and collaboration? Prompts:

- What activities do they engage in to manage their stakeholders? 
2. To what extent does DOC / MAF BNZ place importance on understanding their stakeholders?

\section{NAMES OF KEY STAKEHOLDERS}

3. Can you name DOC / MAF BNZ's key stakeholders?

\section{SEGMENTING STAKEHOLDERS}

4. In what way can these stakeholders be segmented so that they are grouped by common interests?

\section{RELATIONSHIP WITH STAKEHOLDERS}

5. Can you please describe the relationship between DOC / MAF BNZ and (name of stakeholder)?

Prompts:

- What is DOC / MAF BNZ's particular interest in (name of stakeholder)?

- What is (name of stakeholder) interest in DOC / MAF BNZ?

- Would you rate the relationship strong, medium or weak?

6. In what ways do you interact with (name of stakeholder)?

Prompts:

- What are the lines of communication?

- Does DOC / MAF BNZ have regular contact with (name of stakeholder)?

- Are there any other methods that DOC / MAF BNZ employs to maintain the relationship with (name of stakeholder)?

7. Do any of these stakeholders have significant influence over internal planning decisions and process?

Prompts:

- Does DOC / MAF BNZ incorporate (name of stakeholder) into its planning processes? Why / Why not?

- Do you think that the relationship positively effects the outcomes of DOC / MAF BNZ?

8. To what extent is DOC / MAF BNZ able to influence (name of stakeholder)? Prompts:

- Do you think that the relationship is balanced or is one organisation more powerful? 


\section{INTERACTION BETWEEN STAKEHOLDERS}

9. Are you aware of any relationships between DOC / MAF BNZ's stakeholders that were identified above?

Prompts:

- What are the links/association between DOC / MAF BNZ's stakeholders?

10. What is the nature of these relationships?

Prompts:

- $\quad$ Are they strong, medium, or weak? 


\section{APPENDIX 3}

\section{Research Agreement for DOC and MAF BNZ}

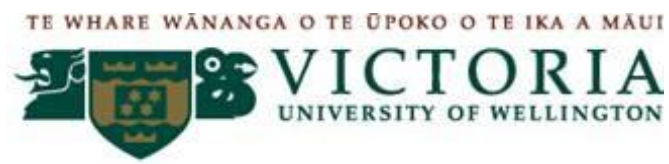

\section{RESEARCH AGREEMENT}

ALL INTERVIEWS

\section{The Practical Application of Stakeholder Networking Theory in the New Zealand Public Sector}

\section{Purpose of agreement}

The purpose of this agreement is to make sure that you are fully informed about the purpose of the research, what it means for you, and your right to confidentiality. A research agreement indicating informed consent and voluntary participation is a standard requirement for obtaining approval from the VUW Human Ethics Committee.

\section{Purpose of interview}

- I understand that the purpose of this interview is to collect relevant data required to complete this thesis, as described in the information sheet I previously received.

\section{Method of interview}

- I agree to this interview being recorded for research purposes. YES $\square$ NO

\section{Confidentiality}

- I understand that information gathered during this research will remain confidential to the researcher and her supervisor.

- I understand that recordings will not be listened to by anyone other than the researcher for transcribing purposes.

- I understand that all information will be reported in summary form that does not specifically link individuals to data.

- I understand that interviews notes, recordings and similar materials will be stored securely and destroyed within a year of the completion of the research. 


\section{Information available}

- I understand that information relating to my interview, including recordings and written notes is available to me upon request.

\section{Consent to participation in research}

$\mathrm{I}$, have been given and have understood an explanation of this thesis. I have had an opportunity to ask questions and have had them answered to my satisfaction. I understand that I may withdraw myself or any information I have provided for this thesis (before data collection is completed). I therefore agree to participate in this research.

Any more conditions to be written in by the participant

Participant

Signature

Date.

\section{Researcher}

Signature

Date

\begin{tabular}{|c|c|c|c|}
\hline Researcher & $\begin{array}{l}\text { Louise Proctor } \\
\text { Victoria Management School } \\
\text { Victoria University of Wellington } \\
\text { PO Box } 600 \\
\text { Wellington } \\
\text { Email: Louise.Proctor@ vuw.ac.nz } \\
\text { Mobile: } 021581521\end{array}$ & Supervisor & $\begin{array}{l}\text { Urs Daellenbach } \\
\text { Victoria Management School } \\
\text { Victoria University of Wellington } \\
\text { PO Box } 600 \\
\text { Wellington } \\
\text { Email: Urs.Daellenbach@ vuw.ac.nz } \\
\text { Work: } 4635732\end{array}$ \\
\hline
\end{tabular}




\title{
APPENDIX 4
}

\section{Department of Internal Affairs Relationship Continuum}

\section{Appendices}

\author{
Appendix One: Partnering Continuum - Key Ingredients \\ Co-Existence \\ - know about each other but don't need to come together \\ - no direct relationships with other agencies \\ - no dependency or need to collaborate \\ Networking \\ - informal discussions \\ - information sharing is the basis \\ - no formal collective agreement on visions, tasks etc \\ - lower level of co-operation \\ - not about shared decision-making \\ - establishing and maintaining relationships \\ - about knowing and understanding who's doing what \\ Cooperation \\ - lower level of collaboration \\ - no fixed term long-term relationship implied \\ - acknowledgement of common issues/interests/agendas \\ - may involve helping another organisation to achieve their project/task etc \\ - may involve documentation such as a Memorandum of Understanding (MOU) that notes \\ what will be worked on together \\ - no ongoing or formal commitment to each other
}

Collaboration

- has trust implicit

- is based on negotiated and agreed actions

- does not have to share same base values but have an agreed set of principles for working together

- has shared decision-making

- means giving up some things (ie. power and control)

- provides an opportunity to add value to others as well as to yourself

- sometimes documentation is prepared to support different types of collaborative effort

Partnership

- emotional/spiritual awareness of each other; that is, involves hearts, minds, passion

- work from an agreed shared values base eg. trust, honesty, openness etc

- sharing:
- risks \& rewards
- resources 
- accountability

- visions and ideas

- decision-making

- has a degree of formality and two/multi-way contractual and relational obligations

- processes, systems, and mechanisms are developed to support the partnership, eg. structures, contracts, principles and visions, plans, conflict resolution etc

- about shared power but not 50/50 notion of equality

- about the way things are done rather than the evenness (or not!) of power, control and resources

- resourcing/contributions about equitable rather than equal contributions; they may be in kind as well as monetary

Taken from Craig and Courtney 2004 - "The Potential of Partnership" pages 38-9

\section{NOTE:}

It has been pointed out that there are other kinds of relationships and potential partnering relationships that are not reflected on the partnering continuum presented. Many of the examples cited reflect organisations working in spaces to the left of the 'co-existence' box' ie. not yet on the continuum. There is a range of reasons why organisations may be in this 'negative' continuum space, for example:

- Unintentional isolation - some organisations may be genuinely unaware of opportunities to link or work with other organisations.

- Competition - these behaviours are often encouraged through the need to compete for limited funding against other organisations.

- Adversarial relationships - due to unresolved historical organisational conflict, personality conflicts, bad experiences of interagency working, and/or perceived differences in visions, values and ways of working.

Further thinking needs to be done to 'unbundle' and repackage the continuum to recognise these other perspectives. 